DOE/BP--1706

DE92 003499

\title{
DRAFT ENVIRONMENTAL IMPACT STATEMENT \\ PUGET SOUND AREA ELECTRIC RELIABILITY PLAN
}

Appendix D

Conservation, Load Management and Fuel Switching Analysis

\section{Bonneville Power Administration \\ U.S. Department of Energy}

Prepared as part of a coordinated plan to addiess a power system problem in the Puget Sound Area. Utilities participating in planning include: Bonneville Power Administration, Puget Sound Power and Light, Seattle City Light, Snohomish County Public Utility District No. 1, and Tacoma City Light.

September 1991

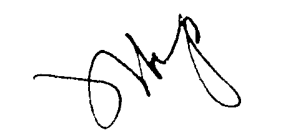




\section{APPENDIX D}

CONSERVATION, LOAD MANAGEMENT, AND FUEL SWITCHING

\section{D.1.0 ANALYSIS OVERVIEW \\ D.1.1 Programs \\ D.1.2 Hourly Models \\ D.1.3 Data Requirements \\ D.1.4 System Impacts \\ D.1.5 Deleted Options}

D.2.0 BASE CASE

D.2.1 System Load Shapes

D.2.2 End-Use Breakdown

D.2.3 End-Use Detail

D. 3.0 CONSERVATION

D.3.1 Overview

D.3.2 Accelerated Weatherization

D.3.3 Accelerated Industrial Conservation

D.3.4 Commercial Retrofit

D.3.5 Low Flow Shower Heads

D.4.0 LOAD MANAGEMENT

D.4.1 Water Heat Control

D.4.2 Time-of-Use Rates

D.5.0 FUEL SWITCHING

D.5.1 Overview

D.5.2 Summary of Results

D.5.3 Market Segments

D.5.4 Costs

D.5.5 Results

D.6.0 PROGRAM INTERACTIONS

D.6.1 Program Ordering

D.6.2 Size of Interactive Effects

D.7.0 HIGH AND LOW LOAD GROWTH

D.7.1 Assumptions by Sector

D.7.2 Tables

\section{D.8.0 REFERENCES}




\section{LIST OF FIGURES}

Figure D-1a

Figure D-1b

Figure $D-2 a$

Figure $D-2 b$

Figure $D-3 a$

Figure $D-3 b$

Figure $D-4 a$

Figure $D-4 b$

Figure $D-5 a$

Figure $D-5 b$

Figure $D-6 a$

Figure $D-6 b$

Figure $D-7 a$

Figure $D-7 b$

Figure $D-8 a$

Figure $D-8 b$

Figure $D-8 C$

Figure $D-9 a$

Figure $D-9 b$

Figure $D-10 a$

Figure $D-10 b$

Figure $D-10 \mathrm{C}$

Figure D-11a

Figure D-11b

Figure $D-11 C$

Figure $D-12 a$

Figure D-12b

Figure $D-13 a$

Figure $D-13 b$

Figure $D-14 a$

Figure $D-14 b$

Figure D-15a

Figure $D-15 b$

Figure $D-15 C$
Water Heat Load Shapes

System Load Shapes

System Impacts, Normal Peak Day

System Impacts, Extreme Peak Day

Annual System Peaks, Normal Peak Day

Annual System Peaks, Extreme Peak Day

Residential Sector, Normal Peak Day

Residential Sector, Extreme Peak Day

Commercial Sector, Normal Peak Day

Commercial Sector, Extreme Peak Day

Space Heat Load Shapes, Existing Homes

Space Heat Load Shapes, New Homes

Residential Water Heat Load Shapes

Residential Other Load Shapes

Office HVAC Load Shapes

Office Lighting Load Shapes

Office Other Load Shapes

Energy Targets, Residential Weacherization

Peak Savings, Residential Weatherization

Energy Targets, Industrial Conservation

Peak Savings, Industrial Conservation

Industrial Conservation Load Shapes

Energy Targets, Commercial Retrofit

Peak Savings, Commercial Retrofit

Office Lighting Conservation

Low Flow Shower Heads, Program Penetration

Peak Savings, Low Flow Shower Heads

Water Heat Control Penetration Rates, Existing Homes

Water Heat Control Penetration Rates, New Homes

Peak Savings, Water Heat Control

Water Heat Control Load Shapes

Time-of-Use Rates, Program Penetration

Peak Savings, Time-of-Use Rates

Time-of-Use Rates Load Shapes 


\section{LIST OF TABLES}

Table D.2.1 Difference Between Morning and Evening Peaks

Table D.2.2 Difference Between Morning Peak and Daily Average

Table D.2.3 End-Use Labels

Table D.2.4 Market Shares of Electricity

Table D.2.5 Number of Households

Table D.2.6 Commercial Floor Space

Table D.2.7 Industrial Sector Consumption

Table D.2.8 Energy Benchmarks

Table D.2.9 Ratio of Peak Day to Average Day Energy Consumption

Table D.3.1 Summary Worksheet, Single Family Weatherization

Table D.3.2 Energy Targets for Weatherization of Residential Buildings

Table D.3.3 Summary Worksheet, Multi-Family Weatherization

Table D.3.4 Summary Worksheet, Industrial Conservation

Table D.3.5 Commercial Retrofit Program Energy Targets

Table D.3.6 Summary Worksheet, Commercial Retrofit

Table D.3.7 Summary Worksheet, Low Flow Shower Heads

Table D.4.1 Water Heat Control Penetration Rates

Table D.4.2 Summary Worksheet, Water Heat Control (Single Family)

Table D.4.3 Summary Worksheet, Water Heat Control (Multi-Family)

Table D.4.4 Summary Worksheet, Water Heat Control (Manufactured Homes)

Table D.4.5 Summary Worksheet, Time-of-Use Rates

Table D.5.1 Households (in Fuel Switching Program)

Table D.5.2 Cost per Household

Table D.5.3 Summary of Fuel Switching Potential

Table D.6.1 Fuel Switching Impact on Other Programs

Table D.7.1 Residential Scale Factors

Table D.7.2 Commercial Scale Factors

Table D.7.3 Industrial Scale Factors

Table D.7.4 Residential Sector Growth Scenarios

Table D.7.5 Commercial Sector Growth Scenarios

Table D.7.6 Low Growth by Building Type

Table D.7.7 Medium Growth by Building Type

Table 0.7.8 High Growth by Building Type 


\section{D.1.0 ANALYSIS OVERVIEW}

Various conservation, load management, and fuel switching programs were considered as ways to reduce or shift system peak load. These programs operate at the end-use level, such as residential water heat. Figure D-1a shows what electricity consumption for water heat looks like on normal and extreme peak days. Load management programs, such as water heat control, are designed to reduce electricity consumption at the time of system peak.

On the coldest day in an average winter, system load peaks near 8:00 a.m. In a winter with extremely cold weather, electricity consumption increases for all hours, and the system peak shifts to later in the morning. System load shapes in the Puget Sound area are shown in Figure D-1b for a normal winter peak day (February 2, 1988) and an extreme peak day (February 3, 1989).

Peak savings from any program are calculated to be the reduction in loads on the entire system at the hour of system peak. Peak savings for all programs are measured at 8:00 a.m. on a normal peak day and 9:00 a.m. on an extreme peak day. On an extremely cold day, some water heat load shifts to much later in the morning, with less load available for shedding at the time of system peak.

Models of hourly end-use consumption were constructed to simulate the impact of conservation, load management, and fuel switching programs on electricity consumption. Javelin, a time-series simulation package for personal computers, was chosen for the hourly analysis. Both a base case and a program case were simulated.

\section{D.1.1 PROGRAMS}

Three groups of proposed programs were analyzed for this study: conservation, load management, and fuel switching. Conservation programs are discussed in more detail in Section 3. Some of the conservation programs are an acceleration of programs already in place in the Puget Sound area. Load management programs, discussed in Section 4, are designed to shift load away from the time of system peak.

\section{Conservation Programs}

Residential Weatherization (Single Family)

Residential Weatherization (Multi-Family)

Industrial Conservation

Commercial Retrofit

Low Flow Shower Heads

Javelin is a trademark of Information Resources, Inc., Waltham. Massachusetts. 


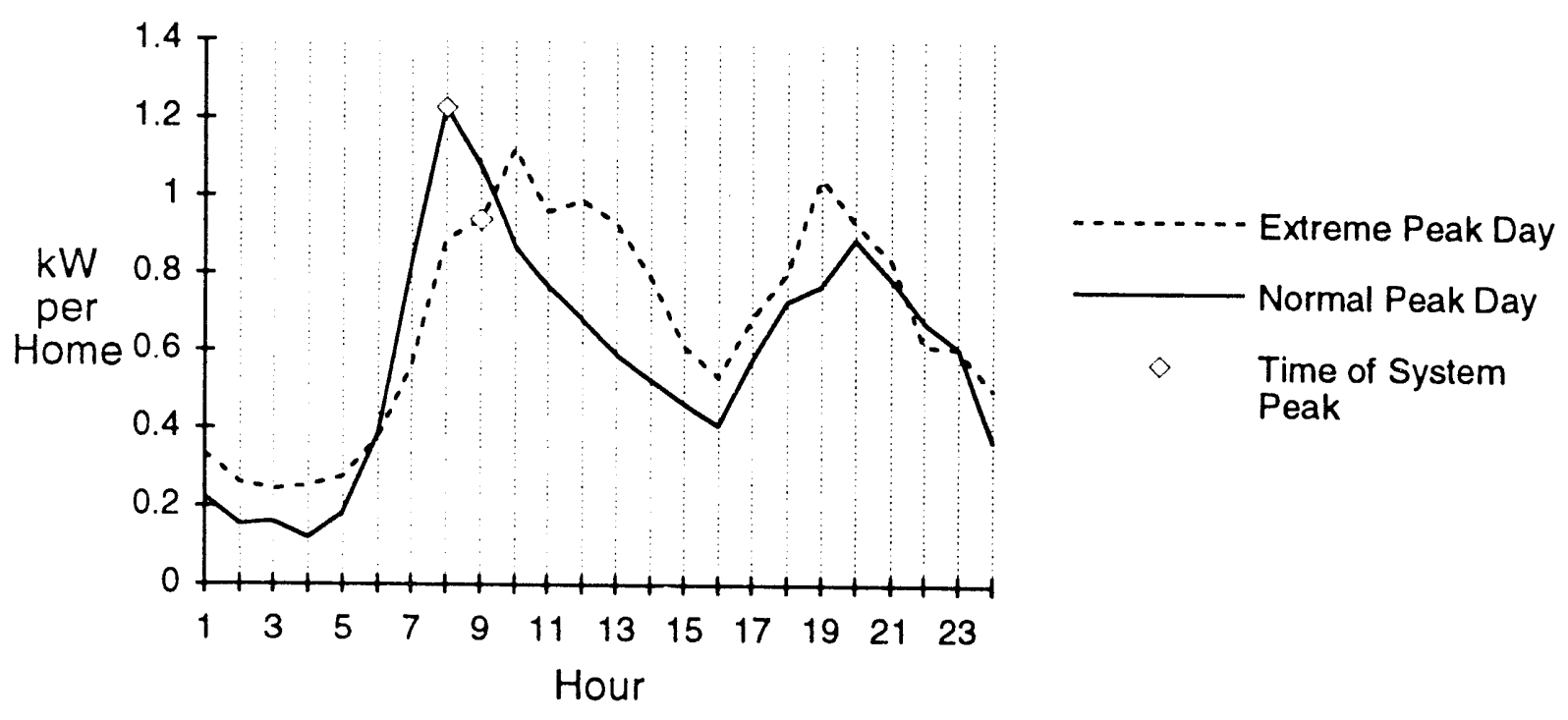

Figure D-1a. Water Heat Load Shapes

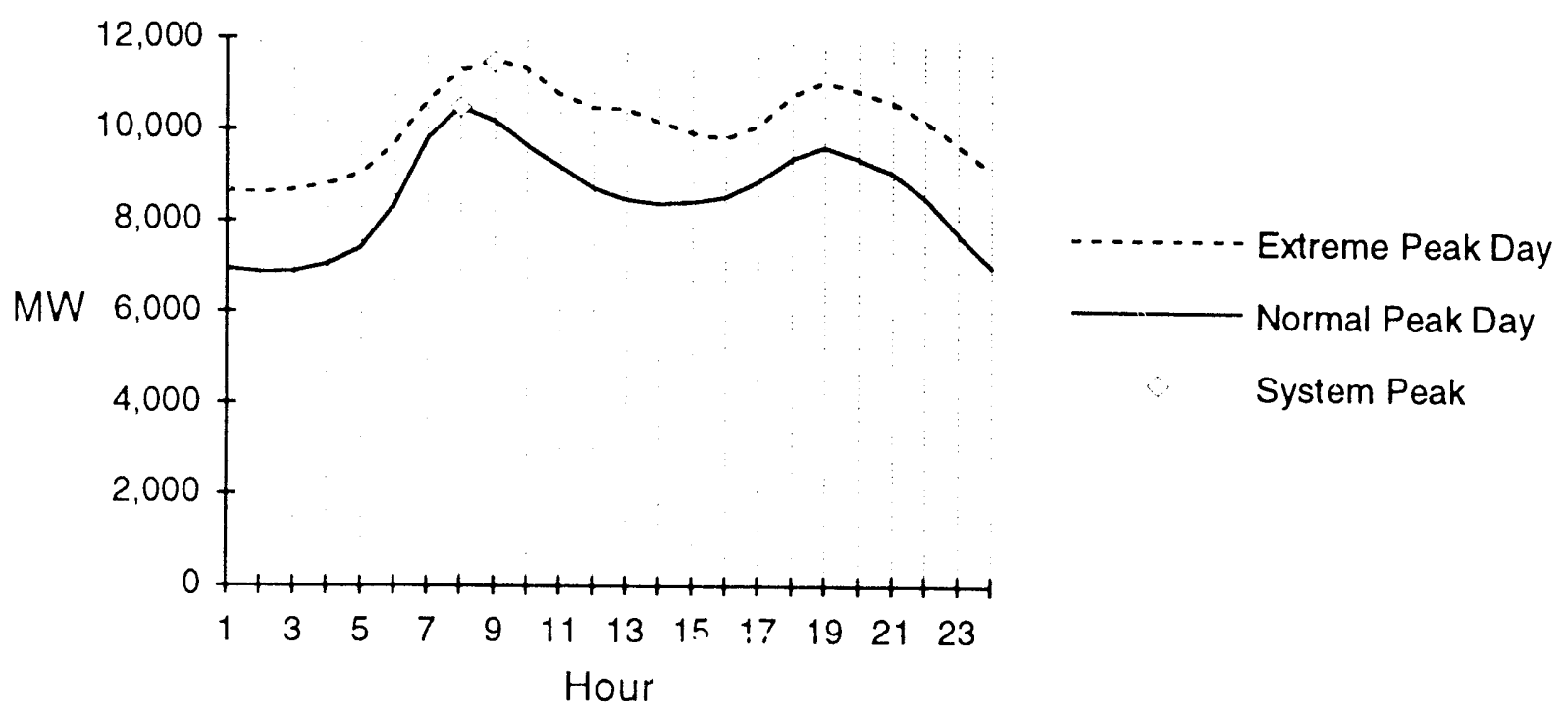

Figure D-1b. System Load Shapes 


\section{Load Management Programs}

Water Heat Control (Single Family)

Water Heat Control (Multi-Family)

Water Heat Control (Manufactured Homes)

Time-of-Use Rates (Residential Single Family)

A fuel switching scenario with seven market segments was constructed for the residential sector. With a fuel switching program in place, some electricity consumption for space and water heat is shifted to natural gas. Fuel switching is covered in detail in Section 5 .

\section{D.1.2 HOURLY MODELS}

Electricity consumption is simulated at an hourly level for each end-use beginning in 1990 and ending in 2010. To avoid providing space for all 8760 hours for each year, only certain day types are simulated. Three day types were chosen to capture the response of hourly load shapes to cold weather.

Average Winter Day

1 in 2 Peak Day (Normal Peak Day)

1 in 20 Peak Day (Extreme Peak Day)

A Normal Peak Day is the coldest day to occur once every two years, representing the coldest day during a typical winter. An Extreme Peak Day is the coldest day to occur once every 20 years.

Load shapes used in the simulation, at least for the residential and commercial sectors, are based on actual metered load shape data obtained from the End-Use Load and Consumer Assessment Program (ELCAP). Residential load shapes are an average across a sample of single family homes west of the Cascades in Washington and Oregon. Commercial load shapes are based on a sample of commercial buildings in the Seattle area.

Electricity consumption in the Puget Sound area is modeled as the sum of 19 end-uses. Resideitial electricity consumption consists of space heat, water heat, and other for three housing types. The commercial sector is broken into HVAC, lighting, refrigeration, and other for two building types. A list of end-uses is provided in Section 2.2.

Hourly models were constructed for all 19 end-uses. Conservation and load management programs were simulated as a change in load shape for one or more end-uses. Fuel switching in the residential sector was simulated by reducing the number of househoids using electricity for the affected end-use.

\section{D.1.3 DATA REQUIREMENTS}

Each end-use model starts with an average load shape and multiplies each hour's value of electricity consumption by the number of units or appliances present during each year. This is done for both a program case and a base

$$
\text { D }-6
$$


case, with the difference being hourly savings due to the conservation or load management program.

Load Shapes - A load shape is a set of 24 numbers showing the pattern of energy consumption over the hours in a day. Both base case and program case load shapes are required for each end-use and day type. For the residential and commercial sectors, base case load shapes are derived by averaging load shapes across a sample of homes or businesses in western Washington and western Oregon. Program case load shapes are constructed from the base case shapes using assumptions about how the conservation or load management program operates.

Energy Data - Annual energy consumption, in kilowatt-hours, is required for each end-use. This is then broken down into energy for January, and further for an average day in January. Also required are the ratios of energy consumed on peak days to energy consumed on an average winter day. Most of the energy data is derived from ELCAP.

Number of Households - Numbers of households, amount of commercial floor space, and megawatts of industrial electricity consumption are taken from a long term forecast of the Puget Sound area prepared by the Long Term Forecasting Section at Bonneville. A detailed end-use forecast was prepared for the medium growth case.

Market Share of Electricity - Each end-use has its own market share of electricity, somewhere between zero and $100 \%$.

Program Penetration Rate - Each conservation, load management, or fuel switching program increases from zero to a maximum penetration rate.

\section{D.1.4 SYSTEM IMPACTS}

Each program affects one or more end-uses. For example, the low flow shower head program affects water heat in single family, multi-family, and manufactured homes. End-use models are set up to simulate both a base case and a program case. Hourly savings at the end-use level are subtracted from system load shapes to derive a system program case.

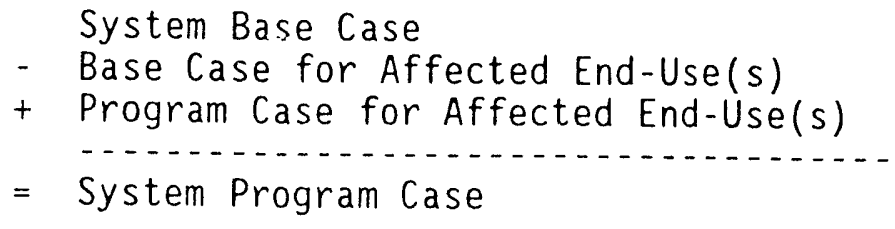

This calculation is done for 24 hours on each of the three day types for 21 years. Figures $\mathrm{D}-2 \mathrm{a}$ and $\mathrm{D}-2 \mathrm{~b}$ show the combined effect on system load of a 11 conservation and load management programs for normal and extreme peak days in 2003. Figures D-3a and D-3b show annual peak impacts of conservation and load management. 


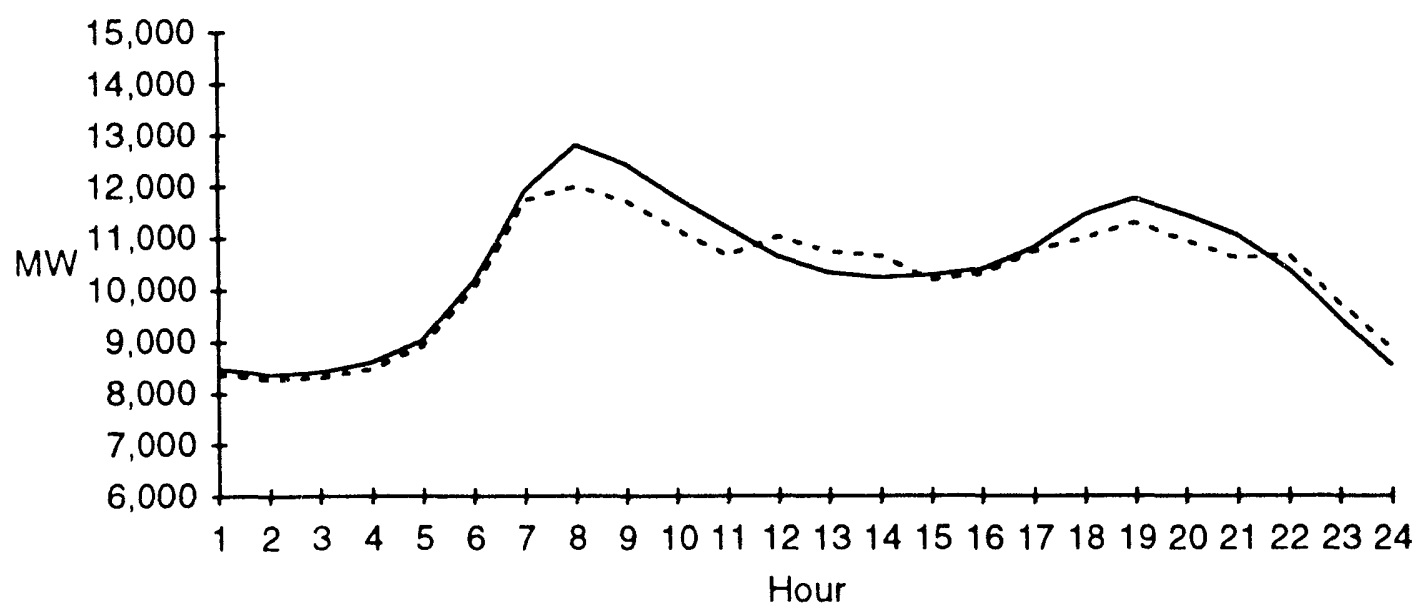

System

.... With C \& LM

Figure D-2a. System Impact of Conservation and Load Management Normal Peak Day in 2003

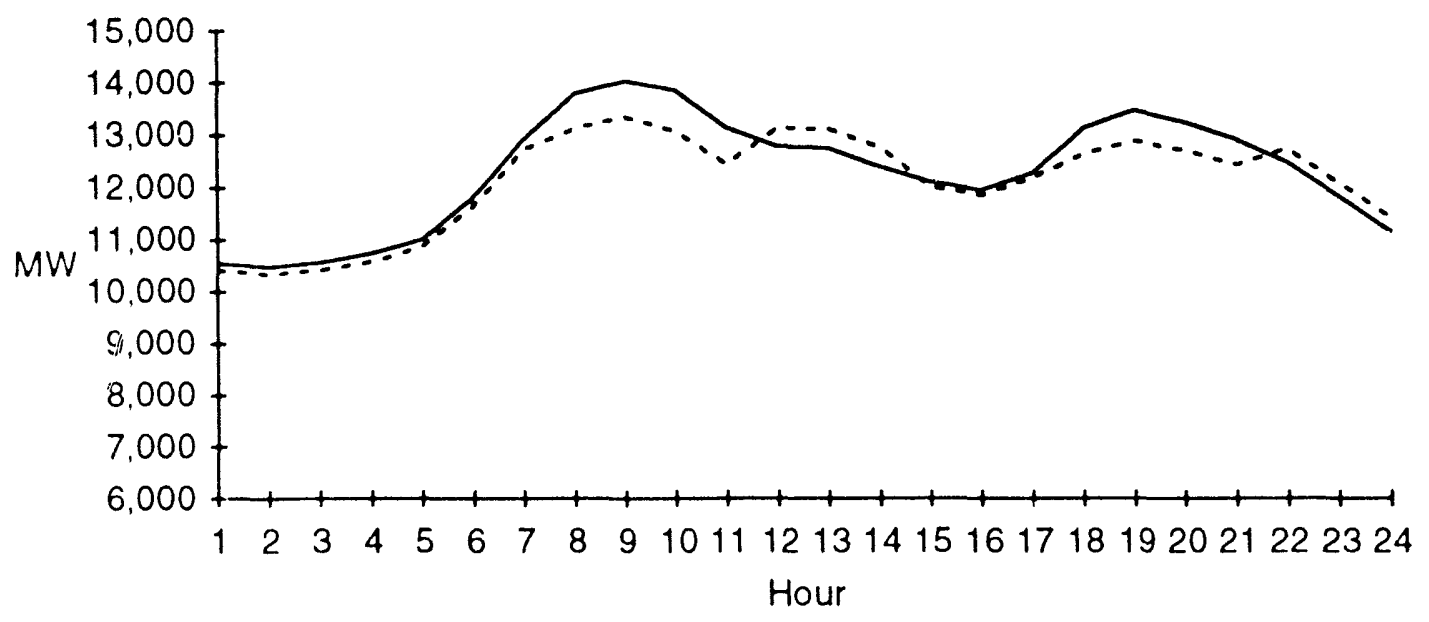

System

- With C \& LM

Figure D-2b. System Impact of Conservation and Loac Management Extreme Peak Day in 2003 


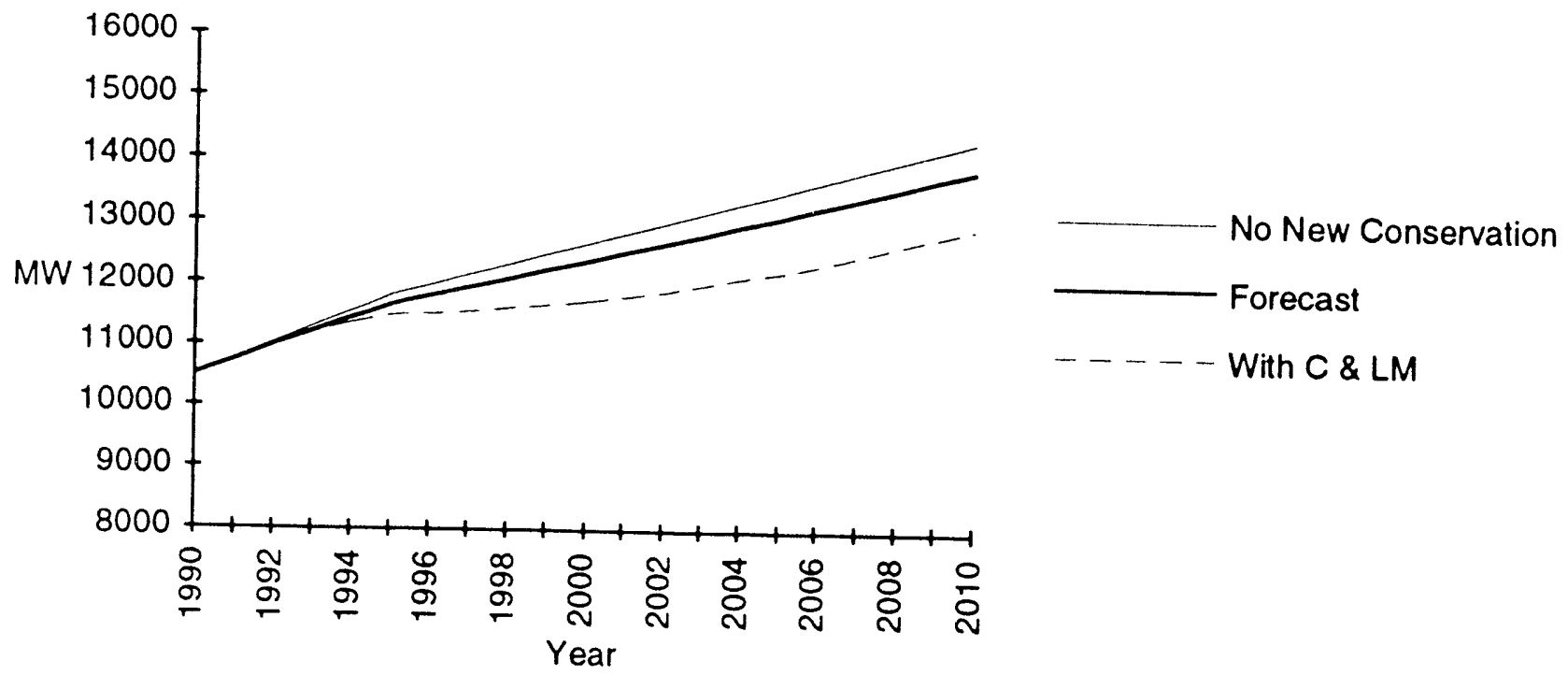

Figure D-3a. Annual System Peaks Normal Peak Days

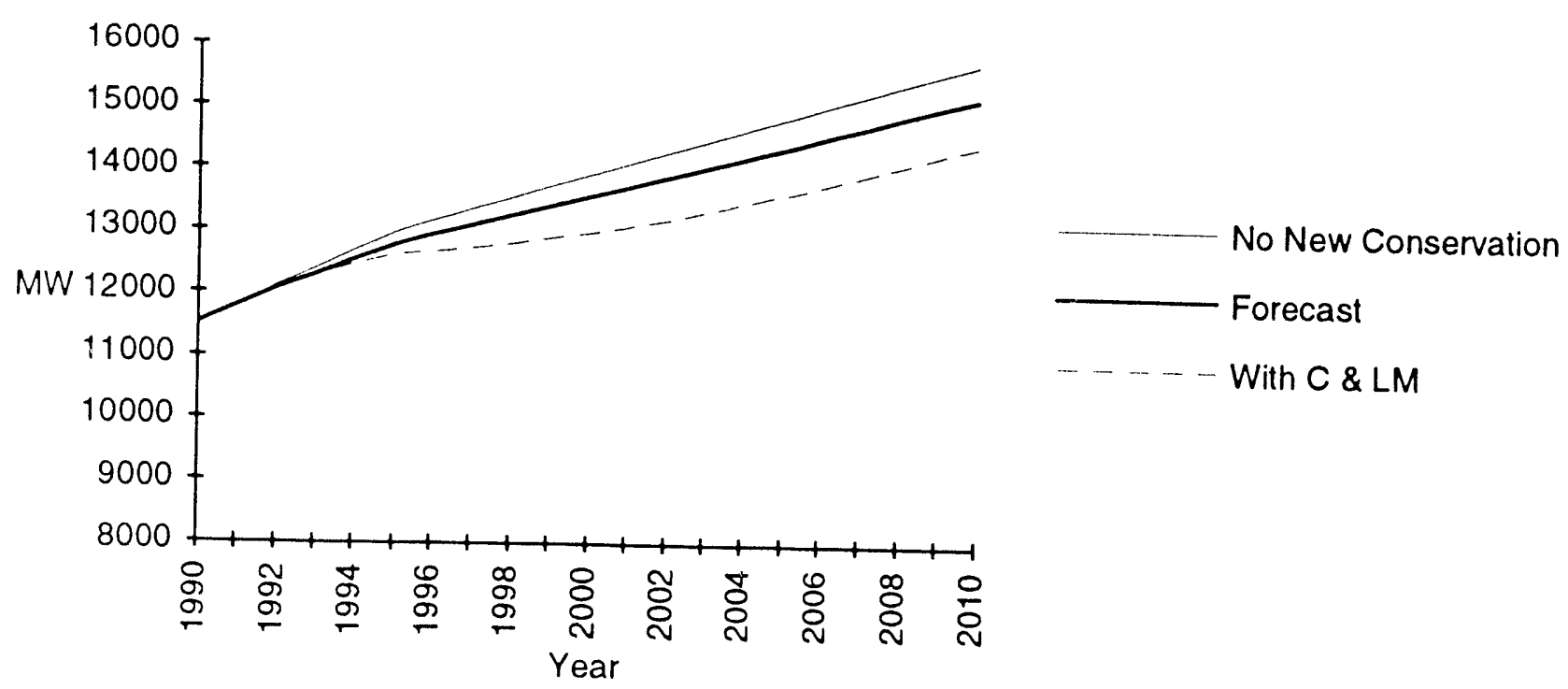

Figure D-3b. Annual System Peaks Extreme Peak Days 
Worksheets were created to summarize each program's impact at the peak hour, for each year from 1990 to 2010. Sample worksheets are provided in the sections containing program descriptions. Normal peak day ( 1 in 2 day) savings correspond to hour 8 , while extreme peak day ( 1 in 20 day) savings correspond to hour 9. The summary worksheets show peak savings, in megawatts, on a normal peak day and an extreme peak day. A column is included on each worksheet for any associated energy savings, in annual average megawatts.

\section{D.1.5 DELETED OPTIONS}

Options included in this analysis are listed in Section D.1.1. Many other conservation and load management options were considered but did not make the final list for formal analysis. Deleted options are summarized below.

Residential Space Heat Set-Back Controls - Clock thermostats were eliminated from further consideration because they may increase peak instead of decrease it. This could happen if heating was reduced during the night or midday and scheduled to recover during peak load hours when the occupants rise in the morning ( $6 \mathrm{a} . \mathrm{m} .-7 \mathrm{a} . \mathrm{m}$.$) and arrive home in the evening ( 5$ p.m. -6 p.m.). Since the recovery period coincides with peak demand, this would adversely affect the problem in the Puget Sound area.

New Commercial Conservation Programs - It is assumed that planned Bonneville and Puget Power programs will capture all energy savings available from new construction in this sector and that no savings above this baseline are possible.

Lighting Efficiency Controls - Lighting efficiency controls also have limited potential for peak reduction. Residential lighting is a minor part of the peak demand. Improved lighting efficiency saves energy over time, but does not do much to reduce peak demand. Some lighting conservation measures will be implemented as part of the retrofit program for existing commercial buildings.

Solar Augmentation for Water Heaters - This conservation measure appears unreliable. The Puget Sound area is often cloudy, and the morning peak period frequently occurs before daylight hours. This measure would be unavailable when it is needed most.

Diese1/Gasoline Generators - Portable gas or diesel generators can create air and noise pollution. They are expensive, and utilities would either require a communication system to start this generation or rely on customers to ensure their use. Customers may object to this measure. There are air quality and noise pollution concerns associated with diesel and/or gasoline generators.

Gas Back-Up for Electric Heat Pumps - Gas back-up for residential electric heat is expensive. It requires replacing furnaces for customers with central electric furnaces and installing gas furnaces and duct work for customers witi zonal electric heat. 
Street Lighting Efficiency and Controls - Street lighting controls turn off some street lights during periods of extreme peak demand. Street lighting efficiency creates savings from lighting demand, but does not affect peak load, and creates safety impacts. It was eliminated from further study.

Dual-Fuel Boilers - This proposal would install dual-fuel capability in electric boilers so load could be shifted to natural gas during peak load. The potential from this is limited because most industrial users who have a choice already use natural gas due to its lower cost.

Commercial and Industrial Time-of-Use Rates - Different rates for electricity tied to peak and off-peak hours are used to encourage customers to shift usage to off-peak. Commercial and industrial time-of-use rates can increase energy use overall when the price difference is large enough to entice peak reduction.

Space Heat Controls - This program would allow direct utility control of residential electric space heat during peak demand periods. Participants' heating systems are cycled on and off by the utility. A typical cycle would be 15 minutes off, 45 minutes on each hour.

Savings for this program were not estimated because there was insufficient data on how space heaters cycle on and off during extremely cold weather. It is difficult to estimate the savings from altering these cycles.

Storage Water Heating - This program is similar to hot water control, except that an additional 52 gallon tank is installed. Due to high capital costs, this measure did not meet the cost screening criterion.

Whole House Demand Control - In this measure, utilities or their customers limit residential peak demand. They use a device called a demand controller. This device monitors electric use in a house and turns off some use when the demand exceeds a certain level. Typically, only larger loads such as resistance heating, hot water heaters, and clothes dryers are controlled.

Thermal Heat Storage - Thermal heat storage systems use off-peak electricity to supply on-peak heating requirements. The units store heat in ceramic bricks or crushed rock during periods of low electrical demand, and use that heat during high demand periods. These units would be installed instead of a new furnace in a new home, or as part of a package when a furnace is replaced in an existing home. Time-of-use rates or a separate storage rate are used as an incentive to encourage consumer participation. This measure may increase energy consumption and does not meet the cost screening criterion. 


\section{D.2.0 BASE CASE}

The base case scenario is an hourly simulation at the end-use level, which can then be aggregated to sector and system levels. Figures $D-4 a$ and $D-4 b$ show how the residential sector breaks down into its major end-uses. Note that electricity consumption remains high during the late morning hours on extreme peak days. Figures $D-5 a$ and $D-5 b$ show a corresponding breakdown for the commercial sector.

\section{D.2.1 SYSTEM LOAD SHAPES}

Two sets of syscem load shapes were considered for this analysis. The first set is the sum of forecasted end-use load shapes from 1990 through 2010. The other system shapes, the sum-of-utility load shapes, start with a historical system shape built up from hourly utility data in the Puget Sound area. The load shapes are then scaled proportionally to simulate load growth over 20 yea:-

Each conservation, load management, or fuel switching program wiil have some impact on the system load shape. Therefore, knowing what the system shape looks like is critical to a peak load study. It was decided to use the sumof-utility load shape as the base case system shape. System load shapes shown in Figure D-1b are sum-of-utility load shapes for February 2, 1988, and February 3, 1989.

\section{Potential Savings}

All of the conservation and load management programs will reduce load at the time of system peak, which occurs in the morning.

Day Type $\quad$ Time of System Peak

$\begin{array}{ll}\text { Average Winter Day } & 8: 00 \mathrm{a} . \mathrm{m} . \\ 1 \text { in } 2 \text { Peak Day } & 8: 00 \mathrm{a} . \mathrm{m} . \\ 1 \text { in } 20 \text { Peak Day } & 9: 00 \mathrm{a} . \mathrm{m} .\end{array}$

All hourly data on electricity consumption is actually an average of electricity use over the previous hour. It is not an instantaneous measure of power. When the peak load is said to occur at 8:00 a.m., it really means that the hour from 7:00 to 8:00 has the highest average electricity consumption over 24 hours. Note that the morning peak occurs later on an extremely cold day.

Each of the three day types also has an evening peak occurring at 7:00 p.m. or hour 19. One way to get a quick idea of peak savings potential is to look at the difference between morning and evening peaks. This shows how much the morning peak can be reduced before it equals the evening peak. Table D.2.1 shows this difference in the year 2010 .

$$
\text { D }-12
$$




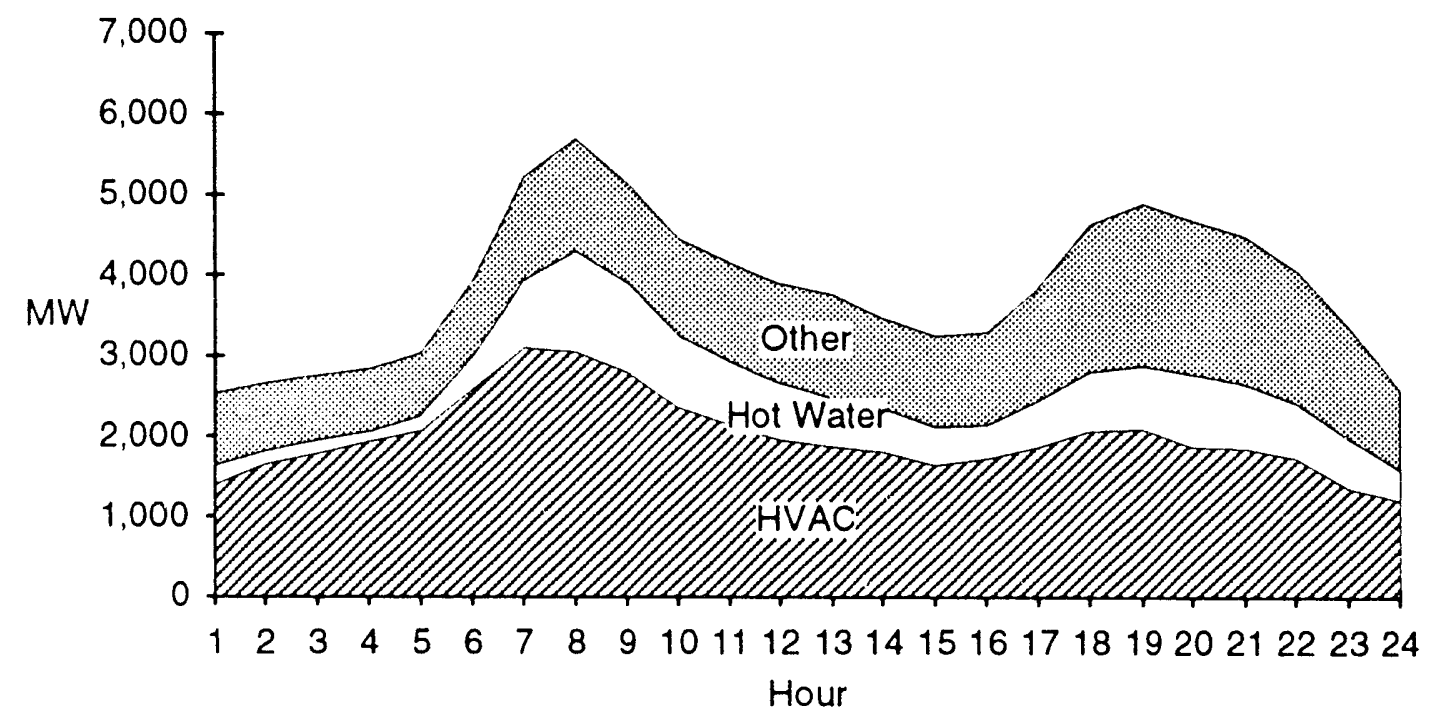

Figure D-4a. Residential Sector Breakdown - Normal Peak Day

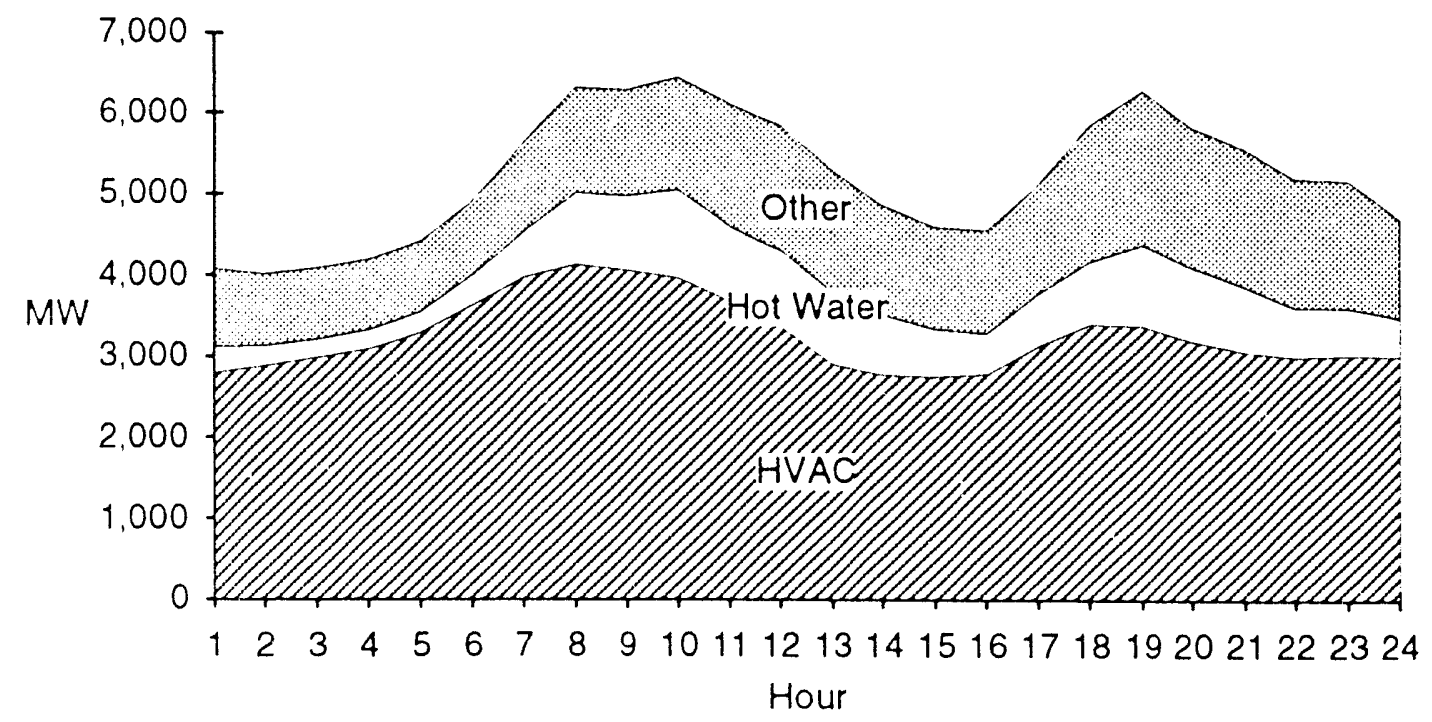

Figure D-4b. Residential Sector Breakdown - Extreme Peak Day 


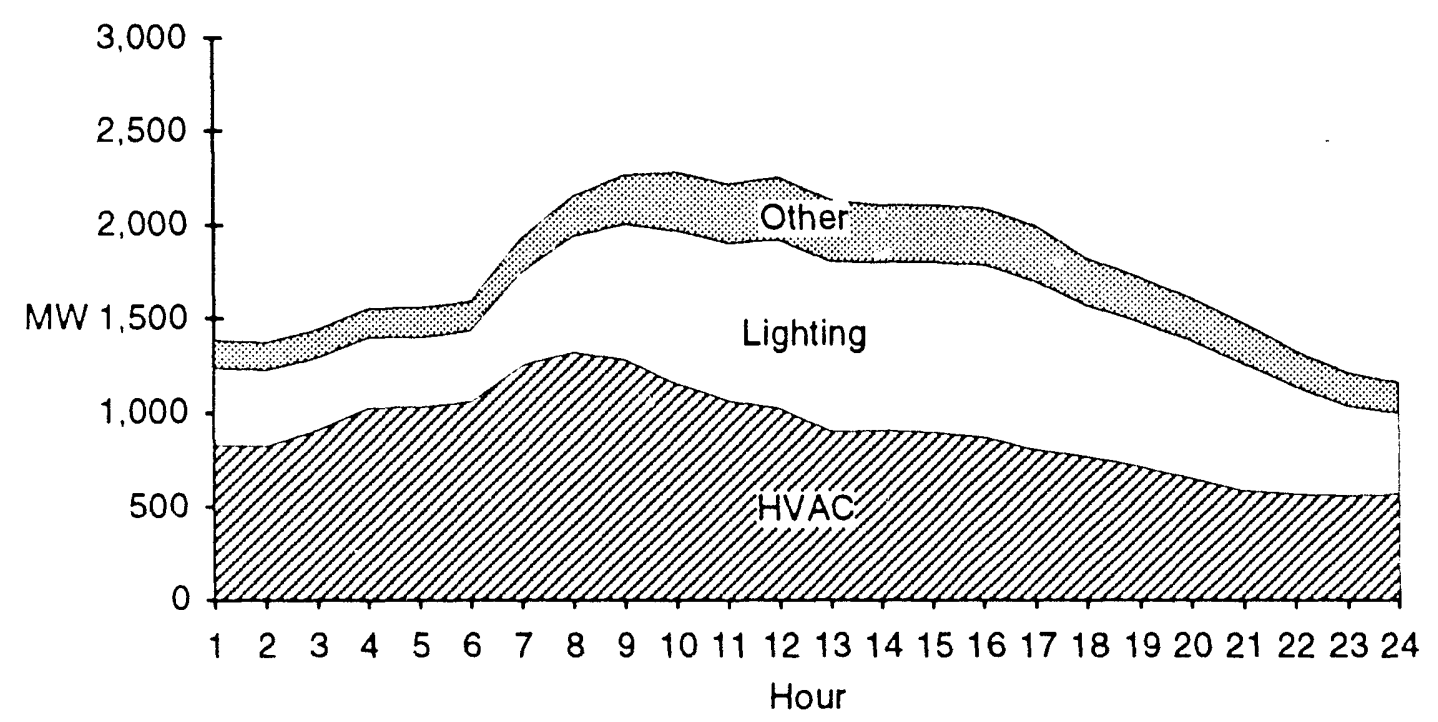

Figure D-5a. Commercial Sector Breakdown - Normal Peak Day

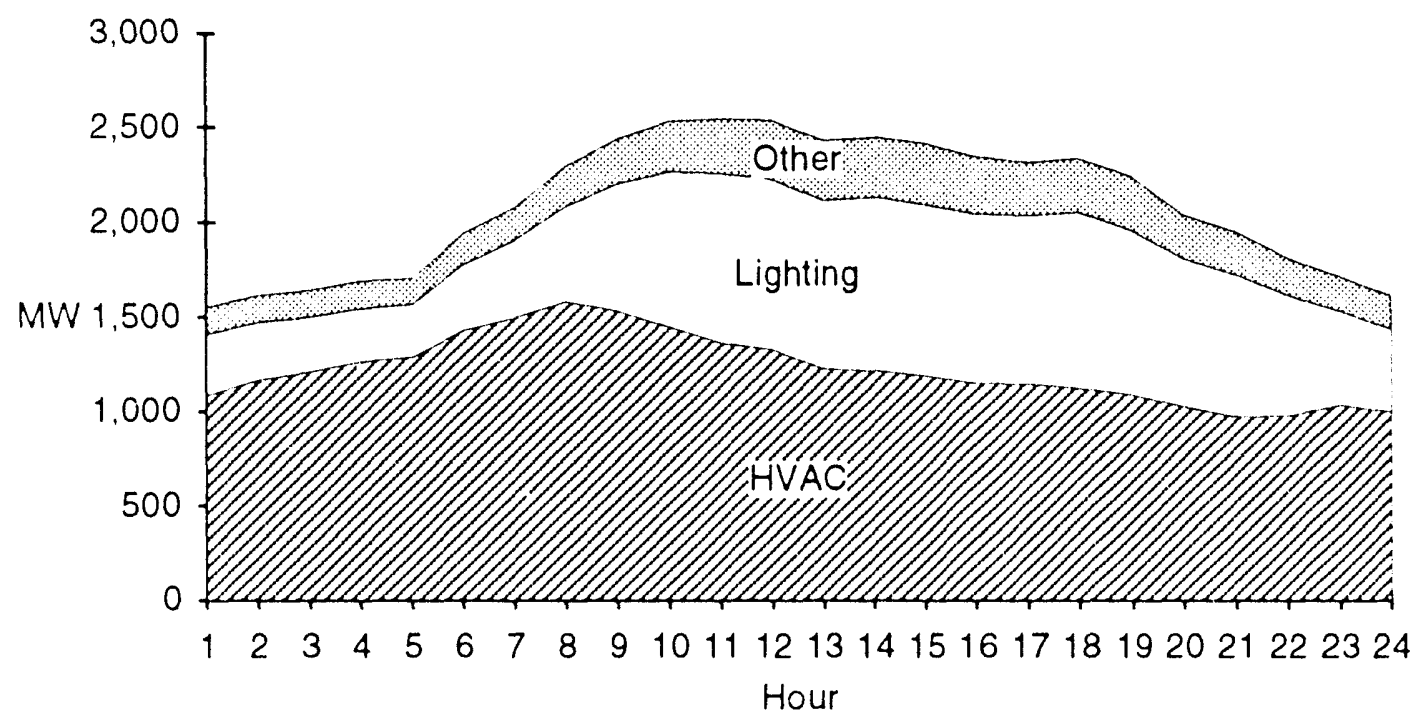

Figure D-5b. Commercial Sector Breakdown - Extreme Peak Day 
Table D.2.1 Difference Between Morning and Evening Peaks Simulation for 2010

\begin{tabular}{|c|c|c|}
\hline $\begin{array}{l}\text { Morning } \\
\text { Peak (MW) }\end{array}$ & $\begin{array}{l}\text { Evening } \\
\text { Peak (MW) }\end{array}$ & $\begin{array}{c}\text { Difference } \\
(M W)\end{array}$ \\
\hline $\begin{array}{l}13,856 \\
15,185\end{array}$ & $\begin{array}{l}12,720 \\
14,578\end{array}$ & $\begin{array}{r}1,136 \\
607\end{array}$ \\
\hline
\end{tabular}

Note that the difference between morning and evening peaks is smaller on an extreme peak day. Another view of potential savings is provided by the difference between peak and average load for a day shown in Table D.2.2. This is the theoretical maximum amount of savings that a load management program could provide.

Table D.2.2 Difference Between Morning Peak and Daily Average Simulation for 2010

\begin{tabular}{|c|c|c|}
\hline $\begin{array}{l}\text { Morning } \\
\text { Peak (MW) }\end{array}$ & $\begin{array}{l}\text { Daily } \\
\text { Average } \\
\text { (MW) }\end{array}$ & $\begin{array}{l}\text { Difference } \\
\text { (MW) }\end{array}$ \\
\hline $\begin{array}{l}13,856 \\
15,185\end{array}$ & $\begin{array}{l}11,278 \\
13,322\end{array}$ & $\begin{array}{l}2,578 \\
1,863\end{array}$ \\
\hline
\end{tabular}




\section{D.2.2 END-USE BREAKDOWN}

Electrical load in the Puget Sound area is modeled as the sum of 19 end-uses. There are three residential building types with three end-uses each for a total of nine. There are two commercial building types, office and nonoffice. File names for the 19 end-uses are listed in Table D.2.3.

Table D.2.3 End-Use Labels

$\begin{array}{lll}\text { RSFSH } & \text { Residential Single Family } & \text { Space Heat } \\ \text { RSFWH } & & \text { Water Heat } \\ \text { RSFOT } & & \text { Other } \\ \text { RMFSH } & \text { Residential Multi-Family } & \text { Space Heat } \\ \text { RMFWH } & & \text { Water Heat } \\ \text { RMFOT } & & \text { Other } \\ & & \\ \text { RMHSH } & \text { Manufactured Homes } & \text { Space Heat } \\ \text { RMHWH } & & \text { Water Heat } \\ \text { RMHOT } & & \text { Other } \\ \text { COFHV } & \text { Commercial Office } & \text { HVAC } \\ \text { COFLT } & & \text { Lighting } \\ \text { COFOT } & & \text { Other } \\ & & \text { HVAC } \\ \text { CNOHV } & \text { Commercial Non-Office } & \text { Lighting } \\ \text { CNOLT } & & \text { Refrigeration } \\ \text { CNORF } & & \text { Other } \\ \text { CNOOT } & & \\ \text { DIS } & \text { Direct Service Industries } & \\ \text { IND } & \text { Other Industrial } & \\ \text { OTH } & \text { Miscellaneous } & \end{array}$

ELCAP data provided load shapes for residential and commercial buildings. Derivation of the shapes is discussed in Gillman, Sands, and Lucas (1990). Figures D-6 through D-8 provide plots of end-use load shapes for an average winter day, a normal peak day, and an extreme peak day. The normal peak day was February 2, 1988 and the extreme peak day was February 3, 1989. 


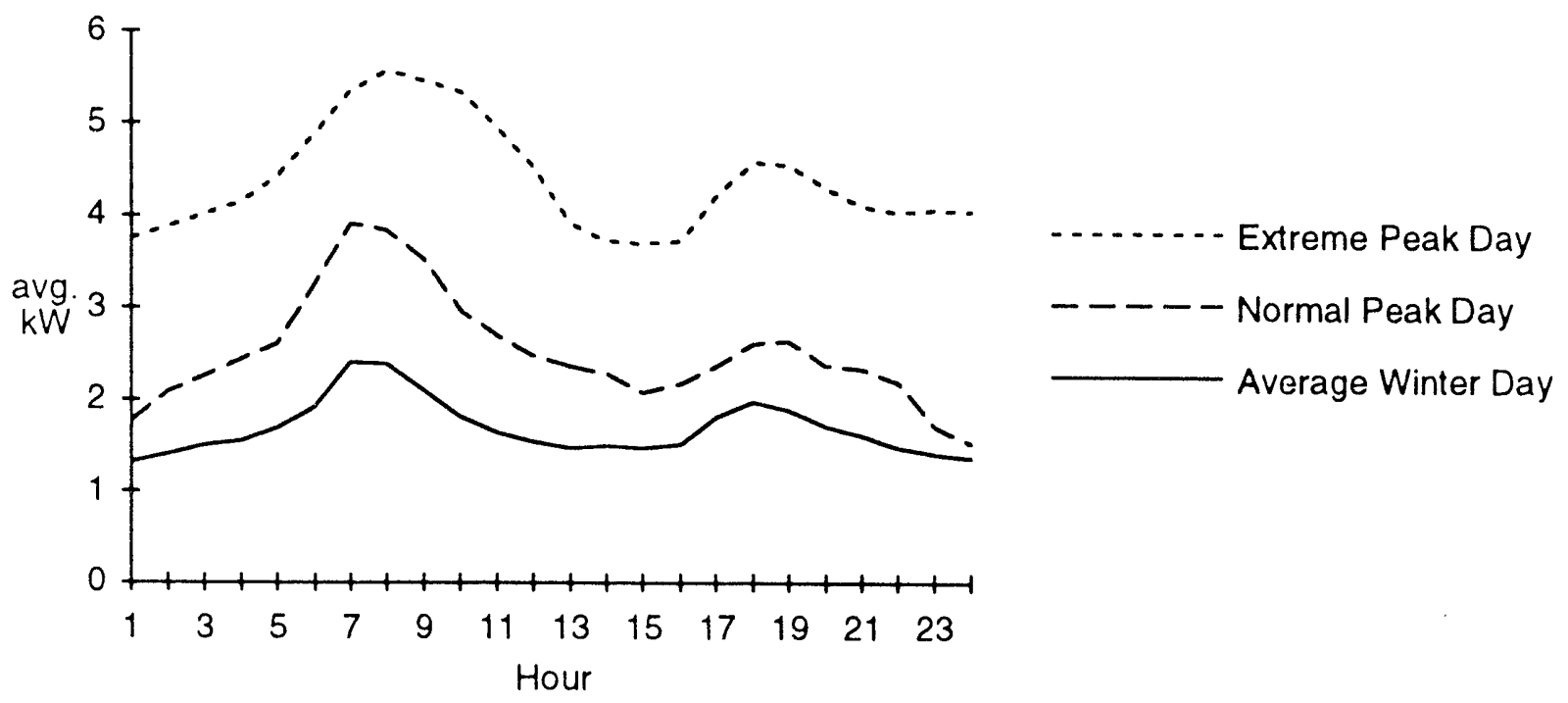

Figure D-6a. Space Heat Load Shapes - Existing Homes

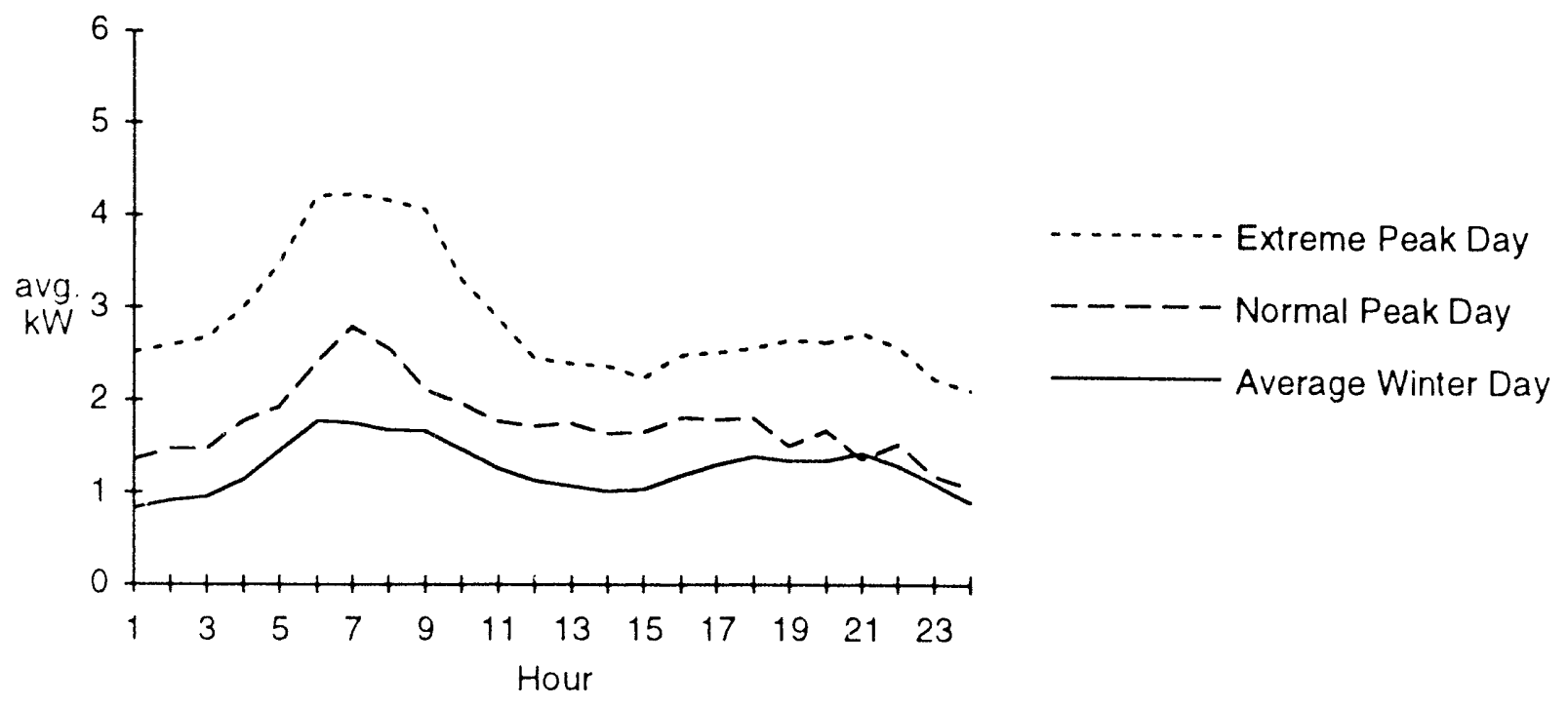

Figure D-6b. Space Heat Load Shapes - New Homes 


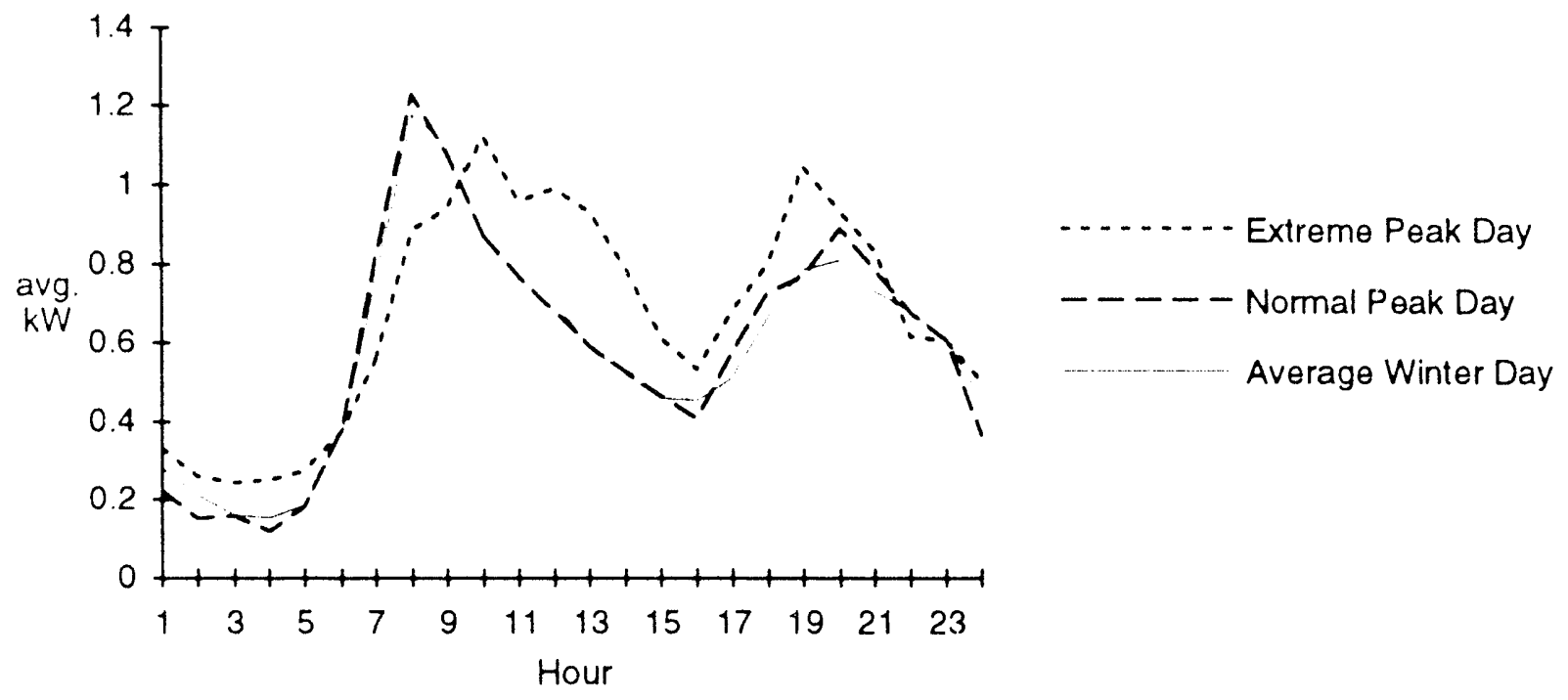

Figure D-7a. Residential Water Heat Load Shapes

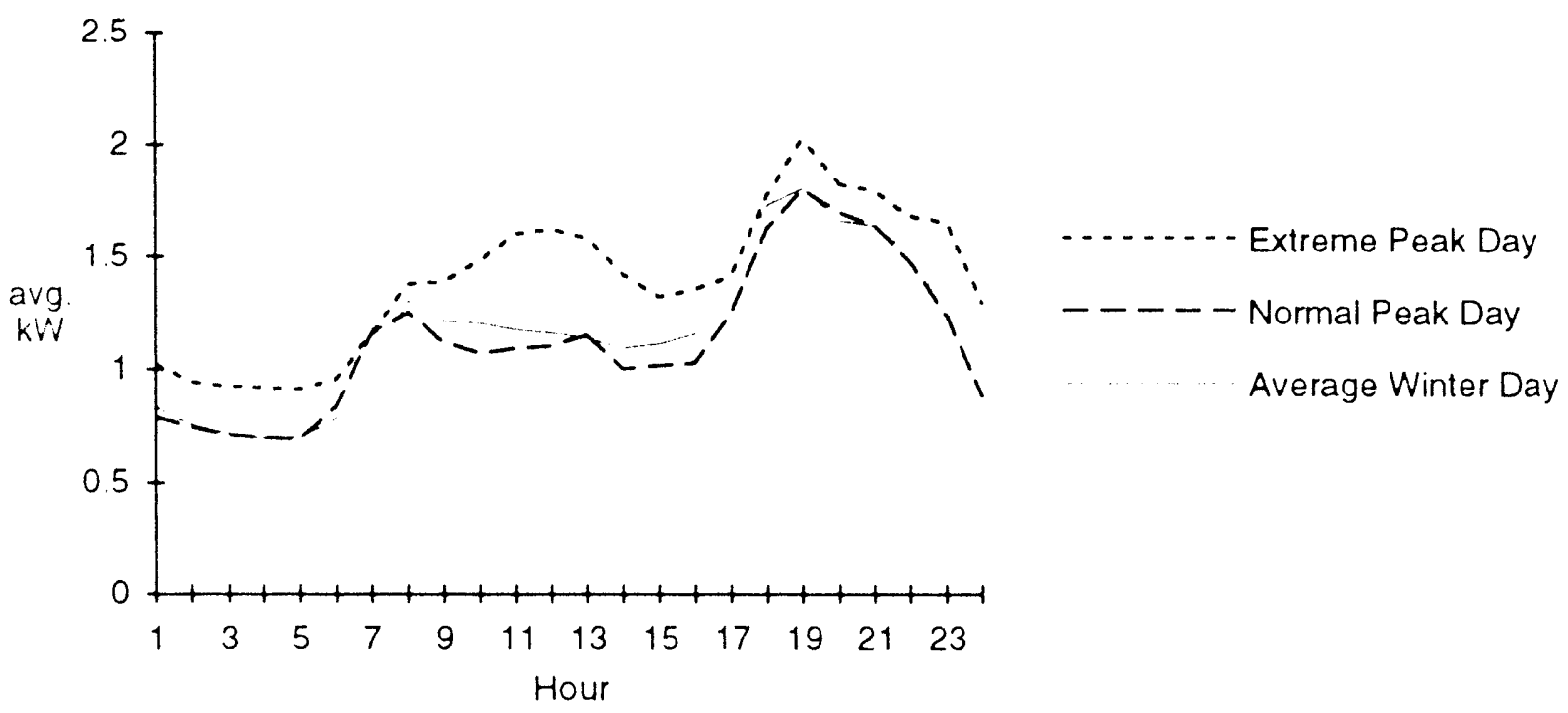

Figure D-7b. Residential Other Load Shapes 


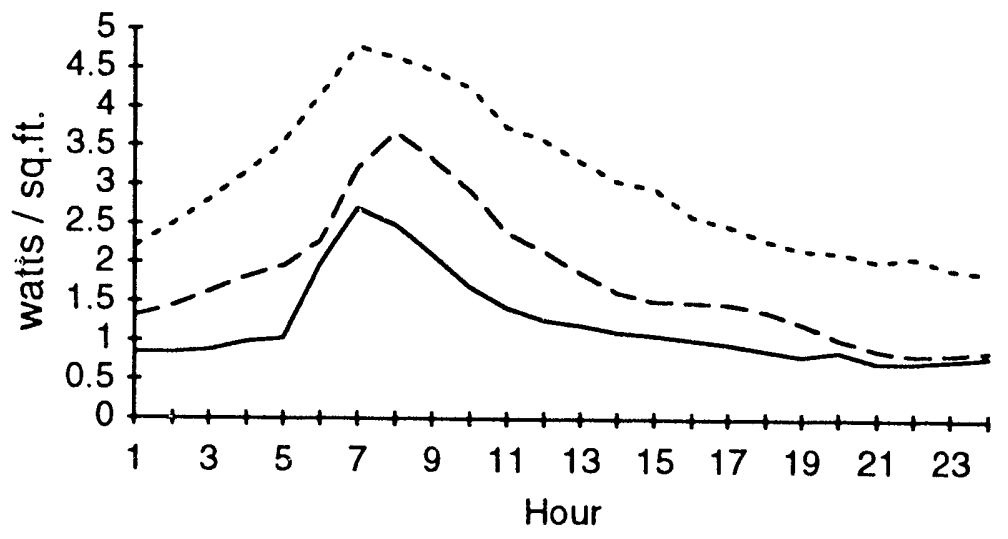

Extreme Peak Day

- - - - Normal Peak Day

Average Winter Day

Figure D-8a. Office HVAC Load Shapes

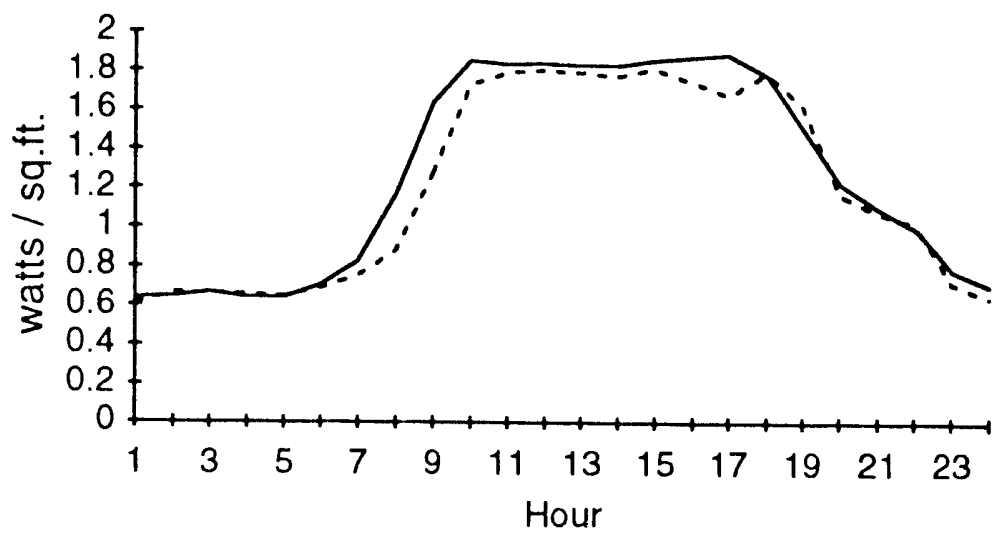

Extreme Peak Day

Average Winter Day

Figure D-8b. Office Lighting Load Shapes

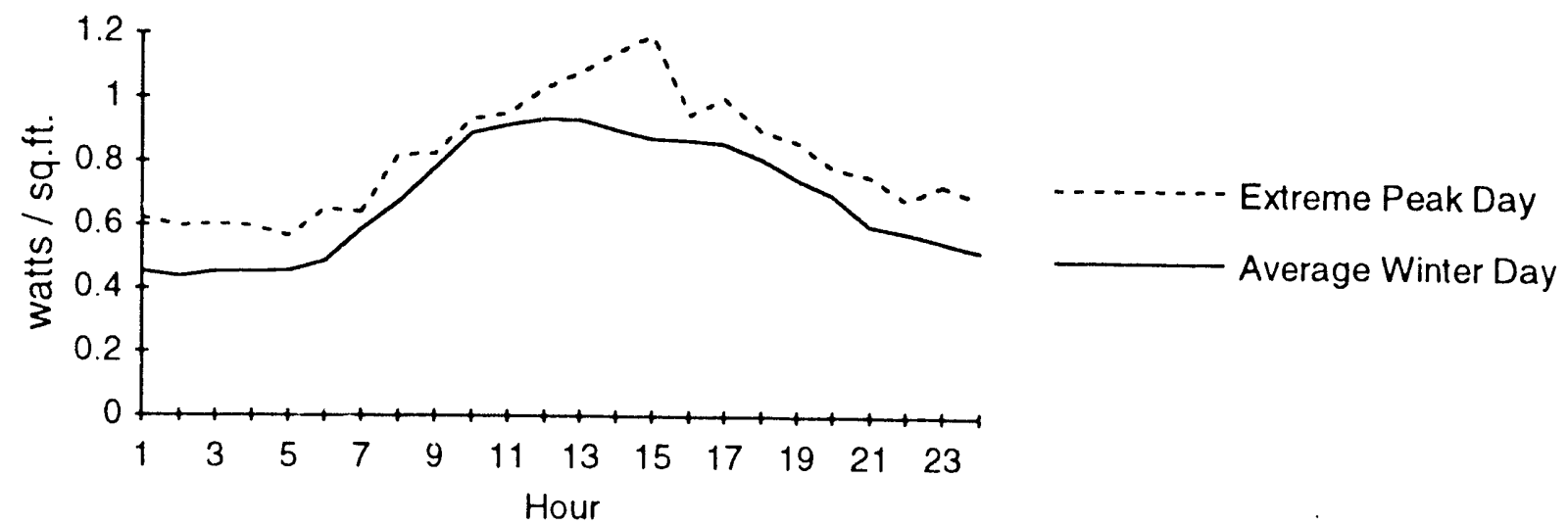

Figure D-8c. Office Other Load Shapes

$$
\text { D - } 19
$$




\section{D.2.3 END-USE DETAIL}

Tables D.2.4 through D.2.9 contain input assumptions for end-use simulations. Existing and new buildings are treated separately in some of the end-use models. Bonneville's Long Term Forecasting Section constructed a 20 year forecast by summing forecasts from utilities in the Puget Sound area.

\section{Table 0.2.4 Market Shares of Electricity}

\begin{tabular}{|c|c|c|c|}
\hline & $\underline{1990}$ & 2000 & 2010 \\
\hline $\begin{array}{l}\text { RSFSH Existing } \\
\text { RSFSH New } \\
\text { RSFWH Existing } \\
\text { RSFWH New } \\
\text { RSFOT }\end{array}$ & $\begin{array}{l}0.39 \\
0.34 \\
0.72 \\
0.36 \\
1.00\end{array}$ & $\begin{array}{l}0.38 \\
0.32 \\
0.69 \\
0.36 \\
1.00\end{array}$ & $\begin{array}{l}0.38 \\
0.30 \\
0.66 \\
0.36 \\
1.00\end{array}$ \\
\hline $\begin{array}{l}\text { RMFSH Existing } \\
\text { RMFSH New } \\
\text { RMFWH Existing } \\
\text { RMFWH New } \\
\text { RMFOT }\end{array}$ & $\begin{array}{l}0.84 \\
0.98 \\
0.85 \\
0.98 \\
1.00\end{array}$ & $\begin{array}{l}0.86 \\
0.98 \\
0.87 \\
0.98 \\
1.00\end{array}$ & $\begin{array}{l}0.87 \\
0.98 \\
0.88 \\
0.98 \\
1.00\end{array}$ \\
\hline $\begin{array}{l}\text { RMHSH Existing } \\
\text { RMHSH New } \\
\text { RMHWH Existing } \\
\text { RMHWH New } \\
\text { RMHOT }\end{array}$ & $\begin{array}{l}0.81 \\
0.80 \\
0.82 \\
0.80 \\
1.00\end{array}$ & $\begin{array}{l}0.80 \\
0.79 \\
0.81 \\
0.80 \\
1.00\end{array}$ & $\begin{array}{l}0.80 \\
0.79 \\
0.80 \\
0.80 \\
1.00\end{array}$ \\
\hline $\begin{array}{l}\text { COFHV Existing } \\
\text { COFHV New } \\
\text { COFLT } \\
\text { COFOT }\end{array}$ & $\begin{array}{l}0.70 \\
0.85 \\
1.00 \\
1.00\end{array}$ & $\begin{array}{l}0.75 \\
0.85 \\
1.00 \\
1.00\end{array}$ & $\begin{array}{l}0.80 \\
0.85 \\
1.00 \\
1.00\end{array}$ \\
\hline $\begin{array}{l}\text { CNOHV Existing } \\
\text { CNOHV New } \\
\text { CNOLT } \\
\text { CNORF } \\
\text { CNOOT }\end{array}$ & $\begin{array}{l}0.41 \\
0.50 \\
1.00 \\
0.65 \\
1.00\end{array}$ & $\begin{array}{l}0.46 \\
0.52 \\
1.00 \\
0.65 \\
1.00\end{array}$ & $\begin{array}{l}0.5 \\
0.5 \\
1.0 \\
0.6 \\
1.0\end{array}$ \\
\hline $\begin{array}{l}\text { DS I } \\
\text { IND } \\
\text { OTH }\end{array}$ & $\begin{array}{l}1.00 \\
1.00 \\
1.00\end{array}$ & $\begin{array}{l}1.00 \\
1.00 \\
1.00\end{array}$ & $\begin{array}{l}1.0 \\
1.0 \\
1.0\end{array}$ \\
\hline
\end{tabular}

$1.00=100$ percent 
Table D.2.5 Number of Households, Medium Growth Case

\begin{tabular}{|c|c|c|c|c|c|c|}
\hline & \multicolumn{2}{|c|}{$\begin{array}{l}\text { Single Family } \\
\text { Households }\end{array}$} & \multicolumn{2}{|c|}{$\begin{array}{l}\text { Multi-Family } \\
\text { Households }\end{array}$} & \multicolumn{2}{|c|}{$\begin{array}{l}\text { Manuf. Home } \\
\text { Households }\end{array}$} \\
\hline & Existing & New & Existing & New & Existing & New \\
\hline כ & $1,097,667$ & 0 & 431,144 & 0 & 106,106 & $v$ \\
\hline & $1,092,656$ & 23,729 & 429,197 & 19,797 & 105,608 & 3,783 \\
\hline 19 & $1,087,669$ & 47,927 & 427,258 & 40,134 & 105,112 & 8,127 \\
\hline 99 & $1,082,703$ & 69,780 & 425,329 & 57,652 & 104,618 & 12,252 \\
\hline 99 & 1,078 & 89,847 & 423,704 & 74,689 & 104,199 & 16,279 \\
\hline 9 & 73,591 & 108,810 & 421,790 & 90,564 & 103,710 & 284 \\
\hline & $1,068,689$ & 127,932 & 419,885 & 105,720 & 103,223 & 22,431 \\
\hline & 1,063 & 147,150 & 388 & 121,791 & 102,738 & 25,729 \\
\hline & 1,059 & 166,555 & 416,392 & 137,994 & 102,327 & 29,204 \\
\hline & 1 & 185 & & 109 & 101,774 & 32,805 \\
\hline & 1 & $20 !$ & & 17 & 101,296 & 36,603 \\
\hline & 1, & 225 & 41 & 18 & 100,820 & 40,211 \\
\hline & 1, & 244 & 40 & 78 & 100,346 & 43,828 \\
\hline & $1,034,982$ & 263 & 40 & 92 & 99,874 & 456 \\
\hline & 1,029 & 28 & 40 & 23 & 99 , & 056 \\
\hline & 1,024, & 545 & 402, & 383 & 98,867 & 54,700 \\
\hline & 1,020 & 183 & 401,005 & 746 & 98,402 & 58,355 \\
\hline & 15,4 & 891 & 399,191 & 287,310 & 97,939 & 62,020 \\
\hline & & 171 & 397 & , 238 & 97,478 &, 695 \\
\hline & 1 , & & 395 & , 758 & 97,019 & 69,382 \\
\hline & 1, & & & 342,741 & 96,563 &, 081 \\
\hline
\end{tabular}


Table D.2.6 Commercial Floor Space in

Thousands of Square Feet, Medium Growth

\begin{tabular}{|c|c|c|c|}
\hline \multicolumn{2}{|c|}{ Office } & \multicolumn{2}{|c|}{ Non office } \\
\hline Existing & New & Existing & $\mathrm{New}$ \\
\hline 182,835 & 1,847 & 621,585 & 6,279 \\
\hline 180,988 & 12,763 & 615,307 & 32,837 \\
\hline 179,142 & 23,680 & 609,028 & 59,396 \\
\hline 177,295 & 34,597 & 602,749 & 85,954 \\
\hline 175,448 & 45,513 & 596,471 & 112,512 \\
\hline 173,601 & 56,430 & 590,192 & 139,071 \\
\hline 171,754 & 65,049 & 583,914 & 162,429 \\
\hline 169,907 & 73,668 & 577,635 & 185,788 \\
\hline 168,061 & 82,286 & 571,356 & 209,147 \\
\hline 166,214 & 90,905 & $\begin{array}{l}565,078 \\
558,700\end{array}$ & $\begin{array}{l}232,505 \\
255,864\end{array}$ \\
\hline $\begin{array}{l}164,367 \\
162,520\end{array}$ & $\begin{array}{r}11,024 \\
111,094\end{array}$ & 552,520 & $\begin{array}{l}230,804 \\
282,657\end{array}$ \\
\hline 160,673 & 122,664 & 546,242 & 309,449 \\
\hline 158,827 & 134,234 & 539,963 & 336,242 \\
\hline 156,980 & 145,804 & 533,684 & 363,034 \\
\hline, 133 & 157,374 & 527,406 & 389,827 \\
\hline 153,286 & 168,944 & 521,127 & 416,619 \\
\hline 439 & 180,514 & 514,848 & 443,412 \\
\hline & 192 & 508,570 & 470,204 \\
\hline 746 & & 502,291 & 496,997 \\
\hline 145,899 & 215,224 & 496,013 & 523,789 \\
\hline
\end{tabular}

D -22 
Table D.2.7 Industrial Sector Consumption in Average Megawatts, Medium Growth Case

Industrial (aMW)

\begin{tabular}{cr}
\hline Existing & New \\
\cline { 2 - 2 } 1,142 & 0 \\
1,142 & 27 \\
1,142 & 54 \\
1,142 & 109 \\
1,142 & 164 \\
1,142 & 219 \\
1,142 & 246 \\
1,142 & 273 \\
1,142 & 300 \\
1,142 & 328 \\
1,142 & 355 \\
1,142 & 373 \\
1,142 & 391 \\
1,142 & 409 \\
1,142 & 428 \\
1,142 & 446 \\
1,142 & 480 \\
1,142 & 514 \\
1,142 & 549 \\
1,142 & 583 \\
1,142 & 617
\end{tabular}

D- 23 
Table D.2.8 Energy Benchmarks,

Annual Electricity Consumption in the Year 2000

Annual kWh per household for the residential sector:

Existing New

$\begin{array}{lll}\text { RSFSH } & 9,650 & 5,050 \\ \text { RSFWH } & 4,400 & 3,850 \\ \text { RSFOT } & 6,450 & 6,500 \\ & & \\ \text { RMFSH } & 3,925 & 1,800 \\ \text { RMFWH } & 2,700 & 2,350 \\ \text { RMFOT } & 3,500 & 3,550 \\ & & \\ \text { RMHSH } & 6,050 & 5,000 \\ \text { RMHWH } & 3,160 & 2,450 \\ \text { RMHOT } & 5,000 & 4,130\end{array}$

Annual kWh per 1,000 square feet for the commercial sector:

Existing New

$\begin{array}{lrr}\text { COFHV } & 11,750 & 11,500 \\ \text { COFLT } & 6,800 & 6,650 \\ \text { COFOT } & 3,600 & 3,700 \\ & & \\ \text { CNOHV } & 11,500 & 10,750 \\ \text { CNOLT } & 6,000 & 5,250 \\ \text { CNORF } & 1,800 & 1,650 \\ \text { CNOOT } & 2,200 & 2,200\end{array}$




\section{Table D.2.9 Ratio of Peak Day to Average Day Energy Consumption}

\begin{tabular}{lcc} 
& $\begin{array}{c}1 \text { in } 2 \\
\text { Peak Day }\end{array}$ & $\begin{array}{c}1 \text { in } 20 \\
\text { Peak Day }\end{array}$ \\
\cline { 2 - 3 } RSFSH Existing & 1.35 & 2.20 \\
RSFSH New & 1.25 & 1.90 \\
RSFWH & 1.02 & 1.10 \\
RSFOT & 1.15 & 1.20 \\
RMFSH Existing & 1.35 & \\
RMFSH New & 1.25 & 1.20 \\
RMFWH & 1.02 & 1.10 \\
RMFOT & 1.15 & 1.20 \\
& & \\
RMHSH Existing & 1.35 & 2.20 \\
RMHSH New & 1.25 & 1.90 \\
RMHWH & 1.02 & 1.10 \\
RMHOT & 1.15 & 1.20 \\
COFHV & & 1.95 \\
COFLT & 1.40 & 1.00 \\
COFOT & 1.00 & 1.00 \\
CNOHV & 1.00 & 1.95 \\
CNOLT & & 0.98 \\
CNORF & 1.45 & 1.00 \\
CNOOT & 1.00 & 0.98
\end{tabular}




\section{D.3.0 CONSERVATION}

Some of the conservation programs described here are accelerated versions of programs that Bonneville currently operates or may operate in the future. These programs were designed to provide annual energy savings and did not emphasize peak savings. This analysis of conservation programs was developed to answer the question, "What peak savings could realistically be achieved through the acceleration and creation of programs designed to meet regional energy needs?"

\section{D.3.1 OVERVIEW}

Conservation programs fall into three categories. The first is an acceleration of existing or planned programs that will capture all of the available conservation potentidl by 2010 . These include residential weatherization and industrial conservation programs. Peak savings for these programs are obtained sooner than previously planned. The second is the acceleration of a program for which the baseline, or planned savings, is not projected to capture all of the potential conservation savings by 2010 . commercial retrofit is such a program. The third is the low flow shower head program for which there is no existing or planned program. Methods used to calculate savirgs and costs are different for each type of program.

Programs in the first category have a baseline of activity that would occur regardless of decisions made to resolve the voltage stability problem in this area. This analysis only counts savings that can be achieved by accelerating these programs above the baseline. Figure $0-9 a$ illustrates this type of program with residential weatherization. The solid line shows the cumulative energy savings that would be achieved in the base case. The dotted line shows the cumulative saving's to be accomplished with the accelerated rrogram. A corresponding plot of peak savings is shown in Figure D-9b. Tha difference between these lines is the savings in each year due to accelerdion. The difference between accelerated and baseline savings reaches a maximum in the year 2000 and drops back to zero by 2010. In 2010 there are no additional savings because the baseline would have accomplished the same level of savings without an acceleration. Savings attributed to the accelerated programs are transitory, first increasing and then declining over the planning horizon.

The cost per kilowatt for accelerated programs is stated as an annual finance charge in place of the initial capital cost. Since the cost of installation would have been incurred anyway, the real social cost of acceleration is only the time value of money because money is spent earlier than previously planned. Annual finance costs shown in worksheets for accelerated weatherization and industrial conservation are equal to $3 \%$ of capital cost. A real interest rate of $3 \%$ is assumed for all cost calculations.

The second category of program is represented by commercial sector conservation. There is a baseline which is not forecasted to capture all of the available conservation potential. Savings from program acceleration are cumulative savings above the baselino. Costs for this type of progran count

$$
D-25
$$




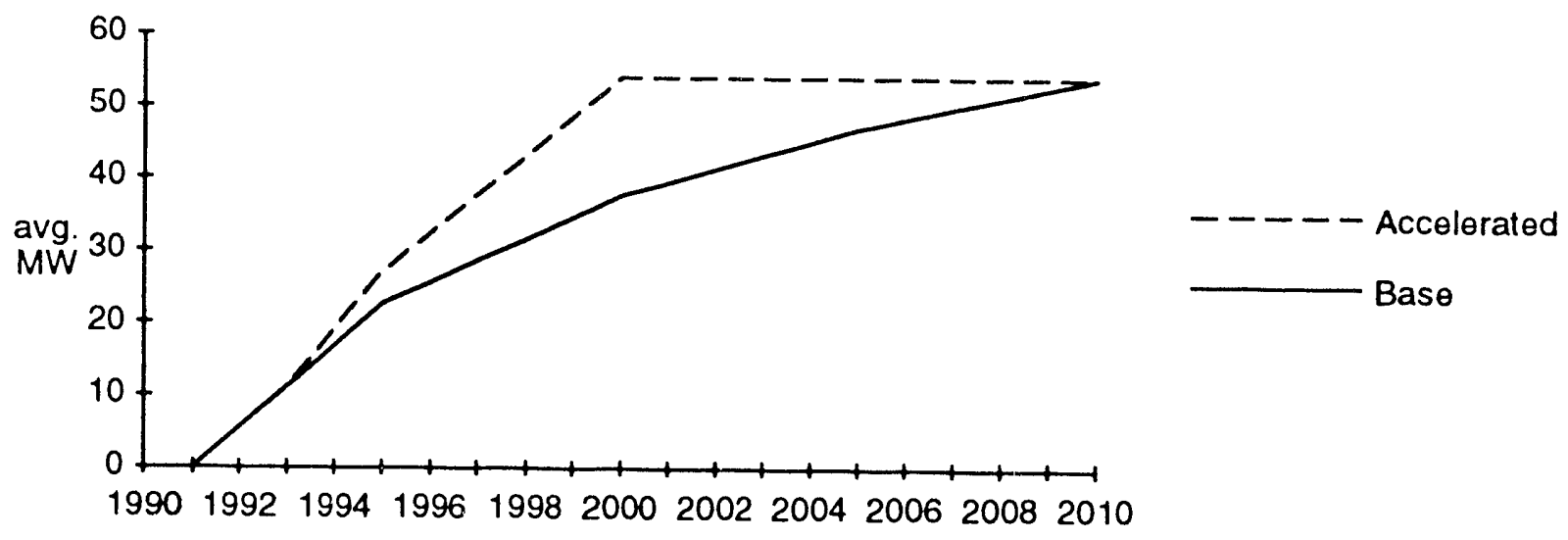

Figure D-9a. Energy Targets - Residential Weatherization

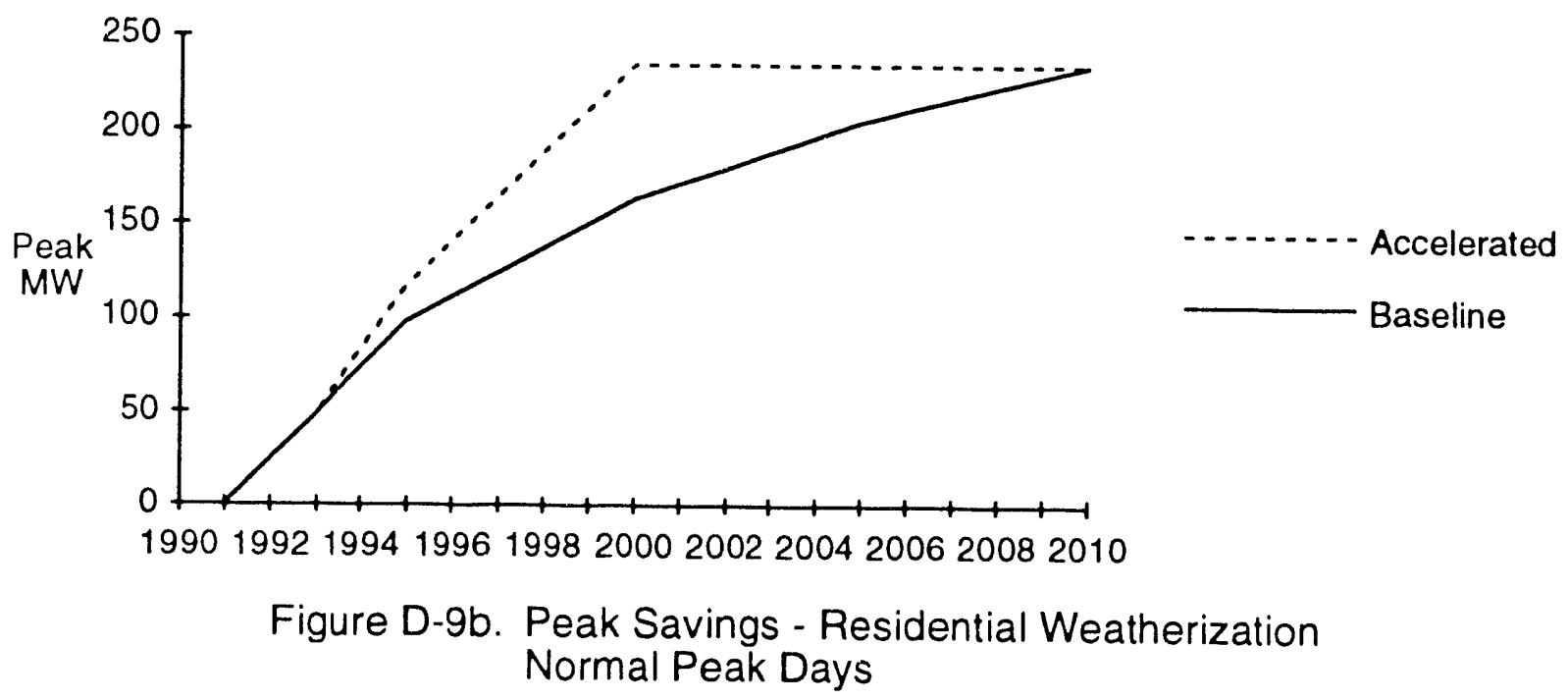

D - 27 
the full capital costs of all conservation measures installed that acquire savings above the baseline. This is appropriate because the program acceleration is assumed to be installing measures that would not have otherwise been installed.

The third type of program is represented by low flow shower heads. No program was previously planned so there is no baseline acquisition level. For this reason, full capital cost is used to calculate cost per kilowatt of peak savings for this program.

\section{Conservation Potential in the Puget Sound Area}

Conservation potential for each sector in the Puget Sound area is the sum of conservation potentials for the public utilities and for Puget Sound Power and Light. Puget Power provided estimates of the conservation potential for its commercial, residential, and industrial sectors. Bonneville calculated the conservation potential for the public utilities by estimating the share of conservation potential within the entire Bonneville service area that will occur in the Puget Sound area. The conservation savings for each sector are assumed to be proportional to the Puget Sound area loads for each sector. For example, $47 \%$ of the residential load in the Bonneville service area is located in the Puget Sound area so it is assumed that $47 \%$ of the conservation potential is also located in the Puget Sound area.

Estimates of conservation potential for the entire Bonneville service area were taken from the 1990 Resource Program documents. These are based on conservation supply estimates developed by Bonneville and summarized in the Draft 1990 Conservation Resources Supply Document.

Conservation potential is a function of the load forecast. Higher load forecasts mean more units that can be weatherized, insulated or otherwise fixed up and a higher conservation or load management potential. All estimates presented in this section are based on a medium load growth forecast.

\section{Conservation Program Baselines and Accelerated Program Levels}

Conservation baselines for the public utility areas were derived from Bonneville's 1990 Resource Program documents. The Resource Program presented budget and savings forecasts through fiscal year 1997 . These were used to develop conservation baselines for the public utilities. Baseline energy targets for 1998 through 2010 were derived by consensus of the Conservation and Load Management Team, which included representatives from utilities in the Puget Sound area. The conservation baseline for the entire Puget Sound area is the sum of the projected savings by Puget Power and the projected savings. from Bonneville programs to be operated by the public utilities.

Program targets were specified in terms of the average annual energy savinus that could be achieved by a new or accelerated program. Peak savings wer. calculated using an hourly simulation model. Plant factors. or annual lod

$$
\text { D- } 28
$$


factors, were derived from the energy and peak numbers. A plant factor is the ratio of mean hourly energy savings over the entire year to the savings that occur during the system peak hour.

The first program analyses, completed in July 1990, scheduled programs to start up or accelerate in 1992. Energy targets were initially set up for 1995, 2000, 2005, and 2010. However, the start year was later delayed to 1994. Part of the delay was due to the fact that peak savings 1 ag program spending. Money spent in fiscal year 1993 (October 1992 through September 1993) will provide little or no peak savings during the winter of 1992-1993. Peak savings cannot be counted on until fiscal year 1994. Penetration ramps show 1994 as the first year with additional peak savings.

Forecasted program levels were developed by the Conservation and Load Management Team and are the result of group judgement rather than any analytical procedure. The team came up with estimates of the percentage of total conservation potential that could be achieved by 1995, 2000, 2005, and 2010 (some of these targets were later delayed by two years). Energy targets for intermediate years were derived by interpolation.

Programs that persuade consumers to switch from electricity to natural gas could reduce the conservation potential from some conservation programs. Fewer houses would be heated with electricity or have electric water heaters so the energy and peak savings from conservation programs would be somewhat reduced. The tables in this section present savings potential in the absence of fuel switching programs. Please see Section 6 for a discussion of the consequences to the cniservation programs of the proposed fuel switching programs.

\section{Summary Worksheets}

A summary worksheet is provided for each conservation and load management program. For example, see the single family weatherization summary in Table 0.3 .1 . The worksheets provide a quick overview of assumptions, costs, and savings for each program.

Each worksheet was printed directly from an hourly end-use simulation model created for this study. At the top of each worksheet are cost assumptions. including initial and maintenance costs. Just below the cost numbers are energy and peak savings per household. Costs are then converted from a per household basis to a per $\mathrm{kW}$ basis.

The bottom half of each summary worksheet contains the number of participating households, average energy savings, peak savings on a 1 in 2 day, and peak savings on a 1 in 20 day. Model output is provided for all years from 1990 through 2010. 
Table D.3.1 Summary Workshent of Accelerated Weatherization (Single Family)

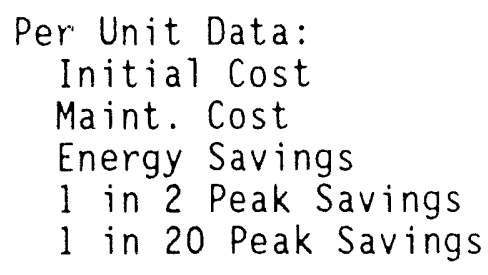

Per KW Costs o 2000: Finance per Year

$$
\begin{array}{rl}
\$ 2,550 & \\
\$ 0 & \\
2,700 & \mathrm{kWh} \text { per year } \\
1.342 \mathrm{~kW} & \text { e } 2000 \\
1.788 \mathrm{~kW} & \text { d } 2000
\end{array}
$$
Plant Factor
0.230
0.172

1990

1991

1992

1993

1994

1995

1996

1997

1998

1999

2000

2001

2002

2003

2004

2005

2006

2007

2008

2009

2010
Energy

Savings

(aMW)

0.0

0.0

0.0

0.0

1.6

3.1

4.8

6.5

8.2

9.8

11.4

10.1

8.8

7.5

6.2

4.9

3.9

2.9

1.9

1.0

0.0

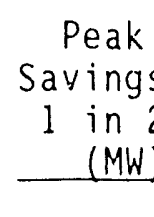

0.0

0.0

0.0

0.0

6.8

13.5

20.9

28.3

35.5

42.6

49.7

43.9

38.2

32.5

26.9

21.3

17.0

12.7

8.4

4.2

0.0
Peak

Savings

1 in 20

(MW)

0.0

0.0

0.0

0.0

9.0

18.0

27.9

37.7

47.3

56.8

66.2

58.5

50.9

43.3

35.8

28.4

22.6

16.9

11.2

5.6

0.0 


\section{D.3.2 ACCELERATED WEATHERIZATION}

This is an acceleration of the existing weatherization program. This program reduces energy consumption for residential space heating in single and multifamily dwellings. These housing types are modeled separately because costs and savings vary by dwelling type. Targeted savings in average megawatts are shown in Table D.3.2.

In the baseline the remaining homes in the area would all have been weatherized by 2010. Accelerated weatherization is assumed to be complete by 2000. Energy and peak savings first increase and then decline back to zero because the accelerated program accomplishes by 2000 what the baseline would accomplish by 2010 .

\section{$\underline{\text { Costs }}$}

Costs for this program are the sum of equipment costs plus a $20 \%$ adder for administrative costs. Costs are reported as annual finance costs, based on a $3 \%$ real interest rate, because this program only accelerates spending that is scheduled to occur anyway. Cost estimates and energy savings estimates are taken from the residential weatherization supply curve as developed for Bonneville's 1990 Resource Program.

Finance costs, reported in Tables D.3.1 and D.3.3, are derived by multiplying the initial cost of weatherizing a home by $3 \%$. Then an adjustment is made to convert costs from a per household basis to a per kilowatt basis. For example, $3 \%$ of the $\$ 2,550$ it costs to weatherize a single family home is $\$ 76.50$. This is divided by $1.342 \mathrm{~kW}$ to obtain $\$ 57$, the annual cost per $\mathrm{kW}$ on a 1 in 2 peak day.

\section{$\underline{\text { Impacts }}$}

Energy savings for a weatherized single family home are assumed to be 2,700 kWh per year and are distributed in the same way as a space heating load shape. The program case load shape is therefore proportional to the base case load shape. Annual energy savings for multi-family homes are $1363 \mathrm{kWh}$ per year.

Energy targets, for single family and multi-family homes combined, are displayed graphically in Figure D-9a. The corresponding peak savings are shown in Figure D-9b.

\section{Issues}

The major issue regarding this program is that conservation case load shapes were derived by simply scaling hourly space heat load shapes. Another method would be to translate the base case load shape, or shift the load shape down by the same amount each hour. The two methods together would provide a range of estimates for peak savings. 
Table D.3.2 Energy Targets for Weatherization of Residential Buildings

Single Family Weatherization

Annual Energy Savings (aMW)

Already

Accelerated

Total

Planned

Conservation

Conservation

1995

2000

2005

2010

15.8

26.1

32.7

37.6

3.1

11.4

18.9

37.5

4.9

37.6

0.0

37.6

Multi-Family Weatherization

Annual Energy Savings (aMW)

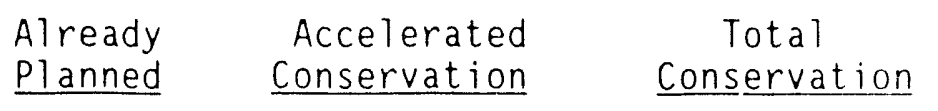

1995

2000

2005

6.8

1.3

5.0

2.1

14.3

16.4

0.0

8.1

16.5

16.5

16.4

Savings reported in Tables D.3.1 and D.3.3 are for the accelerated portion only. Both peak and energy savings reach a maximum in 2000 and then decline to zero by 2010 . Note that peak savings are much larger than average energy savings. 
Table 0.3.3 Summary Works'neet of Accelerated

Weatherization (Multi-Family)

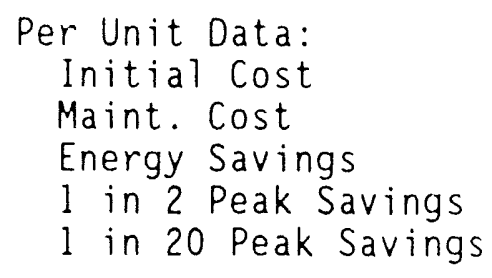

Per KW Costs o 2000:

Finance per Year

Plant Factor

1990

1991

1992

1993

1994

1995

1996

1997

1998

1999

2000

2001

2002

2003

2004

2005

2005

2007

2008

2009

2010
Program

(Households)

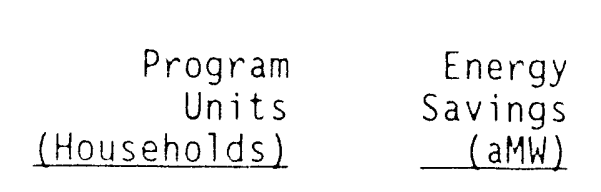

0.0

0.0

0.0

0.0

4,186

8,354

13,151

17,927

22,698

27,416

32,128

28,352

24,600

20,874

17,160

13,485

10,751

8,036

5,340

2, 661
0.7

1.3

2.0

2.8

3.5

4.3

5.0

4.4

3. 8

3.2

2.7

2.1

1.7

1.3

0.8

0.4

0.0

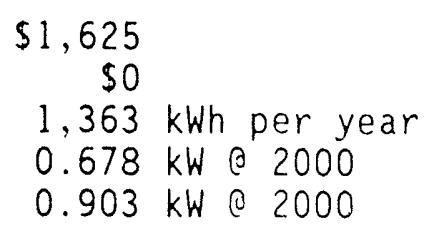

$0.903 \mathrm{~kW} \odot 2000$

$\frac{1 \text { in } 2}{572} \quad \frac{1 \text { in } 20}{\$ 54}$
0.230
0.172

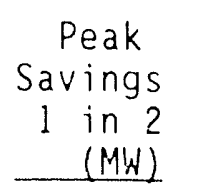

0.0

0.0

0.0

0.0

2.8

5.7

8.9

12.1

15.4

18.6

21.8

19.2

16.7

14.1

11.6

9.1

7.3

5.4

3.6

1.8

0.0
Peak

Savings

1 in 20

(MW)

0.0

0.0

0.0

0.0

3.8

7.5

11.9

16.2

20.5

24.7

29.0

25.6

22.2

18.8

15.5

12.2

9.7

7.3

4.8

2.4

0.0 


\section{D.3.3 ACCELERATED INDUSTRIAL CONSERVATION}

This is an acceleration of the existing industrial conservation Energy Savings Program (E\$P) which seeks out conservation projects in all industrial firms in the Standard Industrial Classifications (SIC) 20 - 39 except for aluminum smelters. These industrial classifications includes food processing, wood products, paper, and chemicals. Since this is an acceleration of an existing program that would capture all potential by 2010 , incremental savings due to acceleration increase to 2002 and decline back to zero in 2010.

Load shapes for the industrial sector were developed by Bonneville's industrial load forecasters. These load shapes are quite flat over the months of the year and hours of the day. Conservation program shapes are assumed to be scaled versions of load shapes prior to conservation. Industrial loads are not temperature-sensitive so they do not peak when the system loads peak.

\section{Impacts}

The baseline assumes the entire conservation potential would be acquired by 2010 and the program case acquires this amount by 2002. The incremental conservation shown in Table 0.3 .4 is the difference between this program case and the baseline which was taken from the 1990 Resource Program. Figures D$10 \mathrm{a}$ and D-10b show the energy and peak savings for the baseline and program cases.

Industrial conservation is modeled as a $5 \%$ reduction in electrical load at all hours of the day because the industrial supply curves indicate that the conservation potential for industries in this area is equal to about $5 \%$ of the industrial loads (see Figure $D-10 \mathrm{C}$ ). Program penetration rates were chosen to meet energy targets in Figure D-10a.

\section{$\underline{\text { Costs }}$}

The industrial supply curve report states that an akW of electricity savings has an average cost of $\$ 1,606$. Adding $20 \%$ for administrative costs brings this to $\$ 1,926$ per akW.

As with residential weatherization, costs are reported as the finance cost of installing conservation measures sooner than otherwise planned. This is done by multiplying $\$ 1,926$ by $3 \%$, the real interest rate, to obtain an annual finance charge of $\$ 57.78$ per akW saved. Finally, the finance charge is divided by peak savings in $\mathrm{kW}$ to derive the $\$ 56$ annual finance cost per $\mathrm{kW}$. 


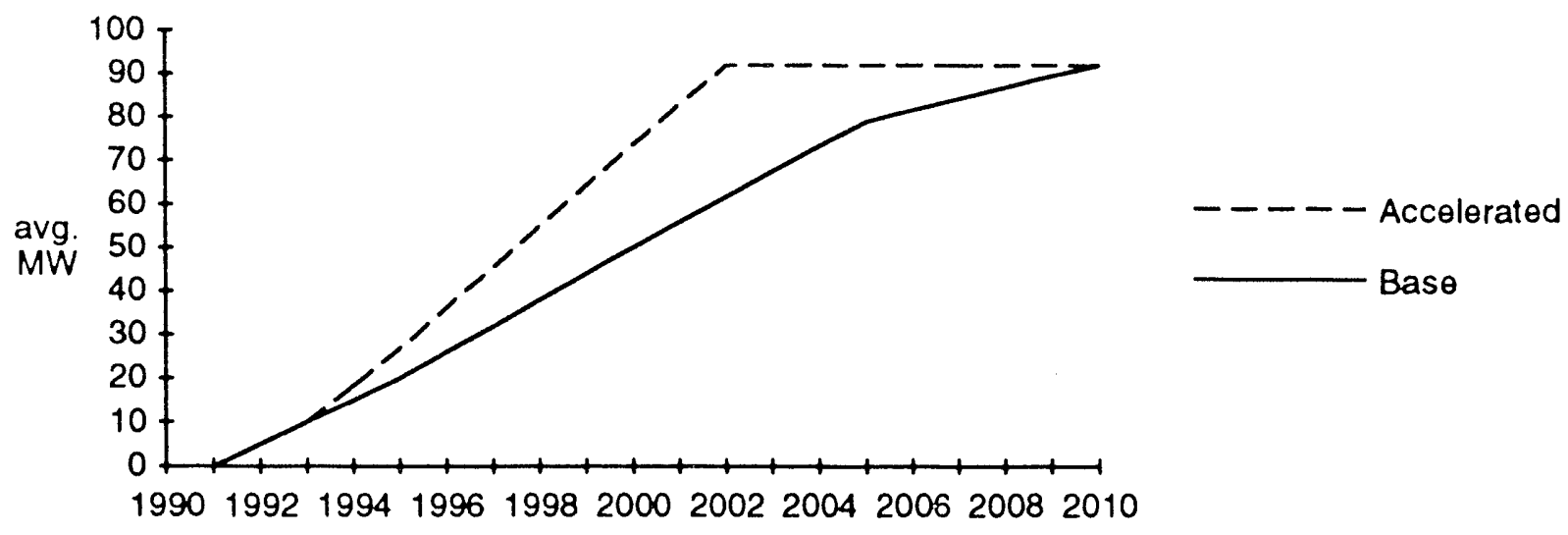

Figure D-10a. Energy Targets - Industrial Conservation

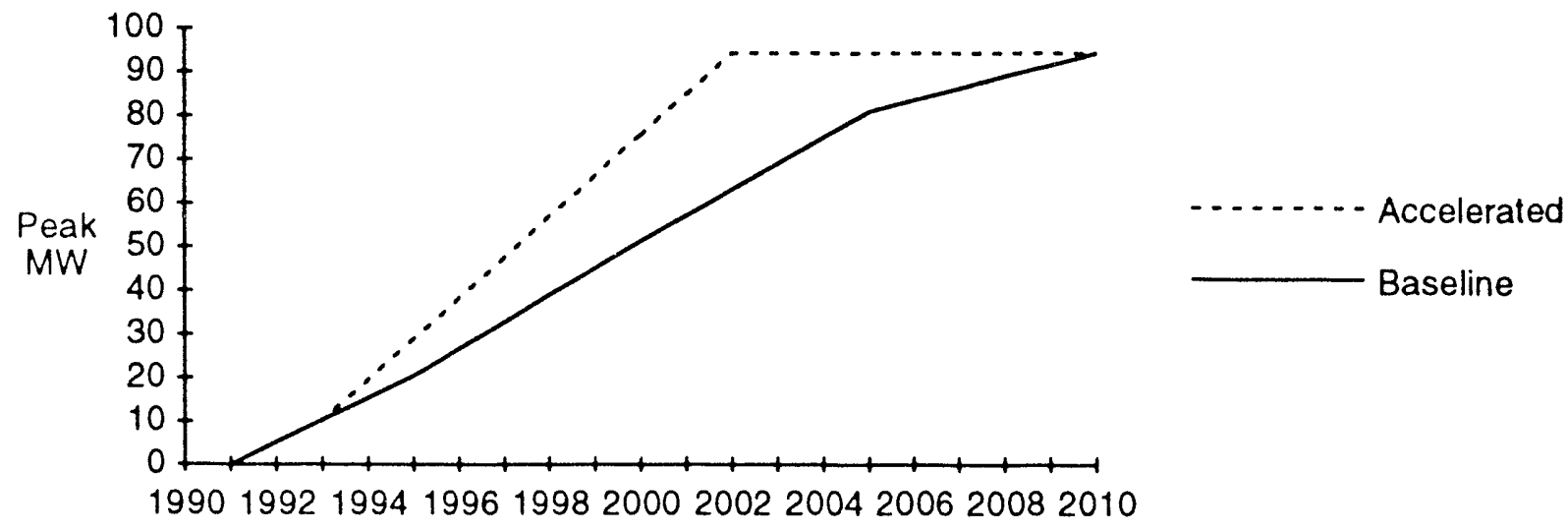

Figure D-10b. Peak Savings - Industrial Conservation Normal Peak Days

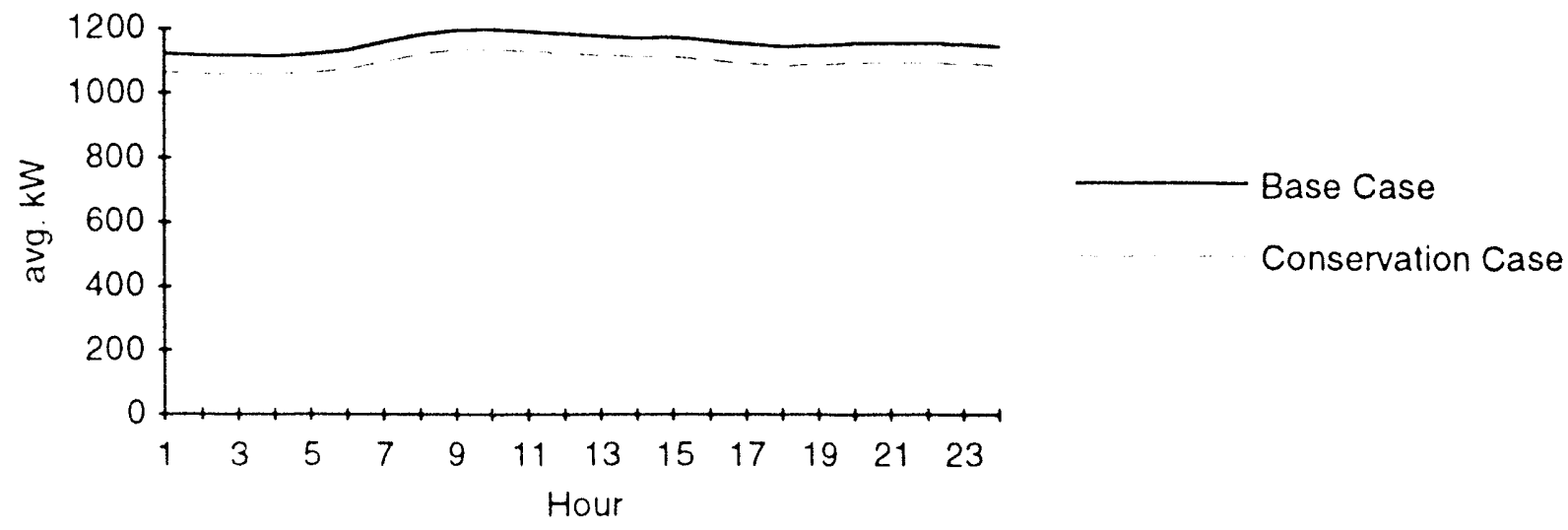

Figure D-10c. Industrial Conservation Load Shapes - All Day Types

D - 35 
Table 0.3.4 Summary Worksheet of

Accelerated Industrial Conservation at Medium Load Growth

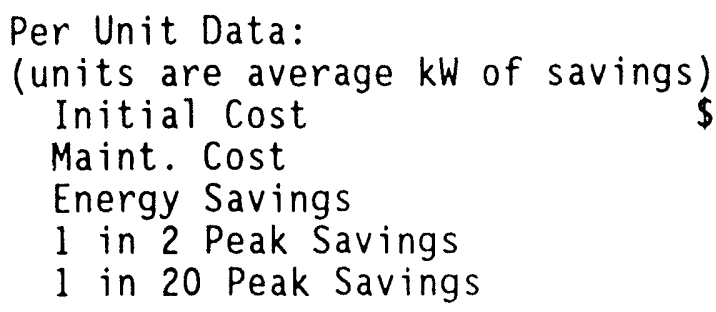

$\$ 1,926$

\section{$\$ 0$}

$8,760 \mathrm{kWh}$ per year

$1.024 \mathrm{~kW}$ e 2000

$1.034 \mathrm{~kW} \odot 2000$ $\begin{array}{ll}0.977 & 0.967\end{array}$

\begin{tabular}{rr} 
Peak & Peak \\
Savings & Savings \\
1 in 2 & 1 in 20 \\
$(M W)$ & $(M W)$ \\
\hline
\end{tabular}

0.0

0.0

$\begin{array}{ll}0.0 & 0.0\end{array}$

$\begin{array}{ll}0.0 & 0.0\end{array}$

$0.0 \quad 0.0$

$4.0 \quad 4.1$

$8.4 \quad 8.5$

$11.4 \quad 11.5$

$\begin{array}{ll}14.5 & 14.6\end{array}$

$\begin{array}{ll}17.6 & 17.8\end{array}$

$21.0 \quad 21.2$

$24.4 \quad 24.6$

$27.7 \quad 28.0$

$31.2 \quad 31.5$

$25.4 \quad 25.6$

$\begin{array}{ll}19.4 & 19.6\end{array}$

$13.3 \quad 13.5$

$10.9 \quad 11.0$

$8.3 \quad 8.4$

$\begin{array}{ll}5.7 & 5.7\end{array}$

$\begin{array}{ll}2.9 & 2.9\end{array}$

$\begin{array}{ll}0.0 & 0.0\end{array}$ 


\section{D.3.4 COMMERCIAL RETROFIT}

This program is an acceleration of the long term commercial acquisition program currently under development at Bonneville. This program will provide a package of retrofit measures for buildings in the commercial sector. The commercial sector includes four end-uses: HVAC, lighting, refrigeration, and other equipment (mostly equipment that plugs into an outlet).

Costs and estimates of the commercial conservation potential are taken from the existing commercial supply curve used in the 1990 Resource program. This program accelerates the existing program. However, the commercial conservation baseline does not capture all of the commercial conservation by 2010. For this reason, it is assumed that all savings from the accelerated program are from measures that otherwise would not be installed at all within the study period.

\section{$\underline{\text { Impacts }}$}

The commercial retrofit program was modeled as a $10 \%$ reduction in load for a portion of commercial buildings in the Puget Sound area. Penetration rates were chosen to meet the energy targets shown in Table D.3.5. Energy targets are shown graphically in Figure D-1la with corresponding peak savings in Figure D-11b. The effect of conservation on a typical office lighting load shape is shown in Figure D-11C. Table D.3.6 summarizes energy and peak savings for each year.

\section{Table 0.3.5 Commercial Retrofit Program Energy Targets (aMW)}

$\begin{array}{llc}\text { Already } & \text { Additional } & \text { Total } \\ \text { Planned } & \text { Conservation } & \text { Conservation }\end{array}$

1995

2000

2005

2010

24
46
66
81

5

38

60

87
29

84

126

168

The conservation and load management team estimated that about $7 \%$ of conservation potential could be acquired by $1995,20 \%$ by $2000,33 \%$ by 2005 and the remaining $40 \%$ by 2010 . A delay in the start of the acceleration from 1992 to 1994 reduces the forecasted accomplishments in the early years. Penetration paths shown in Figures D-1la and D-11b were derived by linear interpolation.

\section{Costs}

A cost of \$2,212 per average kilowatt saved, with no maintenance or incentive costs, was assumed. This cost, in terms of average kilowatts, is then

$$
\text { D }-37
$$


converted to a cost per peak kilowatt. For a 1 in 2 peak day, each averagle kilowatt of savings has a corresponding peak savings of $1.557 \mathrm{~kW}$. This increases to $1.759 \mathrm{~kW}$ on a 1 in 20 day. A summary of cost per kilowatt calculations is provided in Table D.3.6.

\section{Issues}

Conservation in the commercial sector is not broken down into separate programs, as has been done in the residential sector. Conservation case load shapes are simply scaled versions of base case load shapes, with all end-uses treated in the same way. A more detailed study would model each commercial program separately, with savings targeted to specific end-uses. Interactions between end-uses would also need to be simulated. For example, a commercial lighting program will decrease electricity consumption for lights, but increase demand for electric space heat. 


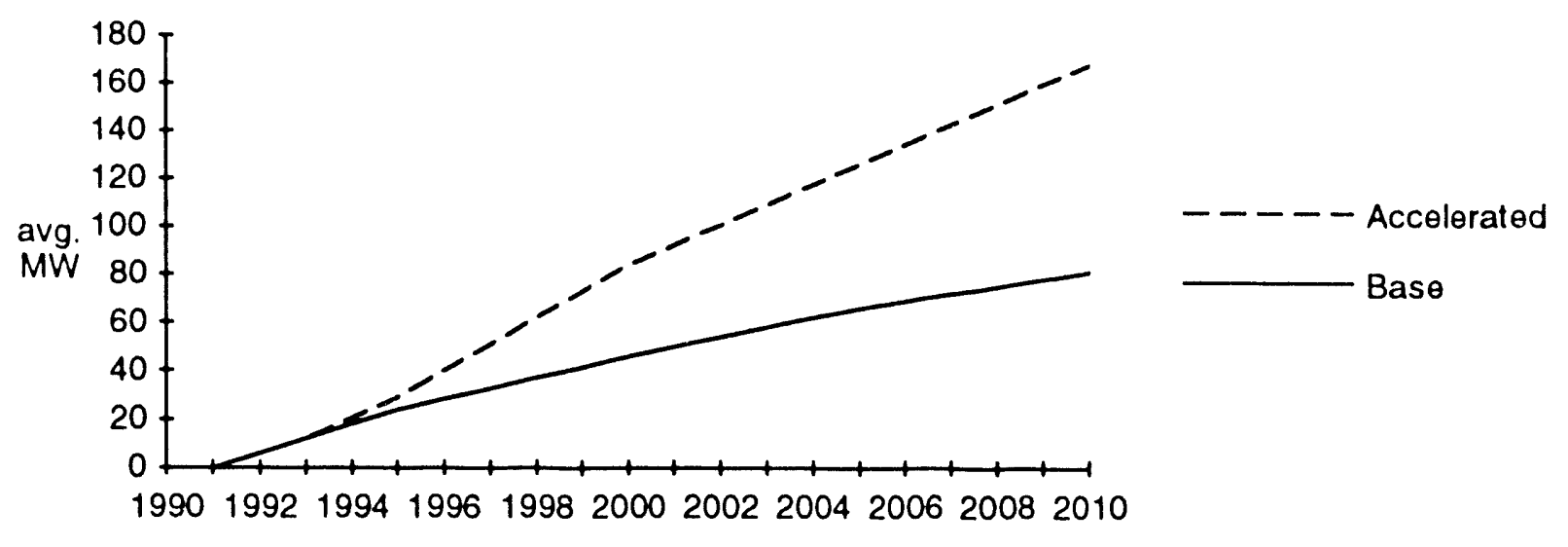

Figure D-11a. Energy Targets - Commercial Retrofit

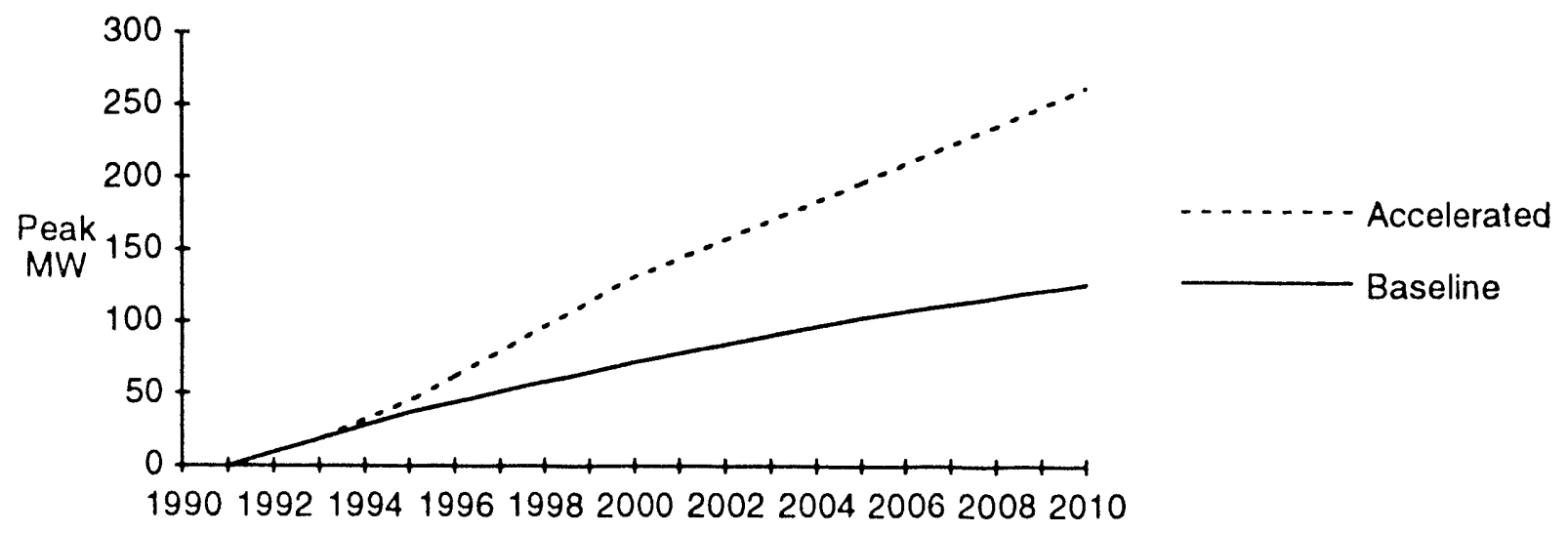

Figure D-11b. Peak Savings - Commercial Retrofit Normal Peak Days

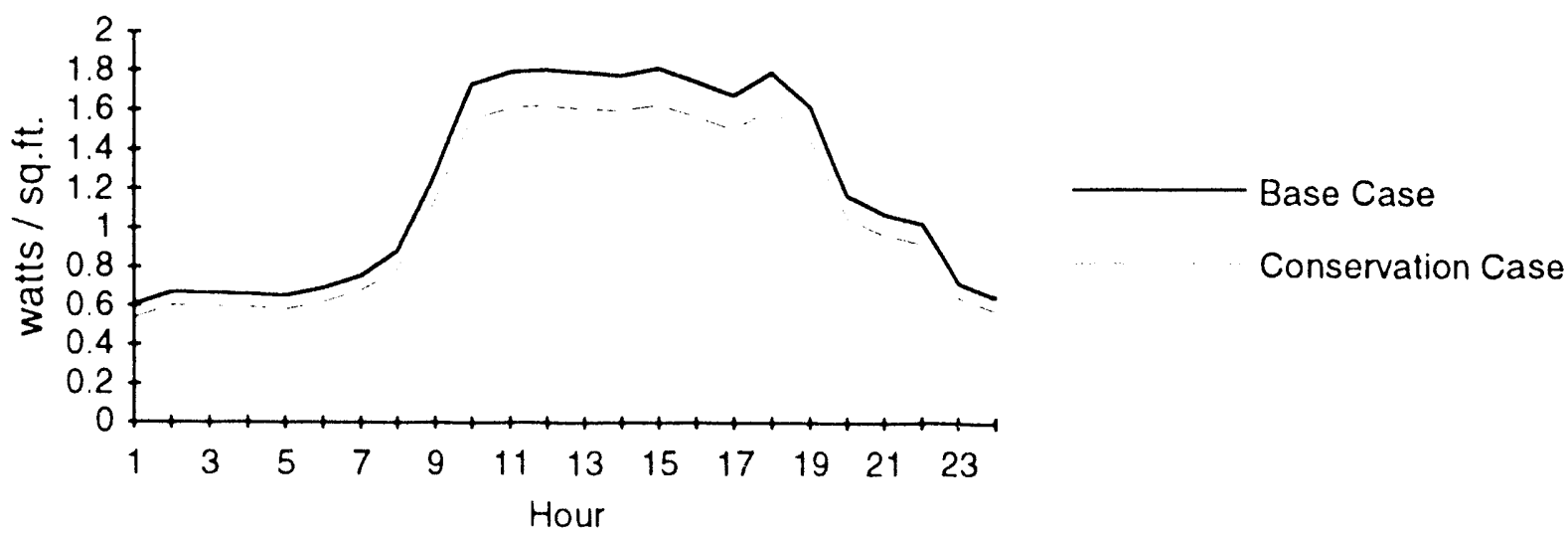

Figure D-11C. Office Lighting Load Shapes - Extreme Peak Day

$$
\text { D. } 39
$$


Table 0.3.6 Summary Worksheet of Commercial Retrofit

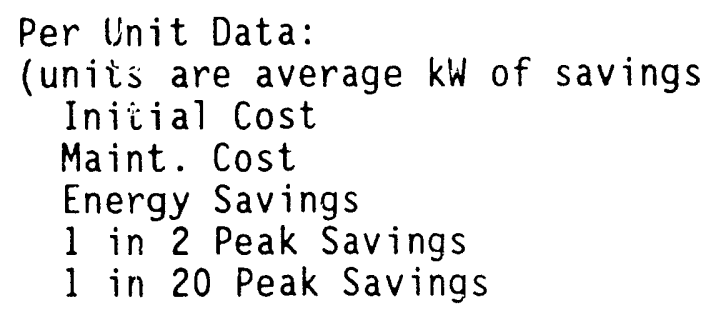

Per Unit Data:

Initial cost

Maint. Cost

Energy Savings

1 in 20 Peak Savings
Per kW Costs:
Initial Cost
Maint. per year
Plant Factor

\author{
$\$ 2,212$ \\ $8,760 \mathrm{kWh}$ per year \\ $1.557 \mathrm{~kW}$ ○ 2000 \\ $1.759 \mathrm{~kW} \odot 2000$
}

1990

1991

1992

1993

1994

1995

1996

1997

1998

1999

2000

2001

2002

2003

2004

2005

2006

2007

2008

2009

2010
1 in 2

$\$ 1,420$

$\$ 0$

0.642

0.568

1 in 20

$\$ 1,257$ $\$ 0$
0.642

Peak

Savings

1 in 2

(MW)

0.0

0.0

0.0

0.0

3.7

7.4

18.2

28.7

39.1

49.2

59.1

66.5

73.8

80.8

87.7

94.4

103.7

112.7

121.5

130.0

138.3
Peak

Savings

1 in 20

(MW)

0.0

0.0

0.0

0.0

4.2

8.4

20.5

32.4

44.1

55.6

66.8

75.2

83.4

91.4

99.2

105.8

117.3

127.5

137.4

147.1

156.5 


\section{D.3.5 LOW FLOW SHOWER HEADS}

This program will distribute low flow shower heads free of charge to residences with electric water heaters. Low flow shower heads reduce the amount of hot water required per shower so the hot water heater operates for less time for each shower. Implementation of the program reduces demand for electricity by reducing the number of hot water heaters operating at any given time. The shower heads will be distributed to existing single family, multifamily, and manufactured houses.

\section{Impacts}

Since there is no low flow shower head program in place, the baseline assumes that no shower heads will be installed in the absence of this program. The maximum potential for this program is assumed to be $60 \%$ of shower heads that use electrically heated hot water. The conservation and load management team estimated that $50 \%$ of this potential can be achieved within three years of the program start year and that the remainder can be completed within the succeeding five years. The penetration schedule is shown in figure $\mathrm{D}-12 \mathrm{a}$.

Each shower head will save an estimated $231 \mathrm{kWh}$ per year and have a measure life of seven years. Peak savings per shower head are $0.060 \mathrm{~kW}$ on a 1 in 2 peak day and $0.043 \mathrm{~kW}$ on a 1 in 20 peak day. As with the water heat control program, peak savings are lower on extremely cold days. Estimated savings for al1 homes combined are shown in Figure D-12b and Table D.3.7.

\section{$\underline{\text { Costs }}$}

Equipment, installation, and administrative costs are estimated to total $\$ 20$ per shower head. Cost calculations are summarized in Table D.3.7.

\section{Issues}

There has been no empirical testing of the extent to which low flow shower heads themselves reduce peak. It is assumed that the savings from this program will be distributed over hours in the same way as electricity consumption for hot water. Customer acceptance and installation of the shower heads are still uncertain. 


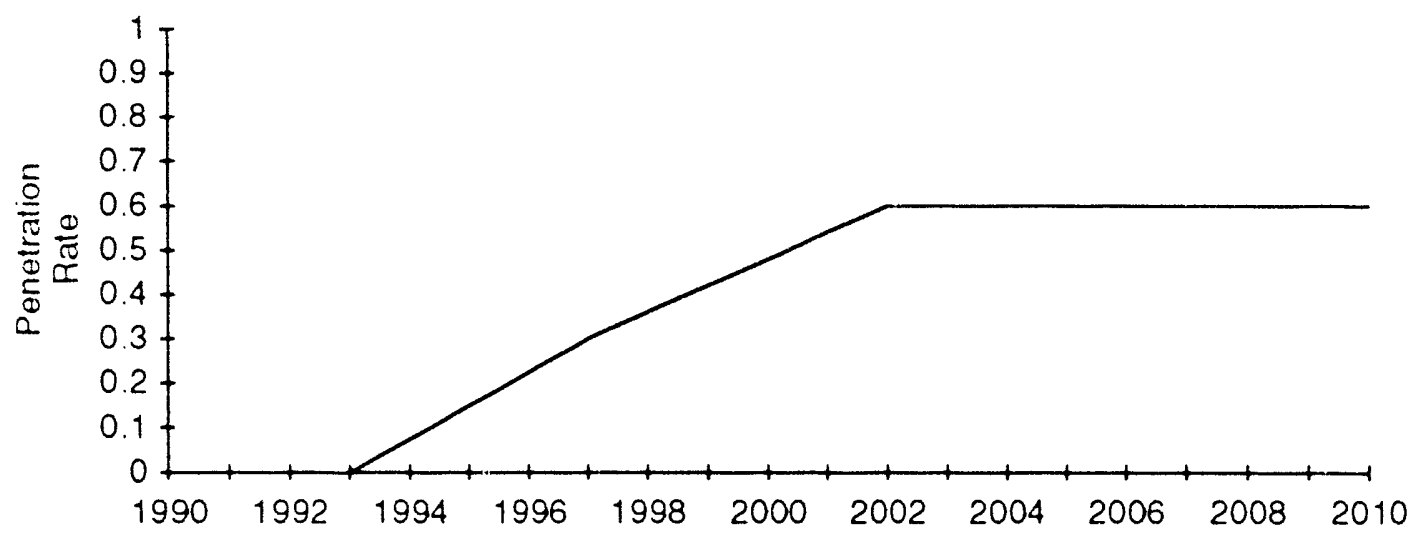

Figure D-12a. Low Flow Shower Heads

\section{Program Penetration}

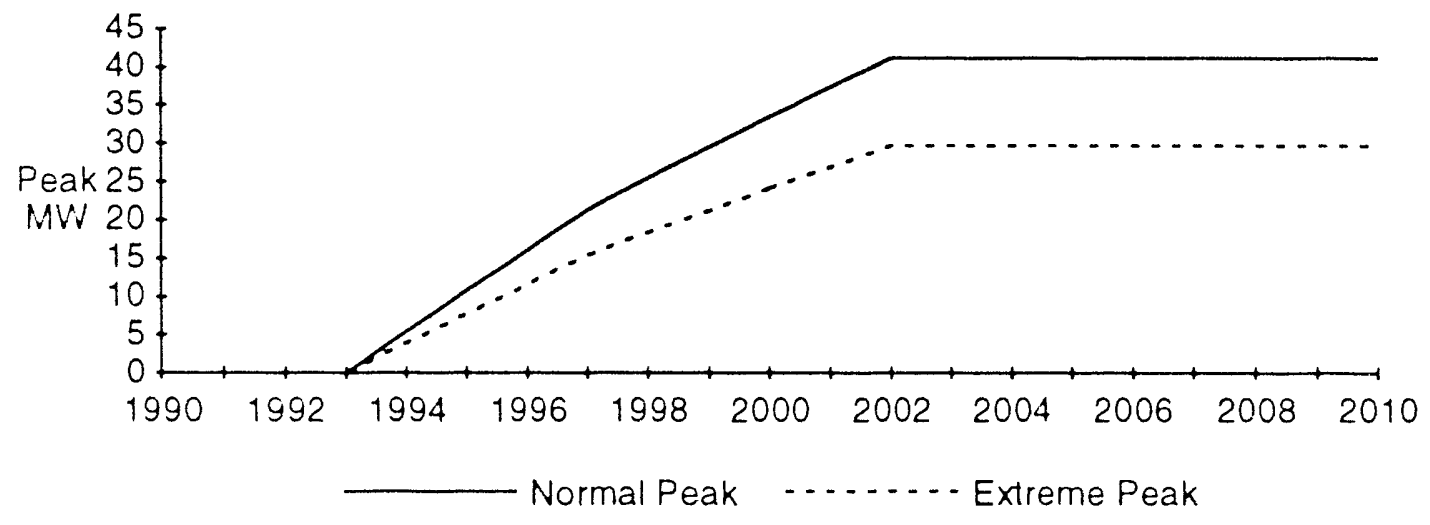

Figure D-12b. Peak Savings - Low Flow Shower Heads Existing Homes Only 
Table D.3.7 Summary Worksheet for

Low Flow Shower Heads

Per Unit Data:
Initial Cost
Maint. Cost
Energy Savings
1 in 2 Peak Savings
1 in 20 Peak Savings

Per kW Costs:

Initial Cost

Maint. per Year

Plant Factor

\author{
$\$ 20$ \\ $231 \mathrm{kWh}$ per year
$0.060 \mathrm{~kW}$ @ 2000
$0.043 \mathrm{~kW} 02000$
}

1 in $2 \quad 1$ in 20

$\$ 335$

$\$ 0$

$\$ 464$

so

$0.441 \quad 0.612$
1990

1991

1992

1993

1994

1995

1996

1997

1998

1999

2000

2001

2002

2003

2004

2005

2006

2007

2008

2009

2010

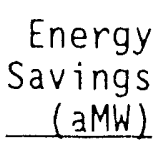

(Households)

$$
\begin{array}{r}
\text { Program } \\
\text { Units }
\end{array}
$$

Households)

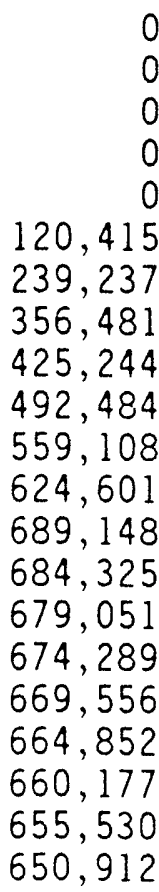

0.0

0.0

0.0

0.0

0.0

3.2

6.3

9.4

11.2

13.0

14.7

16.5

18.2

18.0

17.9

17.8

17.7

17.5

17.4

17.3

17.2
Peak

Savings

1 in 2

(MW)

0.0

0.0

0.0

0.0

0.0

7.2

14.3

21.3

25.4

29.4

33.4

37.3

41.2

40.9

40.6

40.3

40.0

39.7

39.4

39.2

38.9
Peak

Savings

1 in 20

(MW)

0.0

0.0

0.0

0.0

0.0

5.2

10.3

15.4

18.3

21.2

24.1

26.9

29.7

29.5

29.3

29.1

28.9

28.7

28.5

28.3

28.1 


\section{D.4.0 LOAD MANAGEMFNT}

Load management programs are designed to shift load away from the time of system peak. A water heat control program would shut off electricity to water heaters during morning and evening hours. This load is shifted to afternoon or late evening. A time-of-use rate program provides different prices for electricity during peak and off-peak hours.

\section{D.4.1 WATER HEAT CONTROL}

This program will install radio-controlled switches on electric water heaters that will allow the electric utility to centrally unplug water heaters at the utility's discretion. The utility will bear the full cost of the equipment and pay the homeowners $\$ 5$ per month for the privilege of being able to curtail water heater load as needed. The agreement, which provides the equipment and the incentive, will specify that an interruption can occur approximately three to five times per month during the four winter months for which an incentive will be paid. The program will also provide larger, high efficiency tanks for single family dwellings.

The maximum program penetration rate is $60 \%$ for single family homes and $20 \%$ for multi-family and manufactured homes. The Conservation and Load Management Team felt that a $60 \%$ penetration rate was justified when larger tanks were part of the program. Water heaters are assumed to be shut off from 7:00 a.m. until at least 11:00 a.m. and from 5:00 p.m. to 9:00 p.m. They are shut off in the evening so that the evening peak goes down along with the morning peak. Some of the water heaters would not come on until several hours after 11:00 a.m. or 9:00 p.m. It is important to stagger the times at which water heaters come back on so that a new system peak is not created. Some water heat load could be delayed until very late at night to fill the lowest point of the system load shape.

Figure $0-13$ a shows the estimated fraction of existing single family and multi family homes that would participate in a water heat control program. The program penetration rates increase steadily as old water heaters wear out and are replaced. Penetration rates for manufactured homes are the same as for multi-family homes, as shown in Table D.5.1. Corresponding penetration rates for new homes are shown in Figure D-13b.

Table 0.4.1 Water Heat Control Penetration Rates Estimated for Existing Homes

\begin{tabular}{cccc} 
& $\begin{array}{c}\text { Single } \\
\text { Family }\end{array}$ & $\begin{array}{c}\text { Multi- } \\
\text { Family }\end{array}$ & $\begin{array}{c}\text { Manufactured } \\
\text { Homes }\end{array}$ \\
\hline & & & \\
2008 & 0.200 & 0.067 & 0.067 \\
2006 & 0.400 & 0.133 & 0.133 \\
2010 & 0.600 & 0.200 & 0.200 \\
& 0.600 & 0.200 & 0.200 \\
& & 0.44 &
\end{tabular}




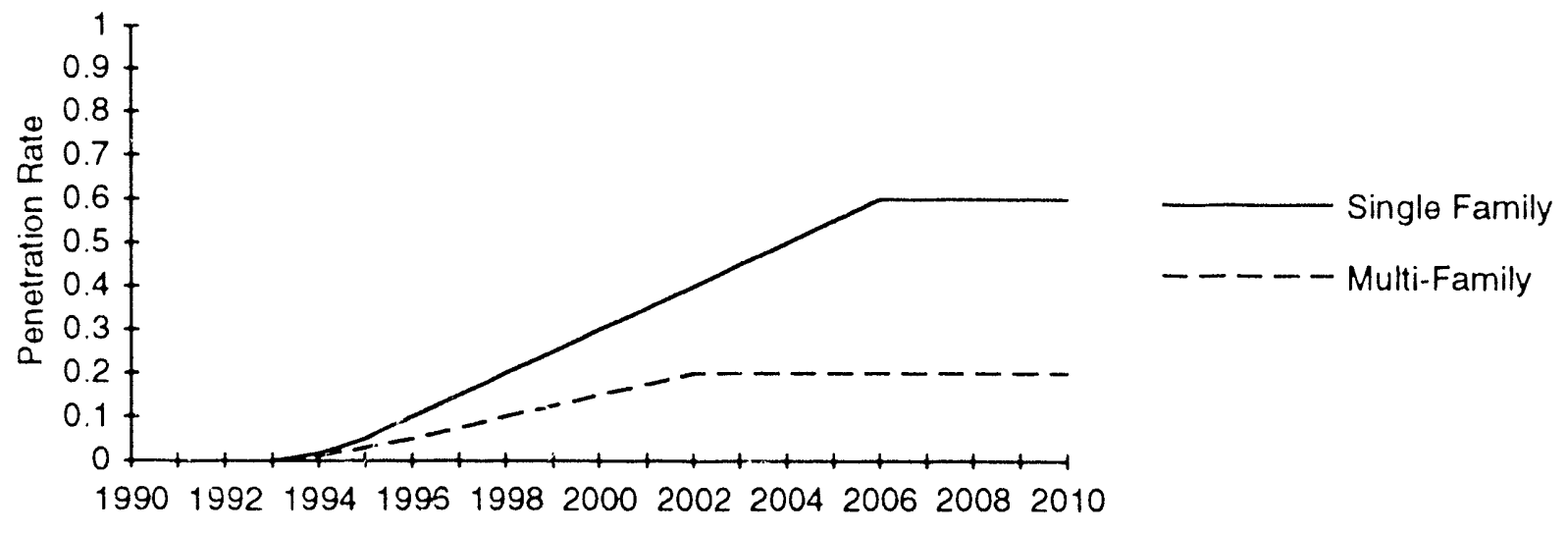

Figure D-13a. Water Heat Control Penetration Rates Existing Homes
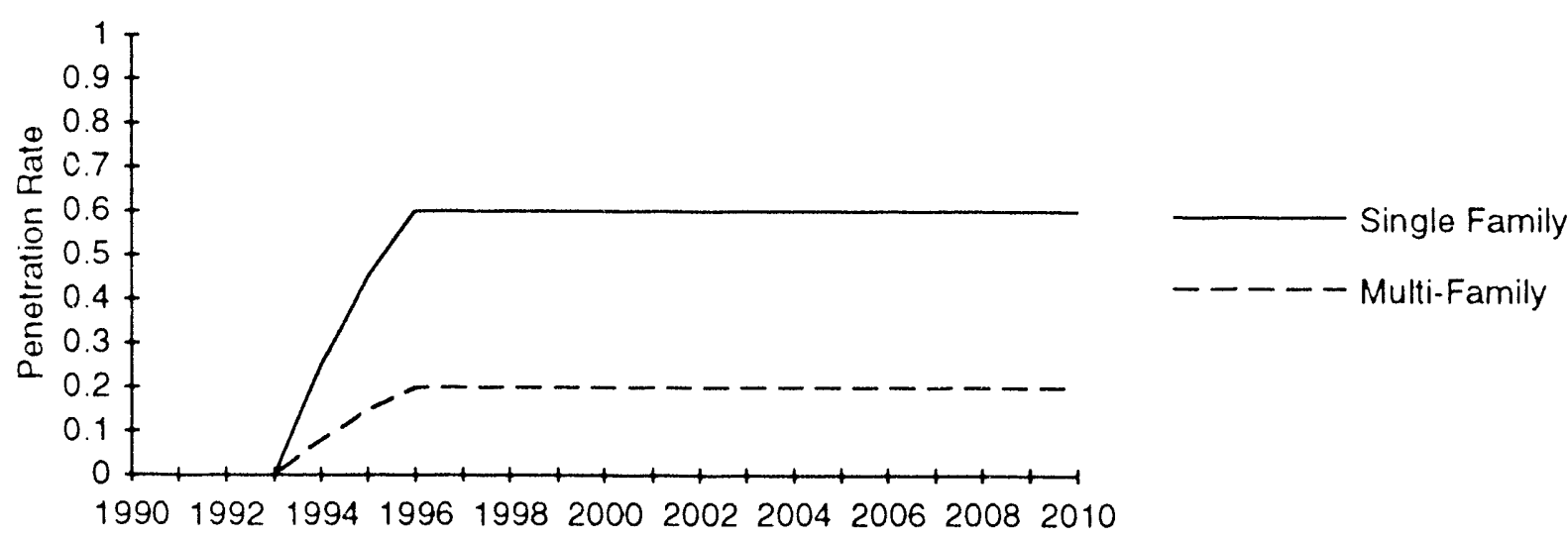

Figure D-13b. Water Heat Control Penetration Rates New Homes 


\section{Impacts}

Coincident peak savings for single family homes, or savings at the time of system peak, are $1.09 \mathrm{~kW}$ on a normal peak day and $0.79 \mathrm{~kW}$ on an extreme peak day. On an extremely cold day some water heat load shifts to later in the morning, with less load available for shedding at the time of system peak. Peak savings are shown. in megawatts, in Figure D-14a.

Base case load shapes for water heat control were derived from a sample of single family homes in Washington and Oregon. The same load shapes were used to simulate water heat consumption in multi-family and manufactured homes. Base case load shapes for an average winter day, a 1 in 2 peak day, and a 1 in 20 peak day were derived from ELCAP data. Water heat load shapes, with and without water heater control by the utility, are shown in Figure D-14b.

The program will also provide larger highly insulated tanks to single family homes along with the water heat controls. The new tanks provide energy savings of $251 \mathrm{kWh}$ per year. A larger tank provides extra storage of hot water for times when electricity is shut off to the water heater.

\section{Costs}

The controls are estimated to cost $\$ 228$ for each house. The incremental cast of a larger tank for a single family home is $\$ 120$. The incentive cost is 55 per month for the 4 months for which the program operates. An additional 58 per year covers administrative costs.

\section{Issues}

The major issue is customer acceptance: allowing someone else to control their access to hot water is something many customers will not consider. at least not at the level of incentive that would be cost-effective for the utility.

Another issue is the effectiveness of the delivery rechanism. In order to capture a significant share of the replacement market. the programs must ha, the cooperation of the contractors who replace the old tanks and the buifor. who install tanks in new construction. This may require some trpe of dealo: incentive.

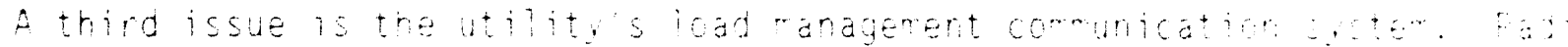

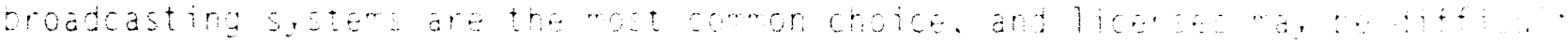
and tire-constroto tat

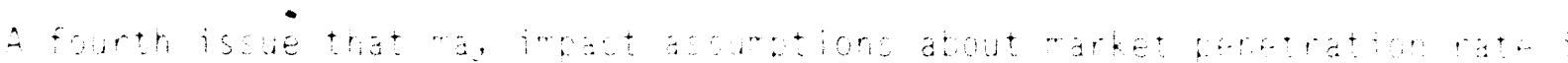

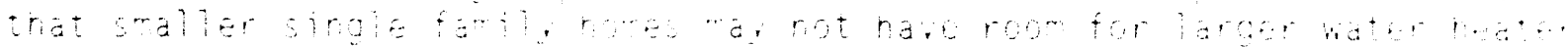
tarks. 


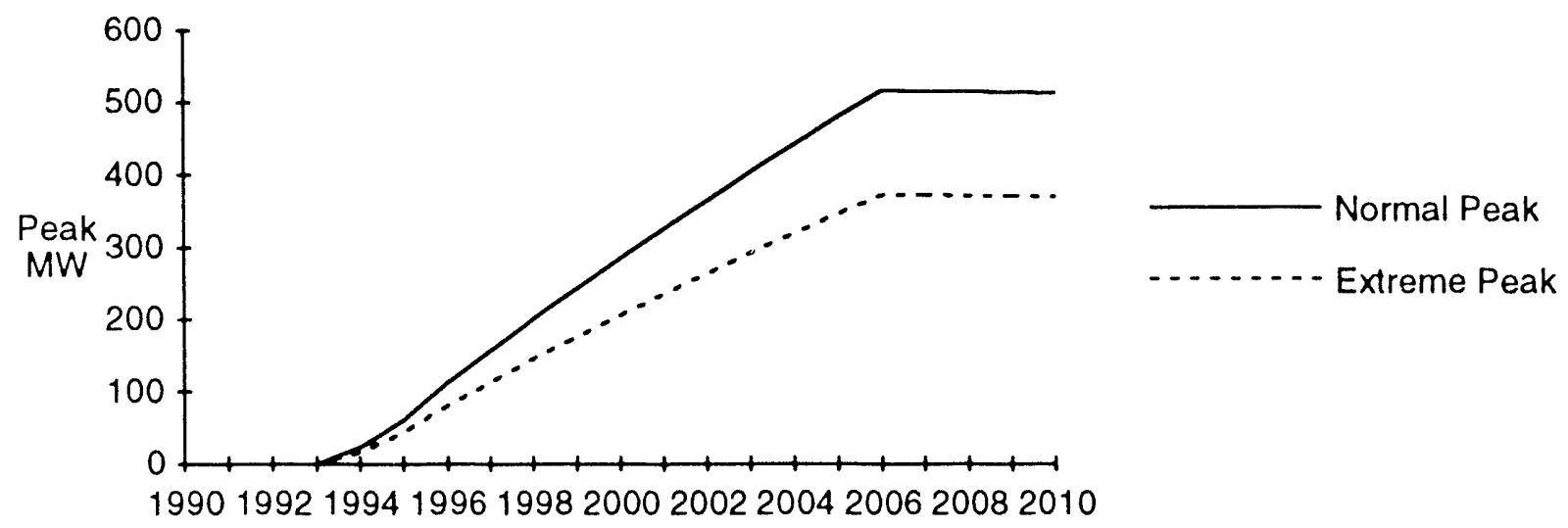

Figure D-14a. Peak Savings - Water Heat Control Single Family Homes

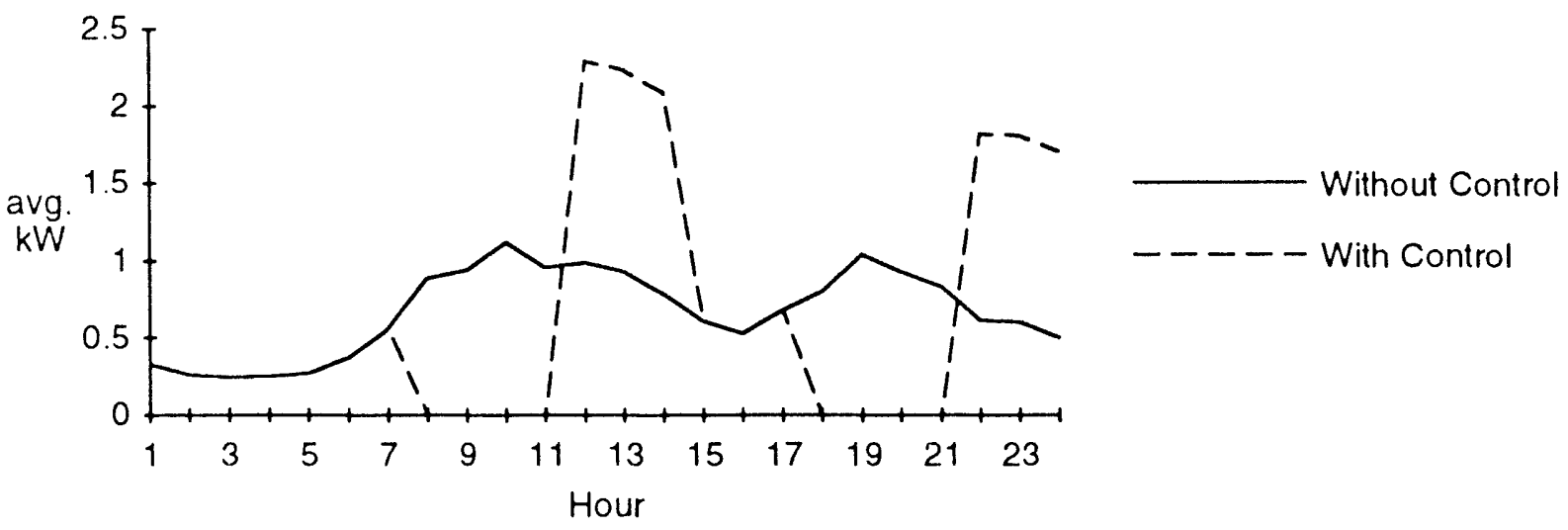

Figure D-14b. Water Heat Control Load Shapes 
A final issue is whether it is necessary to limit program participation to a tank replacement strategy. Many other utilities operate successful hot water heater control programs with only a monthly incentive. This type of program would have a greater peak load reduction potential because it wouldn't be limited to the new or replacement market.

\section{Summary Worksheets}

Summary worksheets are provided for single family, multi-family, and manufactured homes in Tables D.4.2, D.4.3, and D.4.4. Each worksheet combines data for new and existing homes. Single family homes have some energy savings due to replacement with more efficient tanks. Multi-family and manufactured homes have no energy savings.

Note that peak savings on a 1 in 20 day are lower than on a 1 in 2 day. During extremely cold weather, water heat load shifts to later in the morning. This is shown clearly in Figures D-1a and D-7a. This behavior, which may be due to work or school closures, helps to reduce peak loads. The result is that, on a 1 in 20 day at the time of system peak, there is less load available to shed. 
Table 0.4.2 Summary Worksheet for Single Family Water Heat Control, Medium Load Growth

Per Unit Data:

Initial Cost

Maint. Cost

Energy Savings

1 in 2 Peak Savings

1 in 20 Peak Savings

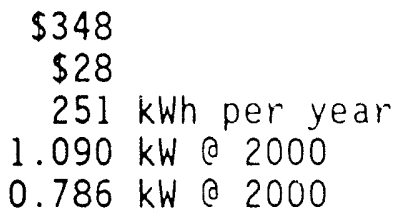

$0.786 \mathrm{~kW}$ ○ 2000

Per kW Costs:

Initial Cost

Maint. per year

Plant Factor

$\begin{array}{rr}1 \text { in } 2 & 1 \text { in } 20 \\ \$ 319 & \$ 443 \\ \$ 26 & \$ 36 \\ 0.026 & 0.036\end{array}$

$$
\begin{array}{r}
\text { Program } \\
\text { Units }
\end{array}
$$

(Households)

1990

1991

1992

1993

1994

1995

1996

1997

1998

1999

2000

2001

2002

2003

2004

2005

2006

2007

2008

2009

2010

$\begin{array}{rr}0 & 0.0 \\ 0 & 0.0 \\ 0 & 0.0 \\ 0 & 0.0 \\ 21,067 & 0.4 \\ 55,471 & 1.1 \\ 102,655 & 2.1 \\ 143,325 & 3.2 \\ 183,485 & 4.2 \\ 222,773 & 5.2 \\ 261,698 & 6.2 \\ 299,754 & 7.2 \\ 337,180 & 8.2 \\ 374,031 & 9.1 \\ 409,959 & 10.0 \\ 445,598 & 10.9 \\ 480,694 & 11.8 \\ 481,243 & 11.7 \\ 481,940 & 11.6 \\ 482,655 & 11.5 \\ 483,400 & 11.4\end{array}$

Energy

Savings

(aMW)

0.0

0.0

0.0

0.4

1.1

2.1

3.2

4.2

5.2

6.2

7.2

8.2

9.1

10.0

11.8

11.7

11.6

11.4
Peak

Savings

1 in 2

(MW)

0.0

0.0

0.0

0.0

23.0

60.7

112.5

157.1

201.0

243.5

285.2

325.4

364.4

403.6

441.5

479.0

515.7

514.8

514.0

513.3

512.6
Peak

Savings

1 in 20

(MW)

0.0

0.0

0.0

0.0

16.6

43.8

81.2

113.4

145.0

175.7

205.8

234.8

263.0

291.2

318.6

345.6

372.1

371.4

370.9

370.4

369.9 
Table 0.4.3 Summary Worksheet for Multi-Family

Water Heat Control, Medium Load Growth

Per Unit Data:

Initial Cost

Maint. Cost

Energy Savings

1 in 2 Peak Savings

1 in 20 Peak Savings

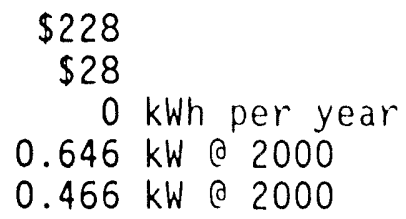

$\$ 28$

$0 \mathrm{kWh}$ per year

$0.646 \mathrm{~kW}$ \& 2000

$0.466 \mathrm{~kW}$ ○ 2000

Per kW Costs:

Initial Cost

Maint. per year

1 in $2 \quad 1$ in 20

Plant Factor

$\$ 353$

$\$ 43$

$\$ 489$

$\$ 60$

0.000

0.000

1990

1991

1992

1993

1994

1995

1996

1997

1998

1999

2000

2001

2002

2003

2004

2005

2006

2007

2008

2009

2010
Energy

Savings

(aMW)

(Households)

0.0

0.0

0.0

0.0

0.0

0.0

0.0

0.0

0.0

0.0

0.0

0.0

0.0

0.0

0.0

0.0

0.0

0.0

0.0

0.0
Peak

Savings

1 in 2

(MW)

0.0

0.0

0.0

0.0

6.3

16.0

25.6

33.5

41.3

48.9

56.3

63.5

70.6

72.0

73.4

74.8

76.3

77.9

79.4

81.1

82.7
Peak

Savings

1 in 20

(MW)

0.0

0.0

0.0

0.0

4.5

11.6

18.4

24.2

29.8

35.3

40.6

45.8

50.9

51.9

53.0

54.0

55.1

56.2

57.3

58.5

59.7 
Table 0.4.4 Summary Worksheet for Manufactured Homes Water Heat Control, Medium Load Growth

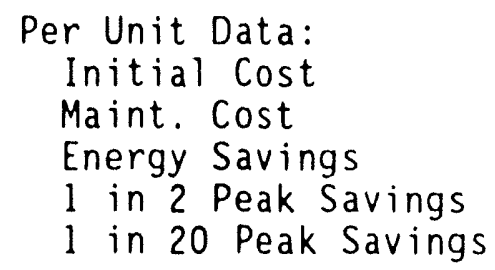

Per kW Costs:

Initial Cost

Maint. per year

Plant Factor

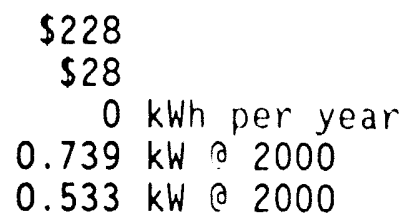

$\begin{array}{rr}1 \text { in 2 } & 1 \text { in } 20 \\ \$ 309 & \$ 428 \\ \$ 38 & \$ 53 \\ 0.000 & 0.000\end{array}$

1990

1991

1992

1993

1994

1995

1996

1997

1998

1999

2000

2001

2002

2003

2004

2005

2006

2007

2008

2009

2010
Energy

Savings

(aMW)

(Households)

\section{0}

0

0

1,892

4,850

7,790

10,381

12,982

15,566

18,164

20,707

23, 228

23,713

24,182

24,670

25,160

25,652

26,147

26,644

27,143
0.0

0.0

0.0

0.0

0.0

0.0

0.0

0.0

0.0

0.0

0.0

0.0

0.0

0.0

0.0

0.0

0.0

0.0

0.0

0.0

0.0

\begin{tabular}{rr} 
Peak & Peak \\
Savings & Sarings \\
1 in 2 & l in 20 \\
$(M W)$ & $(M W)$ \\
\hline
\end{tabular}

0.0

0.0

0.0

0.0

0.0

1.0

2.6

4.1

5.5

6.9

8.3

9.7

11.0

12.3

12.5

12.7

12.9

13.1

13.3

13.5

13.7

13.8 


\section{D.4.2 TIME-OF-USE RATES}

This voluntary program offers an opportunity for electric bill savings to retail single family residential customers that sign up for time-of-use (TOU) rates. The conservation and load management team felt that a voluntary program could be constructed to draw 20\% of single family households (see Figure D-15a). The utility installs a TOU meter on participating houses and sets retail energy rates so that peak rates are twice as high as off-peak rates. Participants that do an average amount of load deferral to the off-peak period can expect to reduce their monthly bills by $\$ 5$. The TOU rates are in effect for four months each winter. Peak hours are 7:00 am to 11:00 a.m.

\section{Inipdets}

The TOU rate program assumes that electrical load is reduced by $15 \%$ at the time of system peak in single family homes that participate (see Figure D15b). With $20 \%$ of homes participating, electrical demand averaged across a 11 single family homes would be reduced by $3 \%$ at the time of system peak.

The 15\% load reduction applies from 7:00 a.m. until 11:00 a.m., with a six-hour payback period following. Energy payback is equal to energy saved from 7:00 to 11:00, so there is no net energy benefit. Figure D-15C shows the assumed hourly pattern of residential electricity consumption with and without TOU rates. The plot is for a typical single family home with electric space heat and water heat.

Because electricity consumption for different residential end-uses is forecasted to grow at different rates, peak savings per household are not constant over time. Electric space heat becomes a smaller share of residential electricity consumption due to new construction and loss of market share to natural gas. Over time, residential electricity consumption becomes less weather sensitive, and average peak savings per household declines.

\section{$\underline{\text { Costs }}$}

The TOU meters cost $\$ 115$ per household. The program will expect to provide bill savings of about $\$ 5$ per month for active program participants. Non participants will end up paying higher bills to offset the lower bills paid by program participants. In addition, it is assumed that administrative costs will come to $\$ 2$ per unit per year. This covers the costs of additional meter readers as well as the costs of program administration and evaluation. Cost calculations are summarized in Table D.4.5. 


\section{Issues}

1. This proposal is based on a Snohomish PUD pilot program. Although Snohomish PUD realized an overall net peak reduction for the ir TOU pilot program, during the cold weather months the peak demand of the evening test group (TOU customers) frequently exceeded that of the evening control group (normal electric rate customers). This included the system peak day of February 3, 1989. In addition, the evening group increased total energy consumption in comparison with the control group. The reasons for these increases need to be studied further.

There is not enough data from Snohomish PUD's TOU pilot program to confidently predict the impacts from a region-wide, long-term program. The load shape impacts from a long-term program may be very different than those from a small, short-term experiment. With a long-term program, customers would be much more likely to make investments in load shifting devices such as clock thermostats and hot water heater timers.

2. A second issue is whether or not a TOU rate program should be aimed toward, or limited to, a specific group of residential customers. A TOU rate program would be more effective if targeted at high electrical consumers: larger, all-electric homes. A larger average peak $\mathrm{kW}$ reduction, at a lower cost, would be realized with this type of home in comparison to smaller homes, or homes with gas heat and gas appliances.

3. Another issue is reliability. The voluntary basis of the program reduces the reliability for peak load reduction, in comparison to programs that employ direst load control.

4. Finally, utilities that adopt Tou rates will have to modify their billing procedures. This may be easy for some utilities, but difficult and costly for others. 


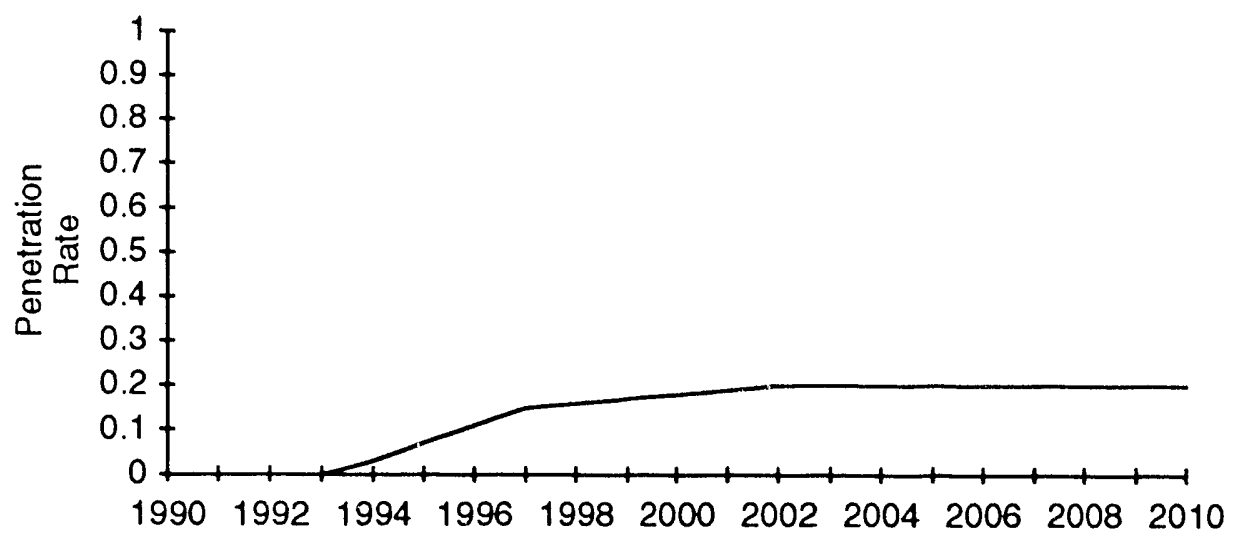

Figure D-15a. Time-of-Use Rates

Program Penetration

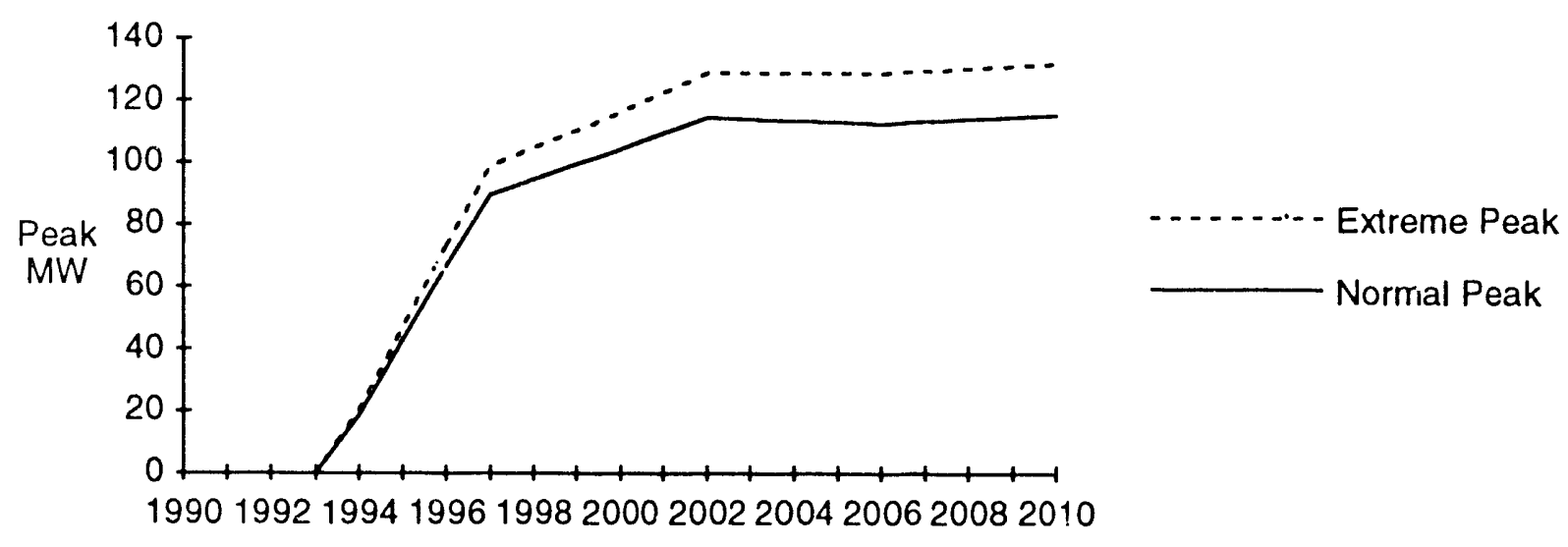

Figure D-15b. Peak Savings - Time-of-Use Rates Single Family Homes

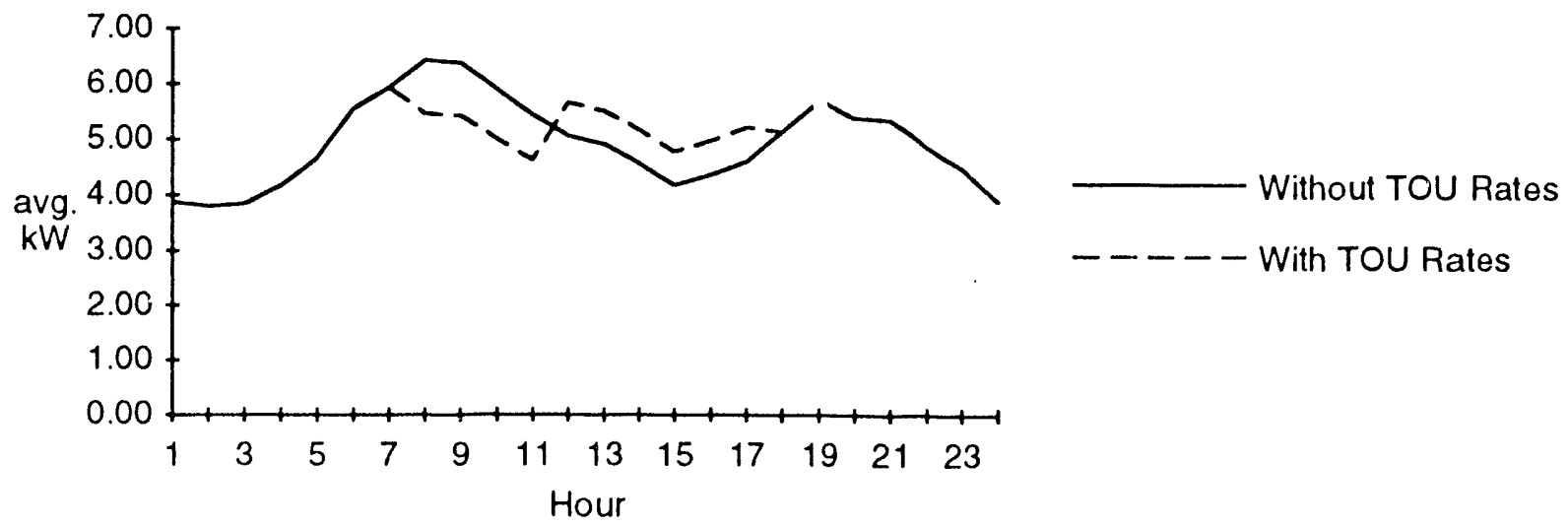

Figure D-15c. Time-of-Ulse Rates Load Shapes

$$
\text { D - } 54
$$


Table D.4.5 Summary Worksheet for

Time-of-Use Rates, Medium Load Growth

Per Unit Data:
Initial Cost
Maint. Cost
Energy Savings
1 in 2 Peak Savings
1 in 20 Peak Savings

Per kW Costs:

Initial Cost

Maint. per Year

Plant Factor

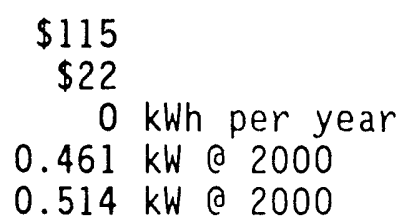

1 in 2

$\$ 249$

$\$ 48$

1 in 20

0.000

$\$ 43$

$\$ 43$

0.000

$\begin{array}{lr} & \begin{array}{r}\text { Program } \\ \text { Units }\end{array} \\ 1990 & 0 \\ 1991 & 0 \\ 1992 & 0 \\ 1993 & 0 \\ 1994 & 35,051 \\ 1995 & 82,768 \\ 1996 & 131,628 \\ 1997 & 181,644 \\ 1998 & 196,200 \\ 1999 & 210,797 \\ 2000 & 225,952 \\ 2001 & 241,208 \\ 2002 & 256,751 \\ 2003 & 259,645 \\ 2004 & 262,340 \\ 2005 & 265,273 \\ 2006 & 268,264 \\ 2007 & 271,273 \\ 2008 & 274,400 \\ 2009 & 277,524 \\ 2010 & 280,658\end{array}$

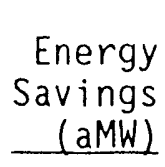

0.0

0.0

0.0

0.0

0.0

0.0

0.0

0.0

0.0

0.0

0.0

0.0

0.0

0.0

0.0

0.0

0.0

0.0

0.0

0.0

0.0
Peak

Savings

1 in 2

(MW)

0.0

0.0

0.0

0.0

18.5

42.8

66.4

89.5

94.6

99.4

104.2

109.4

114.6

114.1

113.6

113.1

112.7

113.4

114.1

114.9

115.6
Peak

Savings

1 in 20

(MW)

0.0

0.0

0.0

0.0

20.2

46.8

72.9

98.7

104.7

110.4

116.2

122.5

128.9

128.8

128.7

128.7

128.7

129.6

130.4

131.2

132.1 


\section{D.5.0 FUEL SWITCHING}

The Puget Sound Area Electric Reliability Plan (PSAERP) is examining a number of alternatives for reducing peak load on the transmission system serving the Puget Sound Area. Because the problem addressed by the PSAERP is a transmission constraint, the load relevant to the fuel switching analysis is annual peak $\mathrm{kW}$.

Switching consumer electric loads to natural gas (fuel switching) is a part of the solution packages being analyzed. The analysis of fuel switching was a joint effort of the Conservation and Load Management and the Load Forecasting Teams.

\section{D.5.1 OVERVIEW}

The fuel switching analysis was based on separating buildings into market segments. Market segments are categories where the response of buildings to a fuel switching program is relatively homogeneous. A preliminary analysis screened out market segments with buildings where fuel switching would be prohibitively expensive. The screening assumptions are described later in this paper.

For market segments analyzed in detail, the number of buildings and the kW per building (under both normal winter and extreme cold weather conditions) were estimated in the PSAERP load forecast. The product of the number of buildings and $\mathrm{kW}$ per building gave the total electric load or "technical potential" for fuel switching. The Conservation and Load Management Team estimated a program participation rate and the costs of switching per building for each market segment. The technical potential multiplied by the participation rate gives the "achievable potential." This achievable load is matched with costs to determine the cost per $\mathrm{kW}$ for programmatic fuel switching. The cost per $\mathrm{kW}$ is used to compare fuel switching with other PSAERP alternative solutions.

\section{D.5.2 SUMMARY OF RESULTS}

Some fuel switching is expected to occur as a result of market forces alone because the price of natural gas is less than electricity throughout the PSAERP planning horizon (this difference is forecasted to narrow between 1990 and 2010). Approximately $200 \mathrm{MW}$ of fuel switching is forecast to occur in response to market forces by the year 2000. After market induced fuel switching is accounted for, approximately 4,200 $\mathrm{MW}$ of load remains in market segments considered available for fuel switching. This is the technical potential for fuel switching. Of this amount, $250 \mathrm{MW}$ of achievable potential is estimated to exist. 


\section{D.5.3 MARKET SEGMENTS}

For analytical purposes, buildings were categorized into relatively homogeneous groups. Preliminary analysis screened out some categories as unrealistic or prohibitively expensive targets for programmatic fuel switching. Seven market segments were arialyzed in detail. In each of these segments the number of buildings and peak load per building were derived from the PSAERP load forecast. The percentage of eligible buildings that would participate in a fuel switching program was estimated by the Conservation and Load Management Team. The product of eligible buildings or total peak load in a market segment and that market segment's participation rate gives the number of achievable households or peak load available for fuel switching in the market segment. The assumptions used to develop the seven market segments are discussed in the following sections.

\section{Screening Assumptions}

Industrial and commercial sectors were screened out due to high costs of switching, limited potential, and institutional barriers. Multi-family units and all existing homes with zonal space heat were also screened out due to cost and institutional barriers. Homes currently using gas were screened out. Although some of these homes do have electric space or water heat, switching was assumed to occur from market forces alone.

\section{Segmentation Criteria}

From the remaining housing stock, market segments are developed by separating the stock by housing type (single family or manufactured housing), housing vintage (new units built in 1990 or later versus existing units built before 1990), and gas availability. Gas availability groups households depending on the requirements of connecting the household to natural gas service. The four categories of gas availability are: 1) household already receiving natural gas; 2) not receiving gas, but requiring only a service drop (also defined as within $1 / 4$ mile of a gas main; 3 ) household requiring both a main extension and service drop; 4) more than main extension required, or significant distribution system expansion.

Housing type and vintage are available directly from the PSAERP forecast. Gas availability was estimated as the percentage of homes in each gas availability category for both new and existing homes by county. The initial estimates were developed by Bonneville from population derisities and natural gas service territories. These estimates were then revised io incorporate comments and improved data from Washington Natural Gas, Cascade Natural Gas, Seattle City Light, Tacoma Public Utilities, Snohomish County PUD, Puget Sound Power and Light, the Washington State Energy Office, and the Washington Utilities and Transportation Commission.

The gas availability ratios represent a midpoint in the time period of the PSAERP planning horizon. The ratios can be expected to change in time due to geographic changes in population density and the expected expansion of natural gas distribution systems. The direction of the changes are uncertain. A rapid expansion and filling in of natural gas distribution systems could place a ialsa part of the population in either the gas-in-home or service-drop-only category, and consequently reduce the proportion of homes in the main. 
extension and not-available categories. Another possibility would be for the gas companies to expand their territories into areas not currently served which would increase the amount of homes in the main extension category and reduce the proportion in other categories. Even if an unambiguous scenario were assumed for population density changes and gas expansion in the future, no data currently exists to estimate the magnitude of these changes.

Therefore, the most appropriate planning assumption is to rely on midpoint estimates based on the available data.

The electric equipment to be switched was specified for each market segment. For most market segments, the most cost effective program is to switch both the space and water heat equipment so that hook-up costs are spread over a larger amount of load. However, for households with low hook-up costs (service drop only), switching only the water heater was also analyzed. In new homes, the space heating equipment is not yet installed and is undetermined. The costs and load associated with space heat in these homes is a weighted average of the current proportions of central forced air and resistance.

\section{Participation Rates}

Experience with conservation programs indicates that only a portion of eligible homes will participate in a program. Program participation rates were assigned to each market segment to indicate this percentage. The rates were developed by the Conservation and Load Management Team of the PSAERP.

The Pacific Northwest gas and electric utilities are forecasting that most new homes built within $1 / 4$ mile of gas mains will choose gas from market forces alone. We assume for the PSAERP that new electric homes within $1 / 4$ mile of existing gas mains have chosen electric space and water heat for reasons that would not be overcome with a fuel switching program. Therefore, the program participation rate for new homes within $1 / 4$ mile of a gas main is set to zero.

The above assumptions yield the following market segments:

\begin{tabular}{|c|c|c|c|}
\hline $\begin{array}{l}\text { Housing } \\
\text { Type }\end{array}$ & $\begin{array}{l}\text { Housing } \\
\text { Vintage }\end{array}$ & $\begin{array}{l}\text { Gas } \\
\text { Availability }\end{array}$ & $\begin{array}{l}\text { Electric } \\
\text { Equipment }\end{array}$ \\
\hline $\begin{array}{l}\text { Single Family } \\
\text { Single Family } \\
\text { Single Family } \\
\text { Single Family } \\
\text { Manuf. Homes } \\
\text { Manuf. Homes } \\
\text { Manuf. Homes }\end{array}$ & $\begin{array}{l}\text { Existing } \\
\text { Existing } \\
\text { Existing } \\
\text { New } \\
\text { Existing } \\
\text { Existing } \\
\text { New }\end{array}$ & $\begin{array}{l}\text { Service Drop } \\
\text { Main Extension } \\
\text { Service Drop } \\
\text { Main Extension } \\
\text { Service Drop } \\
\text { Main Extension } \\
\text { Main Extension }\end{array}$ & $\begin{array}{l}\text { Central Forced Air + Water } \\
\text { Central Forced Air + Water } \\
\text { Water Heat Only } \\
\text { Space + Water } \\
\text { Central Forced Air + Water } \\
\text { Central Forced Air + Water } \\
\text { Space + Water }\end{array}$ \\
\hline
\end{tabular}




\section{D.5.4 COSTS}

The major cost categories are equipment, administrative, hook-up and operating. These costs vary between market segments, but not within a market segment. The cost data was gathered from several different reports by regional energy concerns and a survey of Puget Sound area contractors conducted by Branch Richards Anderson Company (BRACO). All costs are expressed in 1990 dollars unless otherwise noted. For purposes of the PSAERP, it was assumed that nominal nonoperating costs increase at the rate of inflation.

Capital costs (operating costs not included) by market segment are detailed in Table D.5.2. This table shows costs calculated from the social and utility perspective. Cost perspectives are detailed in a later section. Operating costs are forecast annually and detailed in a different section.

\section{Equipment Costs}

Equipment costs include the furnace or water heater, flue, venting, piping, other installation expenses, ductwork, and shell improvements required to meet the housing code. An additional cost in this category is the depreciated value of electric equipment not used after the home is switched to gas. Equipment cost data were collected from two sources: a Northwest Power Planning Council report, Heating New Homes: A Comparison of Heating with Electric, Natural Gas and Fuel Oil Heating Systems, and the BRACO survey.

\section{Administrative Costs}

Administrative costs are those costs associated with design, implementation and oversight of fuel switching program or policies. The methods that may be used to implement fuel switching have not yet been determined. For purposes of the PSAERP Environmental Impact Statement, fuel switching is implemented similar to a conservation program. This requires inclusion of administrative costs. Program administrative costs are set equal to twenty percent of total equipment costs. This is roughly equal to experience in Bonneville's conservation program.

Hook-up Costs

Hook-up costs are the costs of connecting a household to natural gas. A cost was estimated for the gas availability categories of service drop and main extension. The cost of service drop only (gas availability category $\# 2$ ) is $\$ 550$ based on a Washington State Energy Office report, Analys is of Consumer and Marginal Costs for Electric and Natural Gas Space and Water Heat in Sinqle Family Residences in Puget Sound Power and Light Company Service Territory. The cost of a main extension only is $\$ 900$ based on a report from the Association of Northwest Gas Utilities, Coordinated Energy Development in the Pacific Northwest. Therefore the cost of main extension plus service drop (gas availability category $\# 3)$ is $\$ 1,450(\$ 550+\$ 900)$.

\section{Operating Costs}

The operating cost for both gas and electric equipment equals the annual energy expense. This is calculated as the product of annual energy consumption multiplied by the price. For electric equipment, energy consumption is taken directly from the PSAERP forecast. Energy consumption 
for gas equipment equals electric kWh divided by an efficiency factor 0.75 for space heat and 0.53 for water heat.

The price for both fuels is the wholesale marginal cost of the fuel. Retail costs were not used because they may include other costs which are already counted in this analysis as explicitly cost categories, such as hook-up and administration. For electricity, the wholesale marginal cost is that used by the PSAERP evaluation team which is Bonneville's marginal cost for resource planning. The wholesale marginal cost of natural gas is equal to the city gate price as forecast in the Joint Council/Bonneville Long Term Forecast shown in Table D.5.3.

\section{Cost Perspective}

Costs may be calculated from several perspectives. The end-user and society are two common viewpoints. In addition, programmatic costs of fuel switching may be calculated on the basis of a retail gas or electric company, a cooperative effort of energy interests, or Bonneville, a federal wholesale utility. The PSAERP analyzes fuel switching costs from two perspectives, social costs and utility costs. Social costs are used as a resource selection criteria. Utility costs are for a theoretical electric utility choosing to encourage fuel switching.

Social costs are set equal to the incremental costs (the difference between gas and electric) in all cost categories. The treatment of the utility costs requires a policy decision on how the costs will be divided among various parties. A full cost scenario was used in this analysis to determine the maximum cost a utility may incur. This cost scenario assigns all costs associated with switching equipment, hook-up and administration to the utility. Operating costs are borne by the end-user and therefore not included in utility cost calculations. In this scenario, a distinction must be made in the calculations between new and existing homes.

For existing homes in the full cost scenario, the full costs of hook-up and administration are assigned to the utility. The utility also pays full equipment costs except the depreciated value of unused electric equipment. This is a social cost of foregone useful value, but not an out-of-pocket expense which must be paid. Operating costs are assigned to the end-user, not paid by the utility.

For new homes, the full cost scenario retains the assumption of full hook-up costs and administrative costs, and no operating costs. However, equipment costs are incremental for new homes. A full equipment cost assumption for new homes would imply that the utility pays for the space and water heat system in a home not yet built. The working assumption in determining costs is that the utility pays the costs of switching, not the cost involved in supplying the end-use. Therefore, incremental equipment costs are used for new homes.

The utility cost scenario used here is a very conservative planning assumption. If any cost sharing occurs with other parties such as gas utilities or consumers, the cost scenario used here will overstate electric utility costs.

$$
0-60
$$




\section{Free Riders}

It would be difficult, if not impossible, for a fuel switching policy to effectively distinguish between otherwise equal households that will or will not switch due to market forces alone. For the PSAERP it was assumed to be impossible. Therefore, the program is applied both to homes within a market segment that are forecast to remain electric (programmatic fuel switching) and all homes forecast to switch due to the market alone (market induced fuel switching). The homes treated by a program that would have switched without a program are called "free riders." Free riders create an additional cost for a fuel switching program.

The number of homes forecast to switch from market forces was estimated by subtracting the number of electric homes in the base case forecast from the number of homes in a forecast where electric saturation rates were held constant at 1990 stock average levels. The difference is the number of market induced fuel switchers.

The market induced switchers were assumed in the PSAERP to be within $1 / 4 \mathrm{mile}$ of existing gas mains. Homes requiring a main extension to hook-up to natural gas are not able to readily switch and may incur significant additional expense. As a result, market induced fuel switchers fall in to three categories: existing single family / service drop / CFA + water heat; existing single family / service drop / water heat only; existing manufactured homes / service drop / CFA + water heat. The number of homes in each segment is derived directly from the PSAERP forecast.

From a social cost perspective, free riders increase only the administrative expense. Other costs such as equipment or hook-up would have been incurred anyway because these are the homes forecast to switch in the base case. The only difference is which party incurs the cost, but from society's perspective this is a transfer, not an additional cost. The total social cost is increased by the number of free riders multiplied by the administrative cost per household.

From the utility perspective, the utility is now incurring the full program cost for each free rider. These are the homes the utility must also reach with a program in order to reach those homes which would not switch from market forces. The total utility cost is increased by the number of free riders multiplied by the total program cost per household.

\section{D.5.5 RESULTS}

The basic input data and results are summarized in Tables $0.5 .1,0.5 .2$ and D.5.3.

Table D.5.1 shows the forecast data used to derive the number of households in each market segment. The data are categorized by housing type and vintage and equipment type. Reading down a column, the total housing stock is decreased

$$
\text { D- }
$$


by the ratios for electric saturations, central forced air for space heat and the service drop and main extension gas availability ratios.

Table 0.5.2 shows the detail of cost per household by market segment.

Table 0.5.3 combines the data from Tables 0.5 .1 and 0.5 .2 and includes the $\mathrm{kW}$ per household to derive the total load and cost for fuel switching. It is important to note that the costs shown in Table D.5.3 are capital cost only and do not include operating costs.

The cost per $\mathrm{kW}$ is an important basis for comparison of resources. The PSAERP analysis will match the achievable load and capital costs documented in this section with operating costs to derive a levelized cost per $\mathrm{kW}$ for the entire fuel switching program.

In order for annual operating cost to be incorporated, the costs need to be calculated on a levelized basis. The social costs for the entire fuel switching sector are levelized and detailed elsewhere in this document to compare with other resources.

For all market sectors the levelized cost per $\mathrm{kW}$ will be less than the capital cost per $\mathrm{kW}$ from the social perspective. This is because levelized costs will include operating costs which are less for gas space and water heat than for electric equipment. Gas equipment is less efficient than electric (ratios given in Operating cost section), but the loss in efficiency is more than offset by the relatively inexpensive gas prices.

From the utility perspective, the capital cost is a fair approximation of total costs because operating costs do not affect utility costs.

Capital cost per $\mathrm{kW}$ do provide a good indication of the results and the ranking among market segments should be roughly equivalent to the levelized cost ranking, because operating costs tend to act in the same direction for all market segments. The capital cost per $\mathrm{kW}$ by market segment are detailed in Table D.5.3.

From both the social and utility perspectives, the least expensive market segments (in terms of capital cost per $\mathrm{kW}$ ) are also the market segments with the most switchable load, the segments with existing single family homes where both central forced air and water heat are switched. The rank of these two segments varies in the different perspectives because of the free rider issue.

The most expensive segment is for an existing single family home where only the water heater is switched. This is a result of two factors. The hook-up cust is spread over a relatively small amount of load per household because no space heat load is switched and there are large number of free riders in this segment because water heat equipment wears out and is turned over relatively quickly, so there is a lot of market induced switching. 


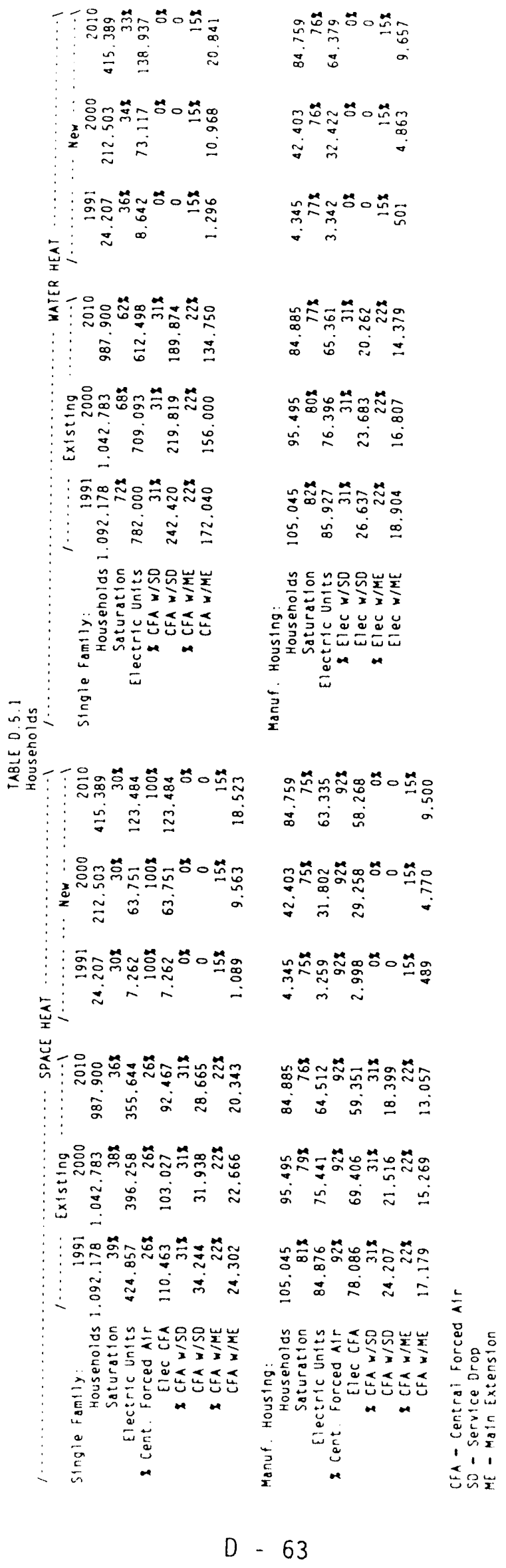


TAELE 0.5 .2

Cost per Housenold

(1990 s)

1 ENST SF. CFA+WH. SERVICE OROP

Electric Gas Social Utility Capital

EOUIPMENT

Water Heat

Replacement Unit

Installation

Flue, venting

NPV remaining life. elect. eqpt

Central Forced Air

Replacement Unit

Installation

Flue, venting

NPV, remaining life, elect. eqpt

Subtotal

ADMINISIRAIIVE

HOOK.UP

Service Drop

IOTAL.

$\begin{array}{rrrrr}240 & 250 & 10 & 250 & 250 \\ 120 & 150 & 30 & 150 & 150 \\ 0 & 150 & 150 & 150 & 150 \\ 0 & 72 & 72 & 0 & 0 \\ 575 & 900 & 325 & 900 & 900 \\ 0 & 855 & 855 & 855 & 855 \\ 0 & 400 & 400 & 400 & 400 \\ 0 & 177 & 177 & 0 & 0 \\ 935 & 2.954 & 2.019 & 2.705 & 2.705 \\ 0 & 0 & 541 & 541 & 541 \\ 0 & 550 & 550 & 550 & 550 \\ 935 & 3.504 & 3.110 & 3.796 & 3.796\end{array}$

2) Exist SF CFA+WH Main Extension

EQUIPHENT

Water Heat

$\begin{array}{llllll}\text { Replacement Unit } & 240 & 250 & 10 & 250 & 250 \\ \text { Insta } & 120 & 150 & 30 & 150 & 150\end{array}$

Installation

Flue, venting

NPV remaining life, elect. eqpt

150

30
150

150

150

150
150

Central Forced Air

Replacement Unit

Installation

Flue, venting

NPV. remaining life, elect. eqpt

Subtotal

ADMINISTRAIIVE

HOOK - UP

Service Orop

Main Extension

TOTAL

$\begin{array}{lllll}575 & 900 & 325 & 900 & 900\end{array}$

$\begin{array}{lllll}0 & 855 & 855 & 855 & 955\end{array}$

$\begin{array}{lllll}0 & 400 & 400 & 400 & 400\end{array}$

$\begin{array}{rrrrr}0 & 177 & 177 & 0 & 0 \\ 935 & 2.954 & 2.019 & 2.705 & 2.705\end{array}$

$\begin{array}{rrrrr}0 & 0 & 541 & 541 & 541\end{array}$

$\begin{array}{rrrr}900 & 900 & 900 & 900\end{array}$

3) Exist SF, WH Only. Service Drop

EOUIPMENT

Water Heat

Replacement Unit

Installation

flue, venting

NPV, remaining life, elect. eqpt Subtotal

ADMINISIRATIVE

HOOK-UP

Service Orop

TOTAL

$\begin{array}{rrrrr}240 & 250 & 10 & 250 & 250 \\ 120 & 150 & 30 & 150 & 150 \\ 0 & 150 & 150 & 150 & 150 \\ 0 & 72 & 72 & 0 & 0 \\ 360 & 622 & 262 & 550 & 550 \\ 0 & 0 & 110 & 110 & 110 \\ 0 & 550 & 550 & 550 & 550 \\ 360 & 1.172 & 922 & 1.210 & 1.210\end{array}$

4) New SF, SH+WH. Main Extension

EQUIPMENT

Space Heat

Weighted Av. Equipment

Envelope effic (1991)

water neat

All equipment and installation

Subtotal

ADMINISTRATIVE

HOOK.UP

Service Drop

Main Extension

4.404

4.010

4,696

4.696

TOTAL

$\begin{array}{rrrrr}2.115 & 4.100 & 1.985 & 1.985 & 4.100 \\ 800 & 420 & .380 & .380 & 420 \\ 400 & 550 & 150 & 150 & 550 \\ 3.315 & 5.070 & 1.755 & 1.755 & 5.070 \\ 0 & 0 & 1.014 & 1.014 & 1.014 \\ & & & & \\ 0 & 550 & 550 & 550 & 550 \\ 0 & 900 & 900 & 900 & 900 \\ 3.315 & 6.520 & 4.219 & 4.219 & 7.534\end{array}$


IABIE 0.5.2 (continued)

cost per Household

(1990 \$)

5) Ixist MH. CFA+WH, Service Orop EQUIPMENT

Water Heat

Replacement Unit

Installation

flue, venting

NPV, remaining life, elect. eqpt Central forced Air

Replacement Unit

Installation

flue, venting

NPV, remaining life, elect. eqpt Subtotal

ADMINISTRATIVE

HOOK.UP

Service Drop

TOTAL

6) Exist MH, CFA+WH. Main Extension

EQUIPMENT

Water Heat

Replacement Unit

Installation

Flue, venting

NPV. remaining life, elect. eqpt

Central Forced Air

Replacement Unit

Installation

Flue, venting

NPV, remaining life, elect eqpt Subtotal

ADMINISTRATIVE

HOOK - UP

Service Drop

Main Extension

TOTAL

7) New MH.SH+WH. Main Extension

EQU I PMENT

Space Heat

CFA Equipment and Installation

Water heat

All equipment and installation Subtotal

ADMINISTRATIVE

HOOK.UP

Service Drop

Mai. Extension

IOTAL
Llectric las Social lithity Capital

$\begin{array}{rrrrr}240 & 250 & 10 & 250 & 250 \\ 120 & 150 & 30 & 150 & 150 \\ 0 & 100 & 100 & 100 & 100 \\ 0 & 72 & 12 & 0 & 0\end{array}$

$\begin{array}{lllll}575 & 1.000 & 425 & 1.000 & 1.000\end{array}$

$730 \quad 730$

$\begin{array}{llll}200 & 200 & 200 & 200\end{array}$

$\begin{array}{rrrr}144 & 144 & 0 & 0 \\ 646 & 1.711 & 2.430 & 2.430\end{array}$

$\begin{array}{rrrrr}935 & 2.646 & 1.711 & 2.430 & 2.430 \\ 0 & 0 & 486 & 486 & 486\end{array}$

$\begin{array}{rrrrr}0 & 550 & 550 & 550 & 550\end{array}$

$\begin{array}{llll}3.196 & 2.747 & 3.466 & 3.466\end{array}$

$\begin{array}{rrrrr}240 & 250 & 10 & 250 & 250 \\ 120 & 150 & 30 & 150 & 150 \\ 0 & 100 & 100 & 100 & 100 \\ 0 & 72 & 72 & 0 & 0\end{array}$

$\begin{array}{lllll}575 & 1.000 & 425 & 1.000 & 1.000\end{array}$

$730 \quad 730$

$200 \quad 200 \quad 200 \quad 200$

$\begin{array}{rrrrr}0 & 144 & 144 & 0 & 0 \\ 935 & 2.646 & 1.711 & 2.430 & 2.430\end{array}$

$\begin{array}{rrrrr}0 & 0 & 486 & 486 & 486\end{array}$

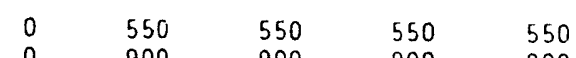

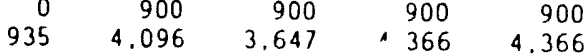

$\begin{array}{rrrrr}1.500 & 2.000 & 500 & 500 & 2.000 \\ 400 & 500 & 100 & 100 & 500 \\ 1.900 & 2.500 & 600 & 600 & 2.500 \\ 0 & 0 & 500 & 500 & 500 \\ 0 & 550 & 550 & 550 & 550 \\ 0 & 900 & 900 & 900 & 900 \\ 1.900 & 9 & 2.550 & 2.550 & 4.450\end{array}$




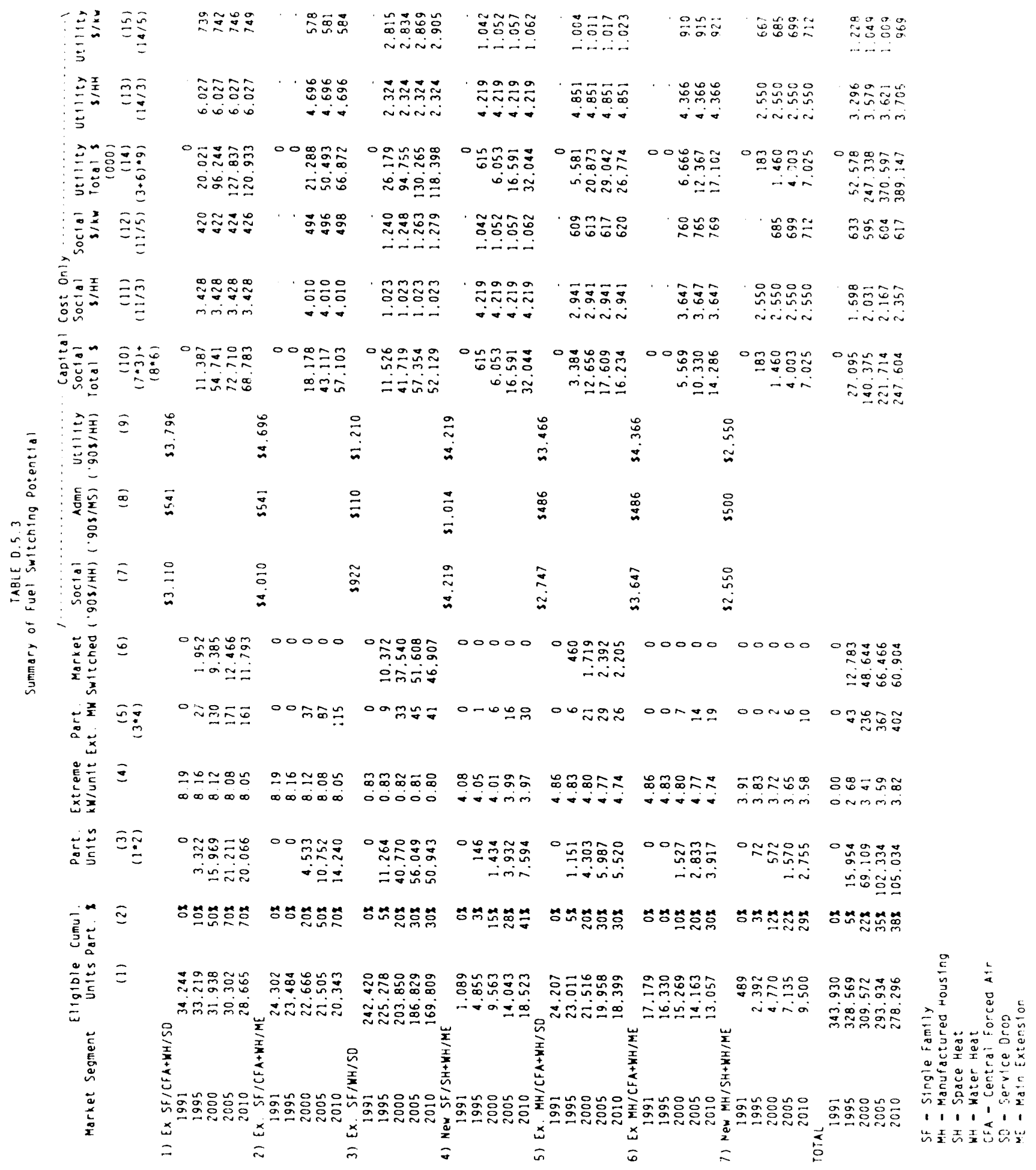




\section{D.6.0 PROGRAM INTERACTIONS}

Estimated peak savings for the following programs are reduced when a fuel switching program is in place.

Residential Weatherization. Fewer households with electric space heat are available for a weatherization program.

Low-Flow Shower Heads. Fuel switching reduces the number of shower heads with electrically heated water.

Water Heat Control. Fuel switching reduces the number of electric water heaters available for a control program.

Iime-of-Use Rates. Time-of-use rates affect all end-uses, including electric space heat and water heat. A fuel switching program reduces the amount of electric space heat and water heat load available for time-of-use rates.

Conservation and load management savings are estimated under two scenarios. one with fuel switching and one without. In the fuel switching scenario, appliances that are planned to be switched away from electricity are not available for any other program. For example, savings for water heat control do not include any water heaters that will later switch over to natural gas.

\section{D.6.1 PROGRAM ORDERING}

If two or more programs affect an end-use, then the total savings of all the programs combined is less than the sum of all programs taken separately. Savings from one or more of the programs must be decreased to account for the impact of other programs already in place. Conservation and load management programs are assigned an ordering to reduce the number of possible interactive effects. Fuel switching comes first, conservation is next, and load management is last.

\section{Residential Space Heat Ordering}

1. Fuel Switching (when present)

2. Weatnerization

3. iime-of-Use Rates

If a fuel switching program is in place, that space heat system is not available for any other program. Energy savings for residential weatherization, in terms of annual kilowatt-hours, are based on consumption data from homes without time-of-use rates. Therefore, weatherization is ordered ahead of time-of-use rates.

$$
\text { D- } 67
$$




\section{Residential Water Heat Ordering}

1. Fuel Switching (when present)

2. Low Flow Shower Heads

3. Water Heat Control

4. Time-of-Use Rates

As with space heat, fuel switching of electric water heaters is ordered first. Conservation is next and load management programs are last. Water heat control comes ahead of time-of-use rates because water heat control is a larger program in this study.

\section{D.6.2 SIZE OF INTERACTIVE EFFECTS}

For each of the conservation and load management programs affected by fuel switching, peak savings with fuel switching are lower than without fuel switching. Estimated peak savings for water heat control are reduced by 30 megawatts, or $8.4 \%$, in the year 2003 with fuel switching in place. Peak savings for time-of-use rates are reduced by 7.2 megawatts or $5.6 \%$. Savings for residential weatherization and low flow shower heads drop by 3.4 and 2.2 megawatts respectively.

Table D.6.1 Fuel Switching Impact on Other Programs Peak Savings in MW Extreme Peak Day

\begin{tabular}{rrrrrrr}
\multirow{2}{*}{1996} & WZSF & LF & WHSF & WHMH & TOU \\
& no FS & 27.9 & 10.3 & 81.2 & 4.1 & 72.9 \\
& with FS & 27.4 & 10.1 & 79.0 & 4.1 & 71.8 \\
2003 & no FS & 43.3 & 29.5 & 291.2 & 12.5 & 128.8 \\
& with FS & 39.9 & 27.3 & 262.4 & 11.5 & 121.6 \\
2010 & no FS & 0.0 & 28.1 & 369.9 & 13.8 & 132.1 \\
& with FS & 0.0 & 25.6 & 326.9 & 12.5 & 123.0
\end{tabular}

\footnotetext{
$F S=$ Fuel Switching

WZSF = Weatherization, Single Family

LF = Low Flow Shower Heads

WHSF = Water Heat Control, Single Family

WHMH = Water Heat Control, Manufactured Homes

TOU = Time- of-Use Rates
} 


\section{D.7.0 HIGH AND LOW LOAD GROWTH}

The Long Term Forecasting Section at Bonneville has provided medium growth forecasts for the Puget Sound area by sector and end-use. The high and low forecasts were derived from the medium forecast by scaling the number of households, square feet, or average megawatts up or down. Scaling factors are based on the 1989 regional long-term forecast. Saturation rates, or market shares of electricity. were not changed.

\section{D.7.1 ASSUMPTIONS BY SECTOR}

\section{Residential Sector}

The medium forecast has household counts for single family, multi-family, and manufactured homes. Scaling factors were calculated for both the high and low cases, but the factors are the same across housing types. Scaling factors are set to 1.0 in 1990 and increase linearly to the year 2010, as shown in Table D.7.1.

\section{Table D.7.1 Residential Scale Factors}

$\begin{array}{llll} & \text { High } & \text { Medium } & \text { Low } \\ 1990 & 1.000 & 1.000 & 1.000 \\ 1995 & 1.071 & 1.000 & 0.940 \\ 2000 & 1.142 & 1.000 & 0.881 \\ 2005 & 1.213 & 1.000 & 0.821 \\ 2010 & 1.284 & 1.000 & 0.761\end{array}$

Key figures are the high and low scale factors in 2010. Other factors are linearly interpolated. Data to calculate residential scale factors in the year 2010 are taken from Table 7 in Forecast of Electricity Use in the Pacific Northwest (Borneville Power Administratior and Northwest Power Planning Council 1989, p.24).

$$
\begin{aligned}
& 1.284=(2.542+3.612) /(1.972+2.819) \\
& 0.761=(1.489+2.159) /(1.972+2.819)
\end{aligned}
$$




\section{Commercial Sector}

The medium forecast has two building types, office and non-office. As in the residential sector, the commercial scale factors are the same for each building type. These are shown in Table D.7.2. Units for the commercial sector are thousands of square feet.

\section{Table D.7.2 Commercial Scale Factors}

$\begin{array}{llll} & \text { High } & \text { Medium } & \text { Low } \\ 1990 & 1.000 & 1.000 & 1.000 \\ 1995 & 1.089 & 1.000 & 0.942 \\ 2000 & 1.178 & 1.000 & 0.885 \\ 2005 & 1.267 & 1.000 & 0.827 \\ 2010 & 1.356 & 1.000 & 0.769\end{array}$

Data to calculate commercial scale factors in the year 2010 are taken from Table 10 in Forecast of Electricity Use in the Pacific Northwest (Bonneville Power Administration and Northwest Power Planning Council 1989, p.29).

$$
\begin{aligned}
& 1.356=(1236.2+2603.0) /(901.5+1929.2) \\
& 0.769=(694.4+1482.1) /(901.5+1929.2)
\end{aligned}
$$

\section{Industrial Sector}

Because of the wide variety of industrial electric loads, units are average megawatts. The industrial scale factors are shown in Table 0.7.3.

Table 0.7 .3 Industrial Scale Factors

$\begin{array}{llll} & \text { High } & \text { Medium } & \text { Low } \\ 1990 & 1.000 & 1.000 & 1.000 \\ 1995 & 1.128 & 1.000 & 0.933 \\ 2000 & 1.257 & 1.000 & 0.865 \\ 2005 & 1.385 & 1.000 & 0.798 \\ 2010 & 1.513 & 1.000 & 0.730\end{array}$




\section{D.7.2 TABLES}

Numbers of households for low, medium, and high load growth are shown in Table D.7.4. Forecasts of commercial floor space are in Table D.7.5. Breakdowns by building type are shown in Tables D.7.5, D.7.6. and D.7.7.

Table D.7.4 Residential Sector Growth Scenarios

Number of Households

1990
1991
1992
1993
1994
1995
1996
1997
1998
1999
2000
2001
2002
2003
2004
2005
2006
2007
2008
2009
2010

$\begin{array}{cccc}\text { Low } & \text { Med } & \text { High } \\ 1,634,916 & & 1,634,916 & 1,634,916 \\ 1,654,756 & 1,674,769 & 1,698,551 \\ 1,675,208 & 1,716,226 & 1,764,967 \\ 1,689,513 & 1,752,334 & 1,826,984 \\ 1,701,805 & 1,787,234 & 1,888,749 \\ 1,709,138 & 1,817,749 & 1,946,809 \\ 1,715,387 & 1,847,880 & 2,005,319 \\ 1,722,009 & 1,879,204 & 2,065,997 \\ 1,729,363 & 1,912,166 & 2,129,388 \\ 1,733,933 & 1,942,891 & 2,191,193 \\ 1,739,666 & 1,975,771 & 2,256,330 \\ 1,743,300 & 2,007,138 & 2,320,653 \\ 1,746,896 & 2,039,337 & 2,386,840 \\ 1,749,377 & 2,071,127 & 2,453,457 \\ 1,750,558 & 2,102,267 & 2,520,198 \\ 1,752,418 & 2,135,142 & 2,589,928 \\ 1,754,147 & 2,168,826 & 2,661,584 \\ 1,755,320 & 2,202,824 & 2,734,585 \\ 1,756,447 & 2,237,798 & 2,809,779 \\ 1,757,201 & 2,273,369 & 2,886,724 \\ 1,757,509 & 2,309,473 & 2,965,363\end{array}$


Table D.7.5 Commercial Sector Growth Scenarios

\begin{tabular}{lrrr} 
& \multicolumn{2}{c}{ Thousands of Square Feet } \\
& Low & Med & High \\
1990 & 812,546 & 812,546 & 812,546 \\
1991 & 832,172 & 841,896 & 856,881 \\
1992 & 851,119 & 871,245 & 902,262 \\
1993 & 869,389 & 900,595 & 948,687 \\
1994 & 886,981 & 929,944 & 996,156 \\
1995 & 903,895 & 959,294 & $1,044,671$ \\
1996 & 915,014 & 983,146 & $1,088,146$ \\
1997 & 925,582 & $1,006,998$ & $1,132,470$ \\
1998 & 935,599 & $1,030,850$ & $1,177,643$ \\
1999 & 945,066 & $1,054,702$ & $1,223,665$ \\
2000 & 953,981 & $1,078,554$ & $1,270,537$ \\
2001 & 967,919 & $1,108,791$ & $1,325,892$ \\
2002 & 981,159 & $1,139,028$ & $1,382,325$ \\
2003 & 993,700 & $1,169,265$ & $1,439,833$ \\
2004 & $1,005,543$ & $1,199,502$ & $1,498,418$ \\
2005 & $1,016,687$ & $1,229,740$ & $1,558,080$ \\
2006 & $1,027,133$ & $1,259,977$ & $1,618,818$ \\
2007 & $1,036,880$ & $1,290,214$ & $1,680,632$ \\
2008 & $1,045,929$ & $1,320,451$ & $1,743,523$ \\
2009 & $1,054,279$ & $1,350,688$ & $1,807,491$ \\
2010 & $1,061,931$ & $1,380,925$ & $1,872,534$
\end{tabular}


Table 0.7.6 Low Growth by Building Type Puget Sound Area

Number of Households

\begin{abstract}
Single -
\end{abstract}
Family

$1990 \quad 1,097,667$

$1991 \quad 1,103,044$

$1992 \quad 1,108,454$

$1993 \quad 1,111,167$

$1994 \quad 1,112,515$

$1995 \quad 1,111,752$

$1996 \quad 1,110,824$

$1997 \quad 1,109,663$

$1998 \quad 1,109,020$

$1999 \quad 1,106,624$

$2000 \quad 1,105,280$

$2001 \quad 1,102,640$

$2002 \quad 1,099,666$

$20031,096,545$

$2004 \quad 1,092,253$

$20051,088,614$

$2006 \quad 1,084,859$

$2007 \quad 1,080,818$

$2008 \quad 1,076,883$

$2009 \quad 1,072,562$

$2010 \quad 1,067,903$

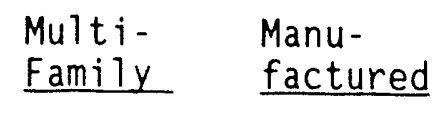

$431,144 \quad 106,106$

$443,629 \quad 108,083$

$456,222 \quad 110,532$

$465,666 \quad 112,680$

$474,570 \quad 114,720$

$481,741 \quad 115,645$

$487,919 \quad 116,644$

$494,626 \quad 117,720$

$501,387 \quad 118,956$

$507,204 \quad 120,105$

$512,966 \quad 121,420$

$518,168 \quad 122,492$

$523,731 \quad 123,499$

$528,390 \quad 124,442$

$533,075 \quad 125,230$

$537,763 \quad 126,040$

$542,503 \quad 126,785$

$547,038 \quad 127,463$

$551,490 \quad 128,075$

$556,019 \quad 128,620$

$560,507 \quad 129,099$
Floor Space (000 sq.ft.)

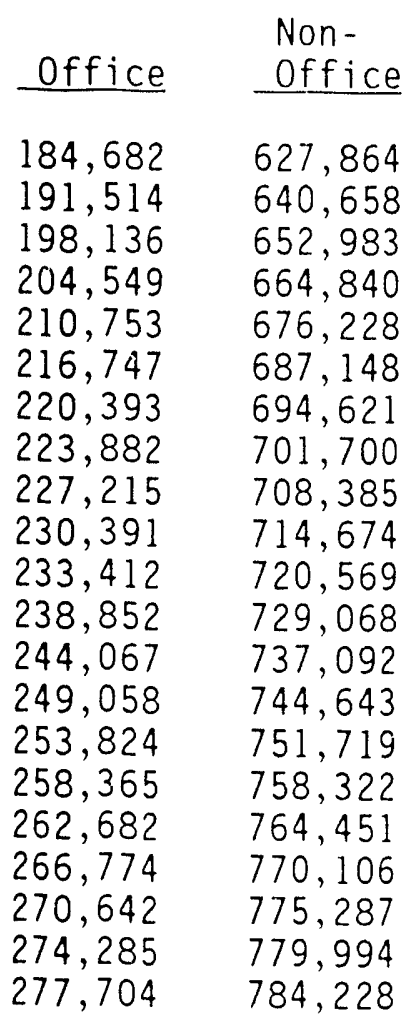


Table D.7.7 Medium Growth by Building Type Puget Sound Area

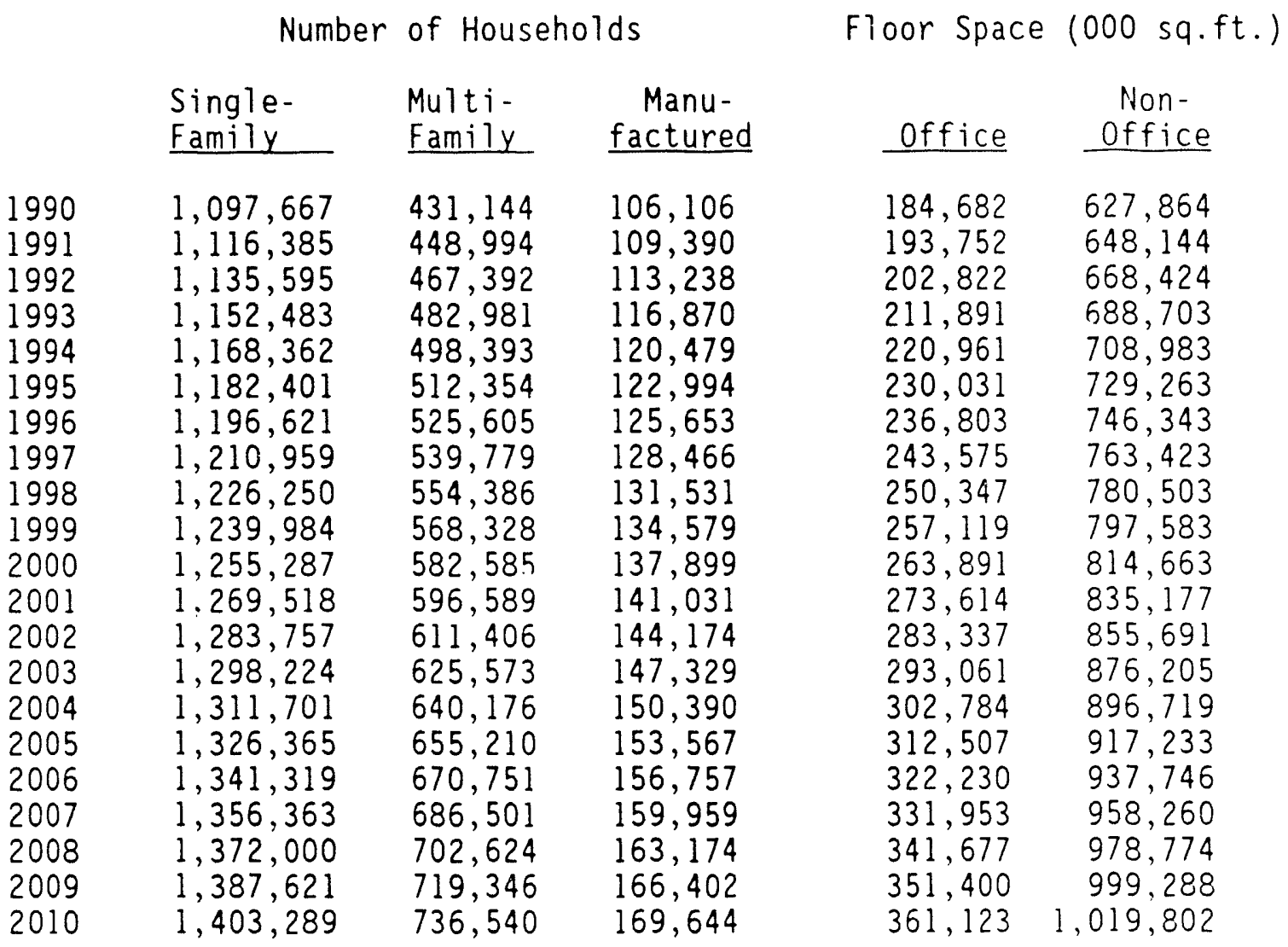


Table 0.7.8 High Growth by Building Type Puget Sound Area

Number of Households

Single-

Family

1990

1991

1992

1993

1994

1995

1996

1997

1998

1999

2000

2001

2002

2003

2004

2005

2006

2007

2008

2009

2010

\begin{tabular}{|c|c|}
\hline $\begin{array}{l}\text { Multi- } \\
\text { Family }\end{array}$ & $\begin{array}{c}\text { Manu- } \\
\text { factured }\end{array}$ \\
\hline $\begin{array}{l}431,144 \\
455,370 \\
480,666 \\
503,556 \\
526,702 \\
548,731 \\
570,387 \\
593,433 \\
617,364 \\
640,960 \\
665,312 \\
689,777 \\
715,590 \\
741,054 \\
767,443 \\
794,769 \\
823,145 \\
852,223 \\
882,215 \\
913,426 \\
945,717\end{array}$ & $\begin{array}{l}106,106 \\
110,944 \\
116,454 \\
121,849 \\
127,322 \\
131,726 \\
136,359 \\
141,236 \\
146,472 \\
151,778 \\
157,480 \\
163,059 \\
168,741 \\
174,526 \\
180,288 \\
186,277 \\
192,372 \\
198,573 \\
204,881 \\
211,297 \\
217,823\end{array}$ \\
\hline
\end{tabular}

Floor Space (000 sq.ft.)

\begin{tabular}{|c|c|}
\hline Office & $\begin{array}{c}\text { Non- } \\
\text { Office }\end{array}$ \\
\hline 184,682 & 627,864 \\
\hline 197,201 & 659,681 \\
\hline 210,042 & 692,219 \\
\hline 223,206 & 725,480 \\
\hline 236,594 & 759,463 \\
\hline 250,504 & 794,167 \\
\hline 262,094 & 826,052 \\
\hline 273,924 & 858,546 \\
\hline 285,996 & 891,647 \\
\hline 298,309 & 925,356 \\
\hline 864 & 959,673 \\
\hline 327,188 & 705 \\
\hline 343,858 & $1,038,466$ \\
\hline 360,875 & $1,078,958$ \\
\hline 378,238 & $1,120,181$ \\
\hline 395,946 & $1,162,13$ \\
\hline 414,001 & $1,204,817$ \\
\hline 432,402 & $1,248,23$ \\
\hline 451,150 & $1,292,37$ \\
\hline 470,243 & $1,337,247$ \\
\hline 489,683 & $1,382,85$ \\
\hline
\end{tabular}




\section{D.8.0 REFERENCES}

Bonneville Power Administration and Northwest Power Planning Council. 1989. Forecast of Electricity Use in the Pacific Northwest. Portland, Oregon.

Gillman, R.A., R.D. Sands and R.G. Lucas. 1990. "Observations on Residential and Commercial Load Shapes During a Cold Snap." in proceedings of ACEEE 1990 Summer Study on Energy Efficiency in Buildings. Vol. 10, pp.81-89. American Council for an Energy Efficient Economy, Washington, D.C. 

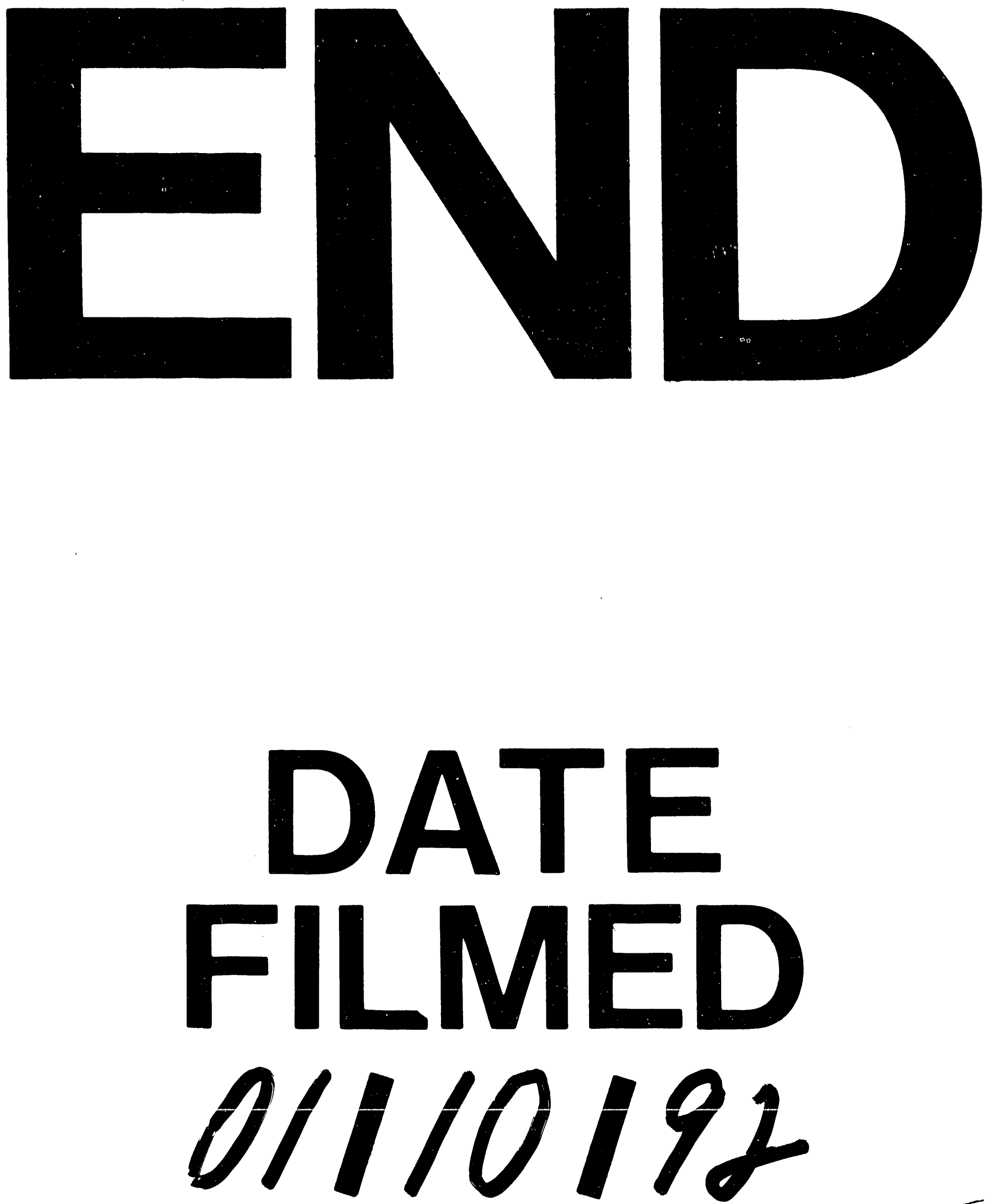
